\title{
ABSTRACT \\ DESIGN A MOBILE AUGMENTED REALITY SYSTEM TO FACILITATE USERS' COMPANIONSHIP NEEDS
}

\section{by Yi-Fan Chen}

With smartphones are ubiquitous, mobile augmented reality systems (MARS) open various opportunities for users to experience and interact with virtual information at physical locations. This study aims to understand how users domesticated Pokémon Go, a MARS which could be seen as the first normalizing MARS for the masses, into their everyday life. A triangulation method combined a participant observation in Kaohsiung, Taiwan and a qualitative content analysis from a popular Taiwanese Facebook Group Page to learn patterns and motivations of the MARS experience. Results show that content is crucial to using the MARS. The MARS facilitates users' socialization and companionship needs as well as adds a "layer of fun" for its users when they navigate places. A "See What I See" MARS is designed based on the primary research findings on users' companionship needs from their social networks and from their mobile media. It is a user-generated situated documentary MARS for users to use in everyday life. A prototype was built and tested. Results show that users report the MARS is highly easy to use and usefulness. It enhances users' experiences in a positive way. Users feel positive companionship from their friends and family members when they use the MARS. 


\title{
DESIGN A MOBILE AUGMENTED REALITY SYSTEM TO FACILITATE USERS'
} COMPANIONSHIP NEEDS

\author{
A Thesis \\ Submitted to the \\ Faculty of Miami University \\ in partial fulfillment of \\ the requirements for the degree of \\ Master of Fine Arts \\ by \\ Yi-Fan Chen \\ Miami University \\ Oxford, Ohio \\ 2017 \\ Advisor: Professor Dennis Cheatham \\ Reader: Dr. James Coyle \\ Reader: Dr. Glenn Platt
}

(C)2017 Yi-Fan Chen This Thesis titled 


\title{
DESIGN A MOBILE AUGMENTED REALITY SYSTEM TO FACILITATE USERS" COMPANIONSHIP NEEDS
}

\author{
by \\ Yi-Fan Chen \\ has been approved for publication by \\ The School of Creative Arts \\ and \\ Department of Art
}

Professor Dennis Cheatham

Dr. James Coyle

Dr. Glenn Platt 


\section{Table of Contents}

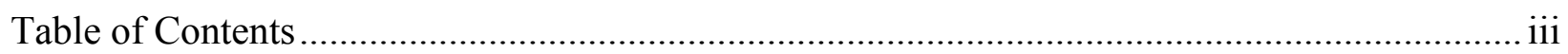

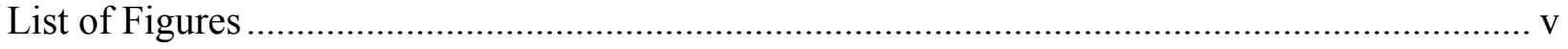

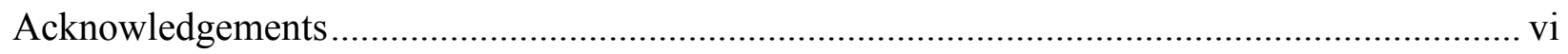

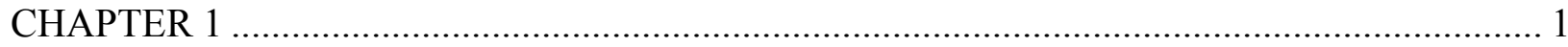

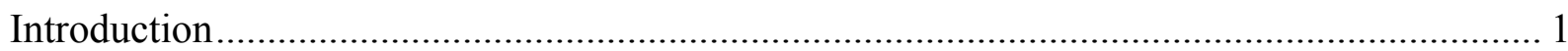

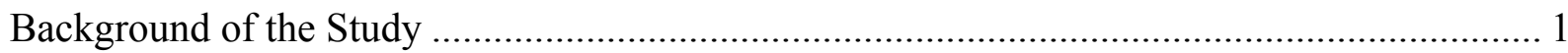

Purpose of the Study …………………………………................................................. 3

Users-Media Figures Para-Social Interactions for Companionship Needs.................................. 3

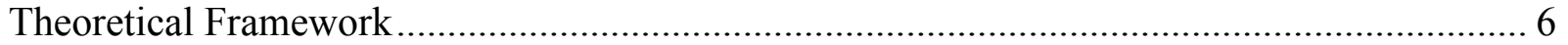

Domestication Approach ................................................................................................. 7

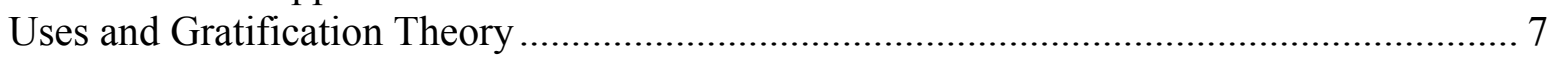

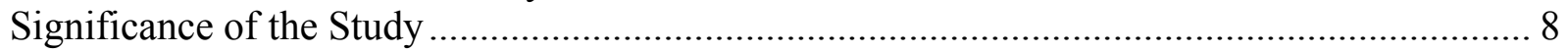

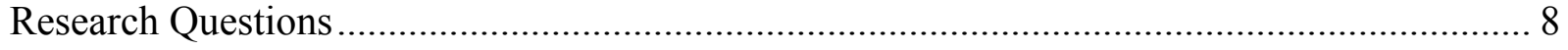

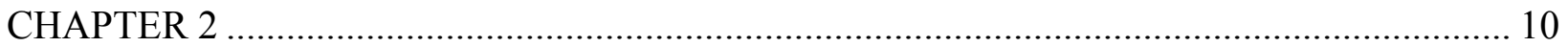

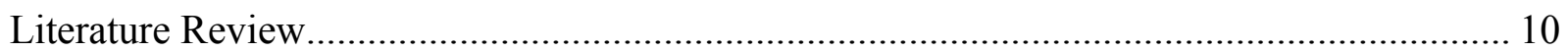

The Domestication of Media in Everyday Life ......................................................... 10

Traditional Media and Companionship .......................................................................... 11

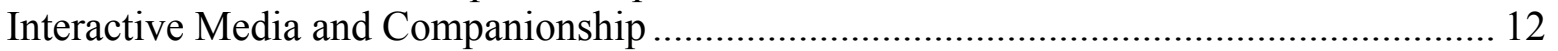

Mobile Augmented Reality System for Location Experience ............................................... 13

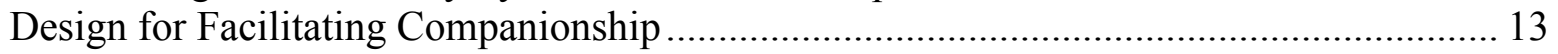

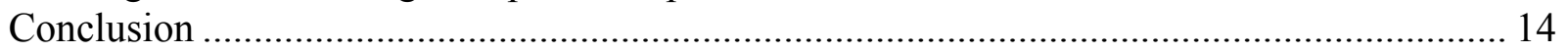

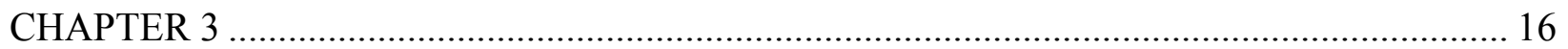

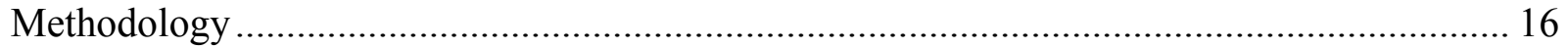

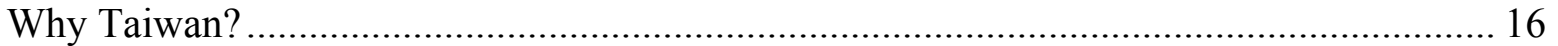

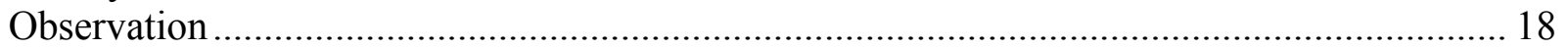

Content Analysis of Posts on the Facebook Group Page...................................................... 21

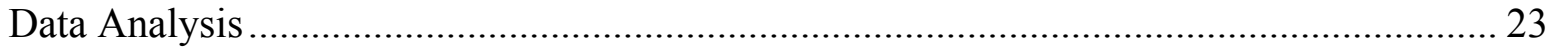

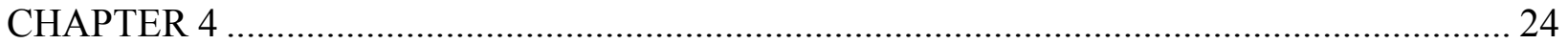

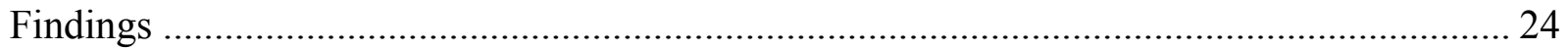

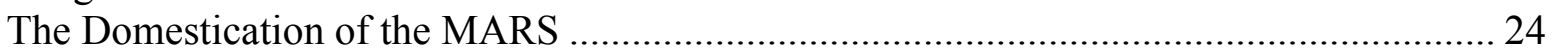

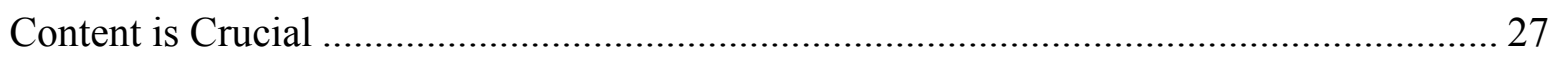

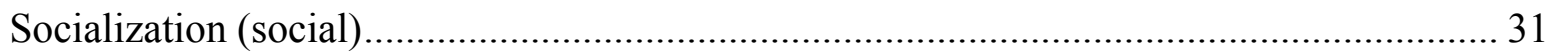

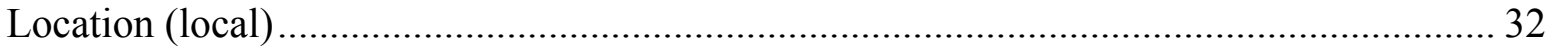

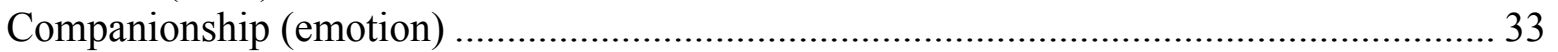

Para-social interactions between the MARS users and their Pokémon/ avatars............... 33

Companionship between the MARS users and other users ............................................. 36

Companionship among the MARS users- Pokémon/avatars- other users ……………..... 38

Mobile Design: Everyone's System (mobile) ....................................................................... 39

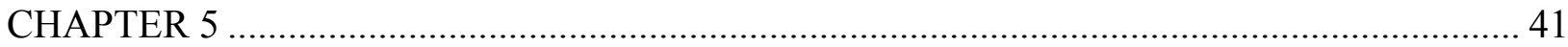

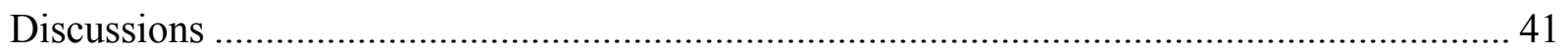




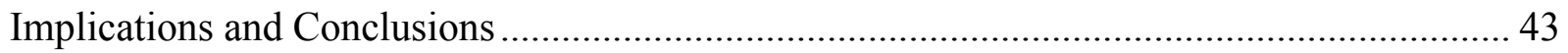

Limitations and Suggestions for Future Studies ....................................................... 44

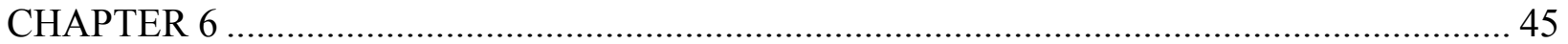

Design a Mobile Augmented Reality System to Facilitate Users' Companionship Needs ...... 45

"See What I See" MARS Design............................................................................... 45

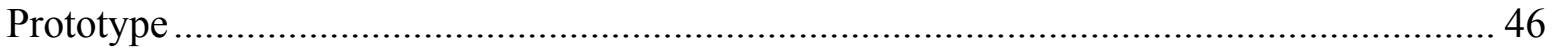

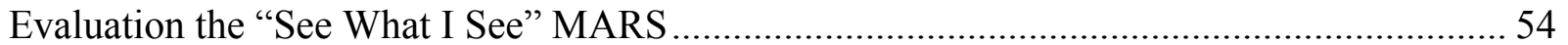

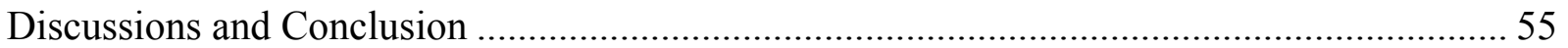

Suggestions for Future MARS Design ....................................................................... 56

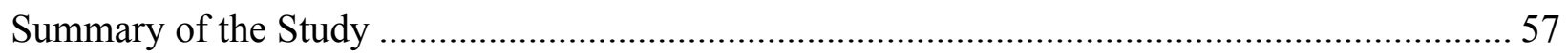

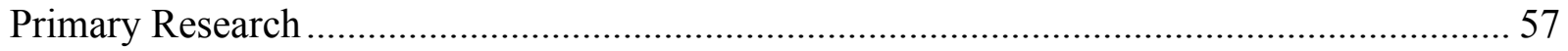

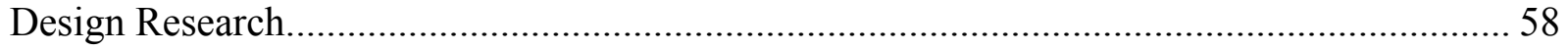

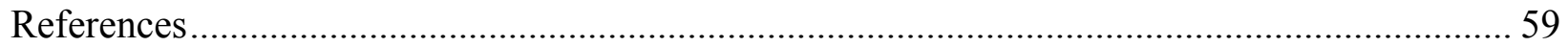

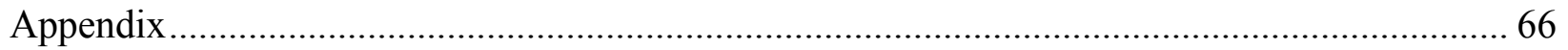

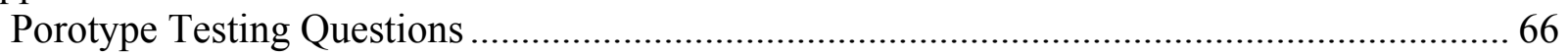




\section{List of Figures}

Figure 1: A group of Pokémon users changed their Pokémon's names to remember one of their group members who lost the battle to cancer...................................................................... 6

Figure 2: A mob chasing a Snorlax in Taiwan …………………………………………….... 17

Figure 3: Pokémon Search Map for the rare Pokémon ............................................................... 20

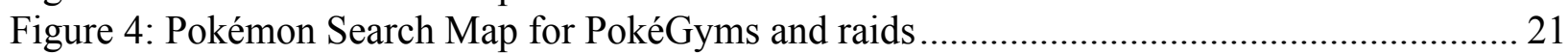

Figure 5: Pokémon Kaohsiung Facebook Group …………………………………………….... 22

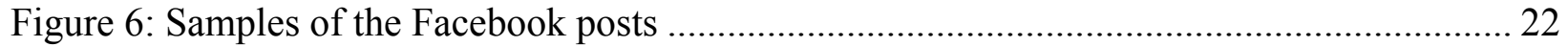

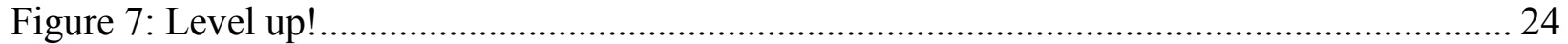

Figure 8: 100\% Tyranitar awesome!

Figure 9: Samples of the MARS users battled raids at PokéGyms............................................. 27

Figure 10: I hear the Legendary Birds are available now. Re-downloaded the system back $\odot$... 28

Figure 11: An image posted on the Facebook Group Page to alarm other users the raid location29

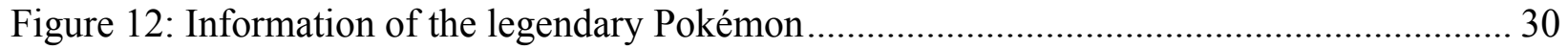

Figure 13: A MARS user questioned about a related product ..................................................... 30

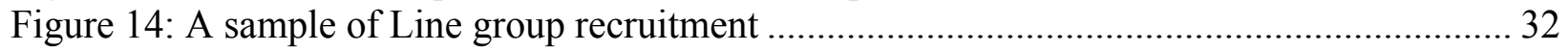

Figure 15: Super cute

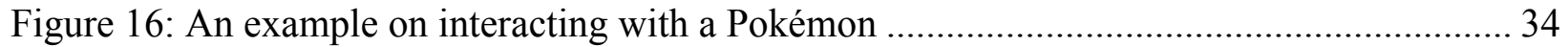

Figure 17: Byebye Articuno. I am right here watching you to leave me. ................................ 35

Figure 18: Dear Baby. It is almost 24 hours. If you are not coming home, daddy is going to call

the police for assistant................................................................................................ 36

Figure 19: A MARS user asked others if Moltres hated her........................................................ 38

Figure 20: A post described how two MARS users met offline for the first time......................... 39

Figure 21: Mapping hotspots by situated documentaries in Kaohsiung based on the travelers'

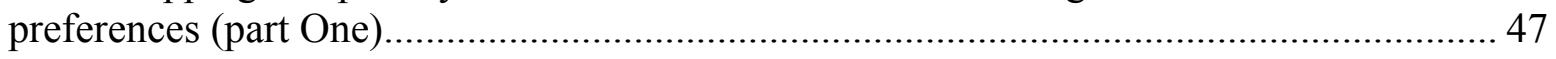

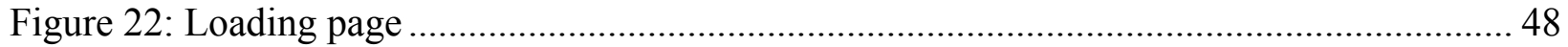

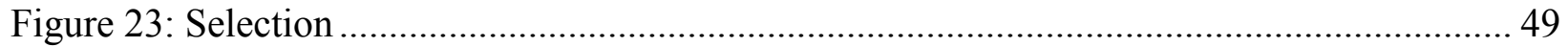

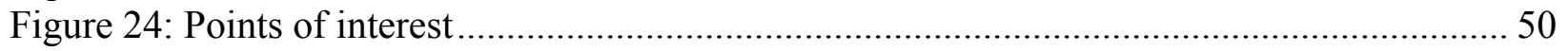

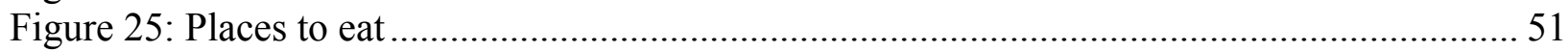

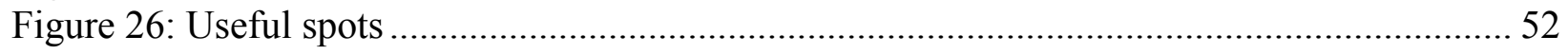

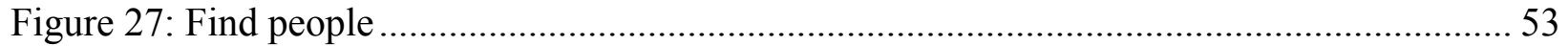

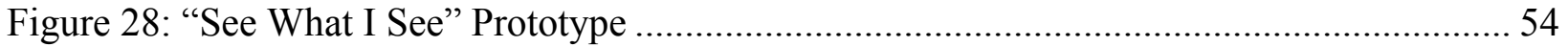




\section{Acknowledgements}

Sincerely thanks all of you in my social network to co-design this experience with love.

Special thanks to my friend Snorlax8284A. As on November 15, 2017, the Snorlax along with some other Pokémon walks with me for over 3,276.1 kilometers. I have chances to build my Pokémon network because of my Pokémon friends. Thank you for always being with me and accompanying me to navigate the world.

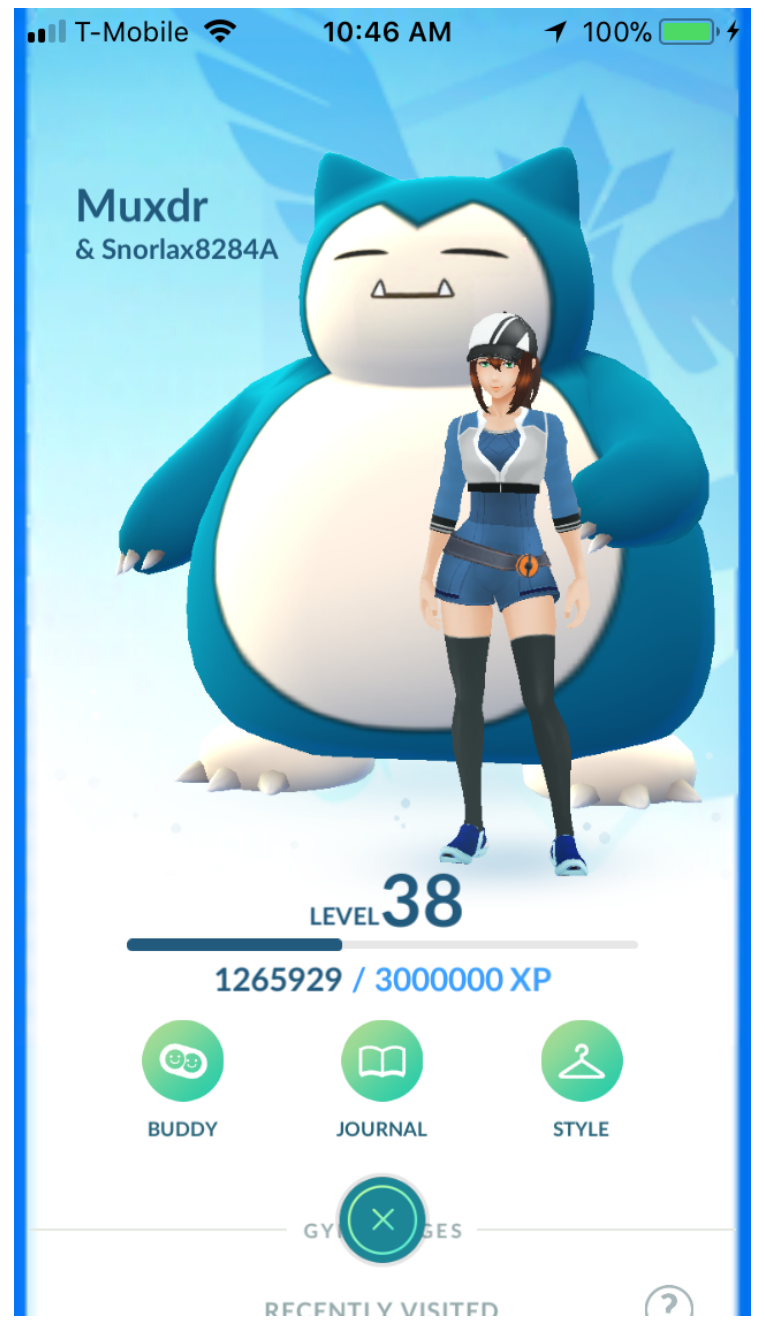




\section{CHAPTER 1}

Introduction

\section{Background of the Study}

Augmented reality (AR) systems are user-interfaces to context-aware computing environments. AR systems integrate virtual information to physical locations and allow users to perceive the relevant information at the locations (Höllerer \& Feiner, 2005). AR systems are studied for over 20 years. With smartphone and wearable communication and information technologies (ICT) are ubiquitous, mobile AR systems (MARS) open various opportunities for users to experience and interact with physical location information on the move (Kourouthanassis, Boletsis, Bardaki, \& Chasanidou, 2015). Scholars and researchers (e.g., Azuma, 1997; Höllerer \& Feiner, 2005; Hollerer, Feiner, \& Pavlik, 1999; Pavlik, 2001) comment that MARS could be utilized in several fields, such as annotation and visualization, architecture and archaeology, assembly and construction, entertainment, geographic fieldwork, journalism, maintenance and inspection, medicine, military training and combat, navigation and path finding, personal information management, tourism, and urban modeling.

One aspect of the MARS is used for storytelling and story consuming at the locations (Pavlik \& Bridges, 2013). John Pavlik and colleagues call those stories as "Situated Documentaries" that the MARS embeds multimedia presentations in the real world for users to consume at the location (Hollerer et al., 1999; Pavlik, 2001). When users are at locations where events reported on originally occurred, they use their MARS to retrieve situated documentaries about the events. Professors and students at Columbia University are working and testing a series of situated documentaries that are demonstrated by the MARS. One of their key results shows that the MARS adds a layer of information at the locations for its users. It brings a different user experience of media consumption at locations (Pavlik, 2001). Pavlik and McIntosh (2006) also argue that a situated documentary is best called "context-aware" media content. With a MARS, users are immersed in a three-dimensional aural and visual re-creation of the past. They believe that a MARS is a virtual time machine enabling the users to visit past time and events. They also argue that the MARS will be more popular with the continued development of mobile interfaces and mobile broadband systems. 
Another aspect of the MARS is used for entertainment, and it creates rich cultural and social consequences among users and non-users. Ingress, a mobile AR game, allows users to use the AR game to capture "portals" at places with significant cultural meanings, such as landmarks and public art. It provides its users different ways to interact with places and other users. It also brings users from the virtual interaction into a traditional face-to-face interaction (Majorek \& du Vall, 2016). Another MARS example is Pokémon Go. Since the release of Pokémon Go in July 2016, news stories have discussed trends, safety concerns, and controversies surrounding the wildly popular MARS. Personal websites and blogs address why the MARS is so popular and addictive. These sites and blogs have begun to explore the social aspects of the MARS, and reveal a wide range of emotional responses to the MARS, ranging from enjoyment and enthusiasm, to grudging acceptance, to revulsion.

For example, Pokémon Go has caught the attention of the public health community. Watanabe's et al. (2017) study finds that the MARS has positive effects on the mental health of the adult working population. Tong's et al. (2017) study reports that the MARS encourages users' physical and emotional activities in a positive way. Another study reports that American Pokémon Go users walk more, increasing their physical activities by 1,473 steps a day on average. The MARS increases physical activities to all genders and ages (Althoff, White, \& Horvitz, 2016). Similar findings are found by Howe's et al., (2016) study. They find that there is no statistically significant difference between Pokémon Go users' genders, ages, and ethnicities. Pokémon Go users report that they walk more in the five weeks after installation of the system. In their study, there are also no usage differences among genders, ages, and ethnicities (Howe et al., 2016).

Although the academic research initially shows there is no gender, age, and ethnicity differences among Pokémon Go users who use the MARS for health reasons (e.g., Althoff et al., 2016; Howe et al., 2016), there is a lack of systematic research to understand social and cultural consequences and implications of Pokémon Go use. For example, Low (2017) reported that seniors were the notable group that uses the MARS around the world. In Low's (2017) news reporting, senior users turned on their MARS every day for exercise. Some of them hit the max level of 40 before the majority of users in Singapore. For them, the MARS was better than "sitting around the house doing nothing." They collected the gold badges and renamed their 
Pokémon with its IV percentage. ${ }^{1}$ They spent their money on the MARS to get PokéBalls or other items. They found the rare Pokémon through a Singapore-based third-party tracker. They enjoyed chasing or combating Pokémon with young people. In Kansas, USA, a senior also used the MARS to keep him fit as well as socialize with family and meet new friends. According to Apple Company, Pokémon Go, which the Company calls it "cultural phenomenon," was ranked the most-downloaded worldwide mobile iOS system in 2016 (Leswing, 2017). Pokémon Go could be seen as the first normalizing MARS for the masses. The MARS is not just a mobile game. The impacts on its users include personal, social, physical, and emotional levels. In this study, it is the reason to select Pokémon Go to learn the MARS users' needs and motivations to use a MARS.

\section{Purpose of the Study}

Theorizing regarding the use of the MARS (as in Pokémon Go) is in the beginning stages, with some published research focusing on how the system increases physical activities and provides health benefits (e.g., Althoff et al., 2016; Howe et al., 2016; Tong et al., 2017; Watanabe et al., 2017). In 2017, both Google and Apple were releasing their AR developing kits (Matney, 2017) and Facebook and Microsoft were also developing AR systems (Molina, 2017). Apple CEO, Tim Cook, predicted both AR and Mix Reality (MR), which combines AR and Virtual Reality (VR), will generate $\$ 30.4$ billion in revenue in 2020 (Molina, 2017). The MARS seems to be increasing in popularity as Pavlik and McIntosh's (2006) prediction with advanced mobile broadband systems and mobile interface development. Additionally, it is important to learn possible social consequences of the MARS use. The current research aims to explore users' attitudes and perceptions toward Pokémon Go and hopes to provide design recommendations for the system or future MARS.

Users-Media Figures Para-Social Interactions for Companionship Needs

Media researchers have studied the perceived relationship that media users develop with media figures, such as celebrities, actors, presenters, and fictional characters. The concept of para-social interaction has become well established in the media and communication fields for

\footnotetext{
${ }^{1}$ The Pokémon IV is a rating of how powerful the Pokémon is. The IV ranges from 0 to 100 that the 100 percent represents the strongest level.
} 
decades (Giles, 2002). Research on traditional media (e.g., TV, radio) use finds media users interact with media figures, but do not identify with those figures. To understand the companionship from media figures to media users, Horton and Wohl (1956) first argue that the interaction between media users and media figures can produce a form of para-social relationship, to which the users respond as though in real world social relationship. In other words, media users react to media figures as if the figures are part of the user's peer groups. Media users and media figures could "claim and achieve intimacy with what are literally crowds of strangers" (p. 216). Media users know the media figures as they would their own friends. Giles (2002) suggests that para-social interaction may be viewed as "usual social activity" (p. 280).

Mark Levy (1979) comments that although the media users cannot communicate directly with the media figures, media users are still said to interact with the personae because users can "benefit from the persona's wisdom, reflect on his advice, sympathize with him in his difficulties, [and] forgive his/her mistakes" (p. 70). In the researcher's viewpoint, para-social interaction is considered complementary to social communication. He studies 24 participants who watch television news regularly in Albany, New York and finds that 53\% of research participants reports that they have some level of para-social relationship with media figures. His participants comment they occasionally respond to a newscaster's opening greeting or sign-off. They also feel "upset" when the anchorman is absent. They seek companionship from television figures. His participants appreciate the "presence" of the newscasters when they are alone. Those participants also feel sorry for the newscaster's mistakes.

Another example is by Orlik (2016). The researcher uses retro TV, which is the updating of a ten- or twenty-year-old television series rather than simply re-airing the original episodes, to examine the media users' needs for companionship. He argues the characters in retro TV have become part of user's lives and become their friends. He cites professor Geist's observations on interactions between the characters in retro TV and media users as users developing a bond with the TV characters because users grew up letting their favorite TV characters into their living rooms every week. It is natural that users want to see those characters again twenty years later and check in with them and make sure the characters are turning out all right. In addition, he cites Michael Antecol's definition of para-social interaction as follows: 
A relationship of friendship or intimacy by a television viewer with a remote media character It is based on affective ties by the viewer with the media character. As such it may take the form of seeking guidance from the characters, making friends with them and imagining being part of the program's social world (Michael Antecol, as cited in Orlik, 2015).

Auter and Palmgreen (2000) comment that the para-social relationship is like interpersonal relationships except that the interaction is one way only. The researchers also believe that understanding para-social relationship from media content to media users might provide significant insight in audience and media relationship. As para-social relationships increases, media consumption might increase to maintain the relationship/friendship (Rubin, Perse, \& Power, 1985). Prior para-social relationship studies examine relationships between children and their favorite television characters (e.g., Hoffner, 1996), listeners and talk show radio hosts (e.g., Rubin \& Step, 2000), fans and celebrities (e.g., Alperstein, 1991), and followers and bloggers (e.g., Colliander \& Dahlén, 2011). Results show media users develop the parasocial relationship with the media figures.

Research also shows that media users utilize the media content (i.e., media figures) to fulfill some of their companionship needs. Rubin and colleagues (e.g., Armstrong \& Rubin, 1989; Rubin, Perse, \& Power, 1985) began to develop scales to test the para-social interaction in the 1980s. They used the term of "companionship" to describe the para-social interaction between media users and media figures. Those relationships include both verbal and non-verbal interaction. The current study is interested in understanding if there is a relationship between the media figures of situated documentaries and their users. It is also interesting to learn if those MARS media figures could fulfill their users' companionship needs. In Low's (2017) report, Singapore Pokémon Go users seemed to develop the para-social relationship with their Pokémon by renaming them and talking with them. Another Taiwanese news report mentions that a group of Pokémon users changed their Pokémon' names to remember one of their friends, Mr. Hsiao, who lost the battle to cancer (please see Figure 1). Because Mr. Hsiao posted his wishes on a social media to catch the forthcoming legendary Pokémon, Entei, before he passed away on October 30, 2017, those MARS users took Mr. Hsiao's phone from his family members to catch an Entei for him on November 1, 2017 (ET Today, 2017). A MARS mediates the "contextaware" media content at locations with high mobility and accessibility. It is important to learn in 
what ways the MARS might influence the para-social relationship between media users and media figures with the locations.

Figure 1: A group of Pokémon users changed their Pokémon's names to remember one of their group members who lost the battle to cancer.
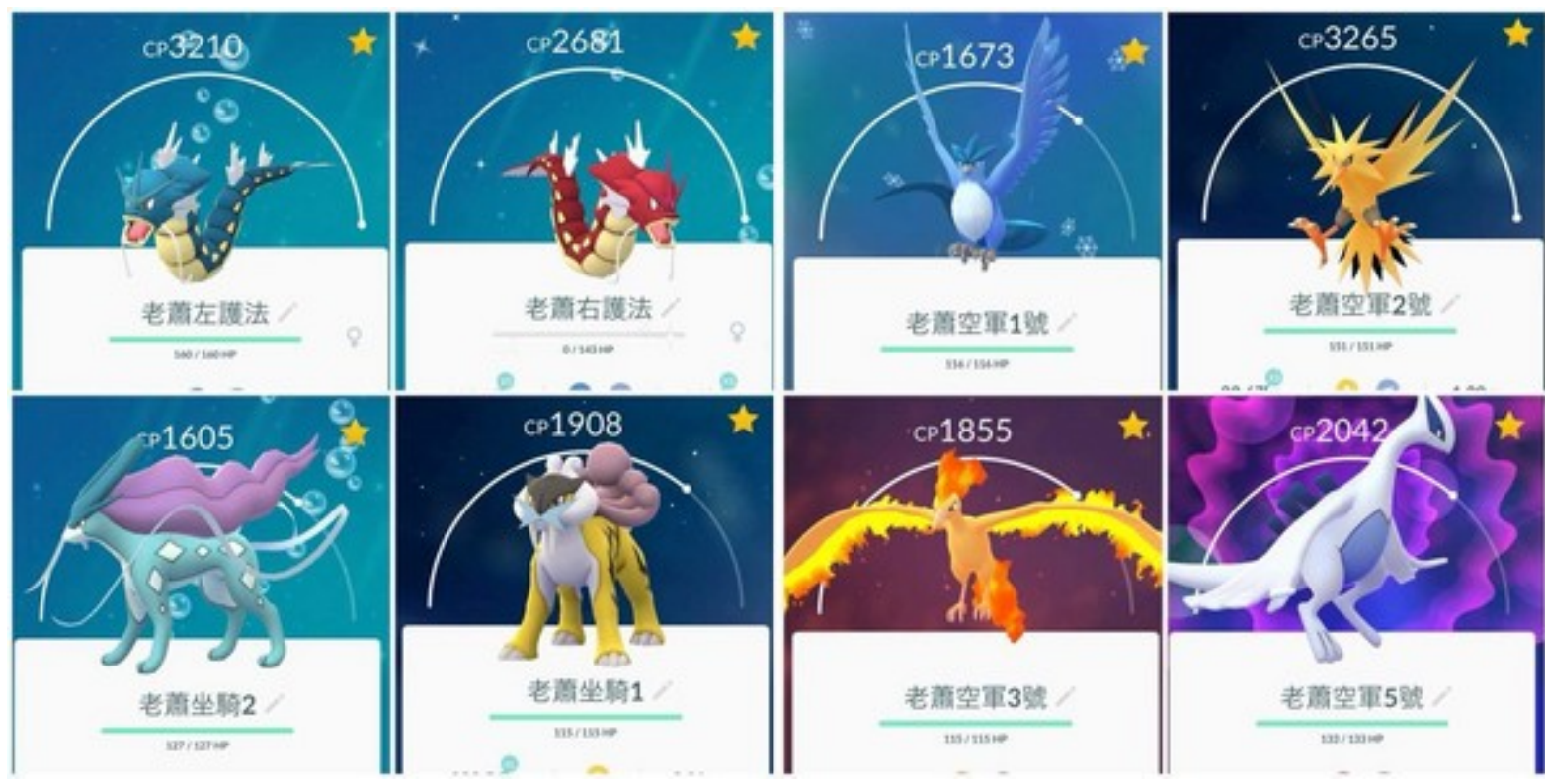

Source: ET Today $(2017)^{2}$

Theoretical Framework

This study aims to investigate users' needs to a MARS (as in Pokémon Go) before designing a better MARS to fulfill users' needs and reach their goals. The Uses and Gratification Theory (Katz et al., 1974) seems to be a fit theory to this study because this study tries to learn "a holistic approach" of users' needs, such as information, communication, decision, entertainment, socialization, and companionship, and how users use a MARS to seek them. Additionally, the Domestication Approach (Haddon, 2003; Silverstone et al., 2005) is an approach that is used to understand the processes by which innovations, especially new media are "tamed" to fit into users' everyday life. It seems to be an appropriate framework to learn MARS adoption and usage patterns.

\footnotetext{
2 Translation: From top left to right: Mr. Hsiao's left bodyguard, Mr. Hsiao's right bodyguard, Mr. Hsiao's Air Force One, Mr. Hsiao's Air Force Two. From bottom left to right: Mr. Hsiao's ride \#2, Mr. Hsiao's ride \#1, Mr. Hsiao's Air Force Three, Mr. Hsiao's Air Force Five
} 


\section{Domestication Approach}

The Domestication Approach advanced by Roger Silverstone and Leslie Haddon is relevant to consider for this research question because it explains the process in which the use of technology becomes an integrated part of everyday life (Haddon, 2003; Silverstone, Hirsch, \& Morley, 2005). The Domestication Approach has four partial phases or processes: appropriation, objectification, incorporation, and conversion (Silverstone et al., 2005). In the context of considering the MARS being 'domesticated', the process is as follows: appropriation is when the MARS leaves the world of a "product" and can be taken by an individual or a household and owned; objectification relates to how the MARS is given a place and role by the individual or household's aesthetic environment; incorporation is the ways in which the MARS is used and how it fits into the individual or household's everyday life; and conversion is the process through which the relationship between the individual or the household and the outside world becomes articulated. Prior studies on the Domestication Approach find mobile media users perceive gratifications in the areas of fashion, status, and sociability (Hijazi-Omari \& Ribak, 2008; Lemish \& Cohen, 2005; Katz \& Sugiyama, 2006). The current research intends to utilize the Domestication Approach to search for using patterns in each stage within Pokémon Go users.

\section{Uses and Gratification Theory}

Diverging from "what media do to their audiences, the Uses and Gratification Theory aims "to explain something of the way in which individuals use communication, among other resources in their environment, to satisfy their needs and to achieve their goal, and to do so by simply asking them (Katz, Blumler, \& Gurevitch, 1974, p. 21). The Uses and Gratification Theory has been widely applied to study users' motivations and intentions to use media and media content. On the other hand, some traditional media scholars comment that the Uses and Gratifications Approach is not a rigorous social science theory. Swanson (1977) described it as "a vague conceptual framework; lack of precision in major concepts; a confused explanatory apparatus, and failure to view perception as an active process" (p. 214).

Therefore, Katz, Haas, and Gurevitch (1973) took a system approach to examine The Uses and Gratification Theory. They identified three categories of social and psychological needs as being the most important. They were (1) needs related to strengthening information, 
knowledge, and understanding, (2) needs related to aesthetic, pleasurable and emotional experience, and (3) needs related to strengthening contact with family, friends, and the world. The Uses and Gratification Theory has been examined in various media use motivations, ranged from media to media content. Examples include television (e.g., Conway \& Rubin, 1991), Internet (e.g., Ko, Cho, \& Roberts, 2005), social media (e.g., Raacke \& Bonds-Raacke, 2008), mobile music device (e.g., Ferguson, Greer, \& Reardon, 2007), mobile phones (e.g., Leung \& Wei, 2000), news (e.g., Diddi \& LaRose, 2006; Rubin \& Perse, 1987), and programs (e.g., Nabi, Stitt, Halford, \& Finnerty, 2006).

\section{Significance of the Study}

Research on other media and companionship has been conducted. There is a need to study the relationship between the MARS users and companionship because mobile devices provide always connect (Ling, 2004; Ling, 2012) and perpetual contact (Katz \& Aakhus, 2002) to its users. It might increase the para-social relationship from MARS figures to the MARS users. Moreover, design research on designing technology system to support companionship for special groups has also been conducted. One example is the Paro, a therapeutic seal robot, that is used in various facilities for the elderly for companionship around the world (Shibata, 2012). However, there is a need of design on offering mobile media companionship to the public in everyday life. The current research aims to study how a MARS support personal companionship with all age groups in everyday life. And then, it designs a MARS to facilitate users' companionship needs.

\section{Research Questions}

The current research first examines Pokémon Go to understand how and why users use a MARS in everyday life. Based on the Domestication Approach (Haddon, 2003; Silverstone et al., 2005) and the Uses and Gratification Theory (Katz et al., 1974) and prior research on social aspects of media use, several research questions are listed as followed:

RQ1: How do users use the MARS in everyday life?

RQ2: To what degree do users dependent on the MARS in their everyday life?

RQ3: What are users' motivations for use the MARS? 
RQ4: Which motives in use of the MARS predict a higher level of the MARS dependency?

RQ5: To what degree does users' MARS dependency increase their companionship? 


\section{CHAPTER 2}

Literature Review

Research on media and companionship has been conducted. Design research on designing technology systems to support companionship for special groups also has been conducted. The current research aimed to study a MARS to support personal companionship with all age groups in everyday life. First of all, it began to review published studies that related to how users "tamed" their media into their everyday life. Second, it reviewed the knowledge and ideas that have been established on both traditional and interactive media and companionship. Third, the literature review summarized studies on MARS and location experience. Finally, it looked into studies on designs for facilitating companionship.

\section{The Domestication of Media in Everyday Life}

Domestication of media was a theoretical framework and research approach to examined processes of media acceptance, rejections, and use. Many studies in the Domestication Approach were focused on inter-relationships between media users, media, and their environments. When the domestication of media has been accepted to the user's everyday life, the media were no longer seen as cold, problematic and challenging consumer products in everyday life, but as comfortable, useful tools that were reliable and trustworthy. The Domestication Approach was not only about technologies diffusion or adoption, it was also about users creating and making shared-spaces in the environment with the media in their daily life. Researchers often used ethnographic observations, interviews, diary keeping and maps of domestic spaces between users and media within an environment (e.g., home or work) to understand how users used media in their everyday life (Berker, Hartmann, Punie, \& Ward, 2006).

Ling, Nilsen, and Granhaug (1999) used the Domestication Approach to understand how Norwegians used video-on-demand (VOD) at home. Their study described how users integrated the media into the mental and physical contexts of their everyday life. Their data showed that the participants of the VOD developed a metaphorical background into which they could place the VOD in their homes. They were able to communicate their understanding of the VOD to others. Their data also showed the VOD was not only simply a physical installation in the home, but it also found a place in the identity of the users that the use of the VOD enhanced the status of the family and user himself or herself as a high-tech family or person. They were willing to learn 
how to master the VOD and finally, they were able to embed the VOD into the context of their daily lives.

Hijazi-Omari and Ribak (2008) used the Domestication Approach to examine how Palestinian young girls in Israel used their mobile phones in their bedrooms. The researchers found young girls used mobile phones that were given by their illicit boyfriends to communicate with them unbeknownst to their parents. In their study, they reported how the intergenerational and traditional cross-gender relationships were challenged by the use of mobile phones. On another side of the global, Katz and Sugiyama (2006) used the same approach to study Japanese young people's mobile phone uses. They found the Japanese youth used their mobile phones as their fashion statements and their relationship/social network status.

\section{Traditional Media and Companionship}

Traditional media, such as televisions and radios, were found to be utilized by their users to keep them companies. Rubin and Rubin's (1982) study found that television users utilized game show and daytime serial viewing rather than news viewing for companionship. Tramer and Jeffres (1983) found that radio users called Cleveland talk radio shows to seek companionship. Those users were also found to be frequent callers to the shows. Larson, Kubey, and Colletti (1989) studied early 5th to 9th graders' media uses for companionship. The researchers found all age groups reported often music listening and reading alone (an average of 58\% of the time and $53 \%$ respectively) for companionship. However, they found younger adolescents reported often watching TV with a family member. In the 5th and 6th graders, almost $2 / 3$ of TV viewing for companionship was with the family. The number declined to about half when asked the same question to 7 th and 8th graders. In this study, age was the key variable to use TV for companionship with family or alone.

Papacharissi and Mendelson (2007) examined uses and gratification model to study reality television shows viewing motivations. Their survey study investigated 157 college students' television viewing motivations. Their study found that television users utilized reality television shows to fulfill companionship needs. Those users were with low mobility and low levels of interpersonal interaction. Users who perceived reality television content as more real and developed more affinity for reality television content were more likely to watch to fulfill companionship needs. Similar findings were found in Armstrong and Rubin's (1989) study. In 
the study, the researchers found that callers to talk radio programs seemed to use the programs to substitute for interpersonal contact. Those callers also were found to be less mobile and reported that interpersonal communication was less rewarding to them.

\section{Interactive Media and Companionship}

Several mobile music device studies found that mobile music device users utilized their devices to keep them company while commuting in cities (Bull, 2000; 2007). Antonucci (1990) argued that companionship referred to direct effect model of social support (as cited in Leung \& Lee, 2005). Leung and Lee (2005) implied that people might receive direct advice, information, suggestions, relaxation, and other types of social support from interactive media (e.g., mobile phones, Internet, MP3). The researchers mentioned that people received positive social support via interactive media in the emotional/informational and positive social interaction dimensions. They conducted a face-to-face structured questionnaire interview study with 1192 respondents in 2002 in Hong Kong. Their study found people who had strong social support (i.e., received and gave love, affection, sympathy, guidance, advice, information, and social companionship and

spent time with others in leisure and recreational activities) both online and offline had better qualities of life.

Various interactive media studies showed that users utilized their media to seek information, get advice, kill time, maintain relationships, and keep themselves entertained while on the move. Examples included Rakow and Navarro (1993) who studied how mobile phones allowed mothers to manage their children and homes when they were away from their homes and children whereas their husbands utilized the mobile phones to fulfill their wives' "special needs of protection" (p. 144). Similar "mobile parenting" findings were found in Timo Kopomaa (2000) and Rich Ling (2004; 2008; 2012) studies.

The mobile phone also can function as a "pacifier for adults" since it supports connections, and in particular emotional connections, with their family. The mobile phone can help users who were away from home to fill in time gaps and deal with loneliness. In addition, it can be used to ask for advice from loved ones at homes (Geser, 2006). Chen and Katz's (2009) study found American college students used their mobile phone to maintain their relationships with their families while they were away from homes and with their friends when they were at school. Participants in their study reported that they made voices phone calls to family members 
and used social media and text messages to communicate with their friends. Participants called their family members anytime because they knew that their family members were going to be always available for their calls whereas they were concerned their friends' time availabilities at the moments. Moreover, another study found that mobile phone users used their devices to ask for prayers for their issues and concerns while they were in need (Baesler \& Chen, 2013).

\section{Mobile Augmented Reality System for Location Experience}

A MARS could be one type of mobile location-based systems (MLBS). MLBS is used in tourism for information seeking and providing a different location experience. Cheverst, Davies, Mitchell, and Friday (2000) designed an mLBS, called GUIDE, to help tourists with up-to-date, context-aware information about a city. Based on a tourist's personal context, such as personal preferences, current locations, and attractions visited, and environmental context, the mLBS made recommendations for its users. van Setten, Pokraev, and Koolwaaij (2004) designed an mLBS, called COMPASS (short for COntext-aware Mobile Personal ASSistant), an application providing tourists with context-aware recommendations and services. They reported that the mLBS helped tourists to find relevant and interesting objects and POIs based on personal interests and current locations and situations.

Recent MARS studies also showed that the MARS could enhance location experience for its users (e.g., Pavlik, 2001). Examples included that studies found MARS could enhance informal learning and interpersonal interactions in tourist locations (Kounavis, Kasimati, \& Zamani, 2012). Yovcheva, Buhalis, and Gatzidis (2012) argued that a MARS (1) provided location-based systems (LBS) information for tourists to know where they were; (2) enabled access to content for tourists to know what to do in real time; (3) were flexible to share and find texts, photos, and videos of locations. CityView, a MARS, provided geographical information about destroyed buildings and historical sites that were affected by earthquakes in 2010 and 2011 at the city of Christchurch, New Zealand. The results showed the MARS users had a richer experience of the locations by using the system (Lee, Dunser, Kim, \& Billinghurst, 2012).

\section{Design for Facilitating Companionship}

A master student design team at Carnegie Mellon University studied senior's companionship needs. They found that seniors kept their children's photos with them all of the 
time and they also showed and talked about the stories of their children's accomplishments to others. The wanted more interaction with their family members, especially for passing their knowledge to the next generations. However, they also did not want to burden their children and grandchildren. The research team designed a wearable and stationary device called ShareComp: Sharing for Companionship. The ShareComp allowed senior users to record their activities and document past activities in multimedia formats to share with family and friends. In addition, it also allowed others to know the user's location for safety reasons (C.-Y. Chen, Kobayashi, \& Oh, 2005).

Vardoulakis, Ring, Barry, Sidner, and Bickmore (2012) designed a virtual agent, The Remote Wizard of Oz System, that could provide social support and wellness coaching to isolated seniors at their homes. This companion agent had many functions including companionship dialogue, connections with family and friends, and memory improvement tasks, among others. Their findings included that the agent-participant conversations were highly individualized. The topics included discussions of family and friends to music, news, and fashion. Top three discussion topics were family, weather, and storytelling. Their results showed a strong pattern between the technology and companionship.

Another area of technology to support companionship was the relational agent. Relational agents were autonomous, embodied agents designed to form relationships with their users by building trust, rapport, and therapeutic alliance over time. These agents were typically designed as computer-animated, humanoid agents that simulate face-to-face dialogue with their users. The researchers in this study designed a FitTrack, an easy-to-use relational agent. One of the FitTrack functions was that the conversational agent asked users' prior day physical activities, showed users a self-monitoring graph of their progress, provided positive feedback when warranted, discussed obstacles to exercise, and negotiated a walking goal for the following day. The researchers found that users accepted and liked their relational agents. In addition, the agent was significantly more efficacious at increasing physical activity (daily steps walk) to their senior users (Bickmore, Caruso, Clough-Gorr, \& Heeren, 2005).

\section{Conclusion}

In summation, prior studies show media themselves (e.g., mobile phone, television, music device) or media content (e.g., messages from family and friends, mass media content) 
could facilitate users' companion needs. Research on the MLBS showed that the MLBS provided different location experiences to its users. It is interesting to learn how the MARS and the situated documentaries that were retrieved by the MARS might impact on its users. This study aimed to examine if a MARS could also provide companionship to its users. 


\section{CHAPTER 3}

Methodology

In this study, the Domestication Approach (Haddon, 2003; Silverstone et al., 2005) was used to examine the use patterns of Pokémon Go whereas the Uses and Gratification Theory (Katz et al., 1974) was utilized to investigate use motivations. A triangulation method combined a participant observation in Kaohsiung, Taiwan and a qualitative content analysis from a popular Taiwanese Facebook Group Page to learn patterns and motivations of the MARS experience.

Why Taiwan?

Taiwan was selected to be the research site because Taiwan is one of the countries whose citizens have enthusiastically embraced Pokémon Go. According to a news report by Time, a mob of the Taiwanese MARS users was "pushing through an intersection" in a city "with the urgency and intensity one usually expects of marathons or attempts to escape alien invasions or terrorist attacks" for a Snorlax (please see Figure 2). "Thousands" of the Taiwanese MARS users could gather together to try to catch the particularly exotic Pokémon when the Pokémon appeared at a location. Because of the overcrowding, the police reinforcements and the civildefense brigade had to be called in (Jenkins, 2016). Additionally, when counting the monthly active users, Pokémon Go was ranked the number one mobile game in Taiwan (along with the United States, United Kingdom, Canada, Australia, Mexico and Thailand) as of the May 2017 (Hollister, 2017). It seems to be Taiwan is a fit research location to study a MARS use patterns and motivations. 
Figure 2: A mob chasing a Snorlax in Taiwan

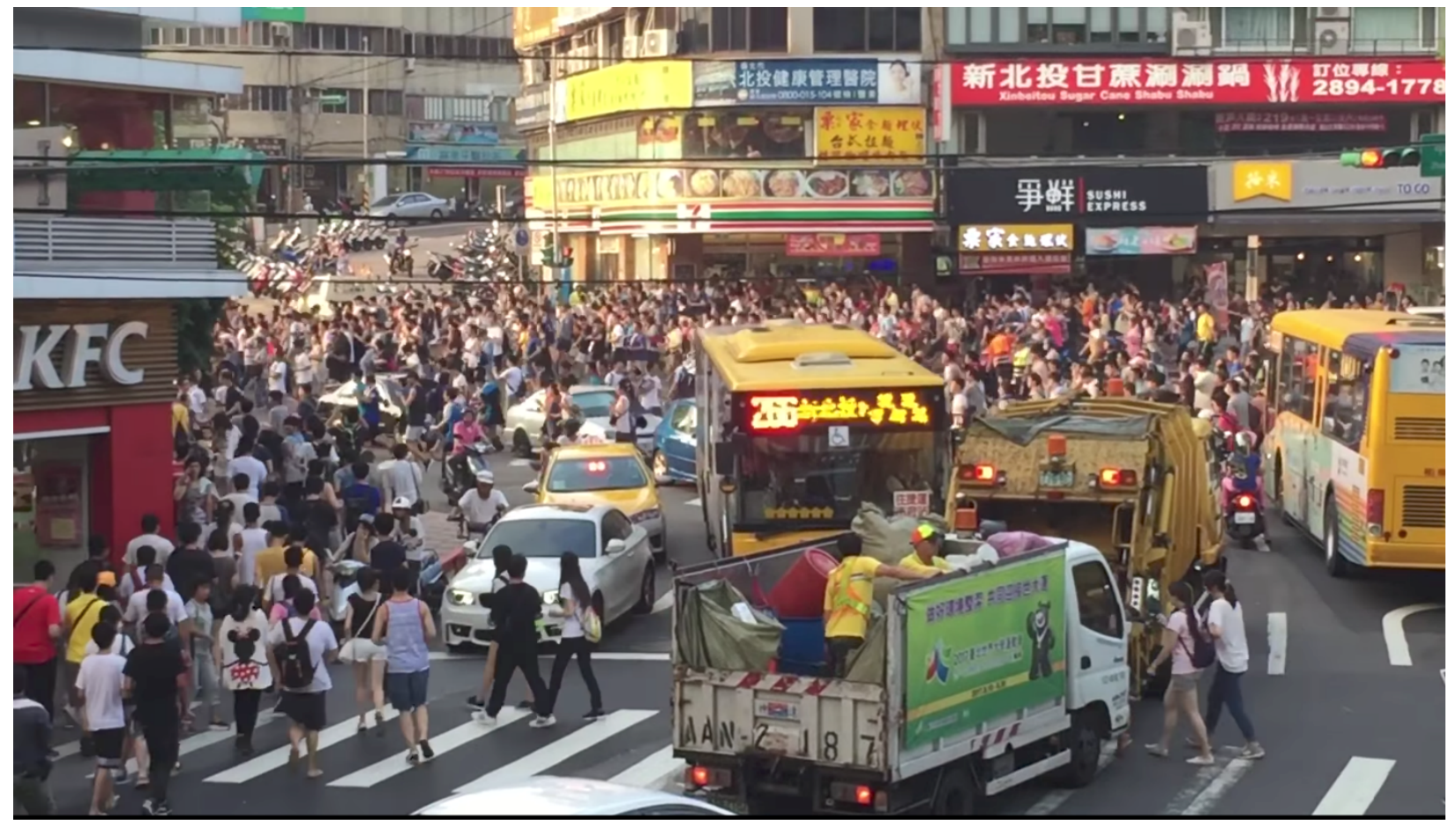

Source: Jenkins (2016)

Many researchers and scholars (Television: A. M. Rubin, 1983; Radio- Rubin \& Step, 2000; MP3 player- Ferguson, Greer, \& Reardon, 2007; mobile phone- Leung \& Wei, 2000) examined Uses and Gratifications Theory from a quantitative way. Weaver (1993) argued that most Uses and Gratification research has shown people much about general patterns, trends, and relationships, and can enable people to generalize with more accuracy than their personal experience and impressions. However, Pool (1983) noted when a medium is in the early stages of development, Uses and Gratifications Theory's predictions might be inaccurate. Additionally, Leeds-Hurwitz (1992) suggested researching human behavior in various methodologies, such as “cultural studies, critical theory, postmodernism, semiotics, phenomenology, structuralism, hermeneutics, naturalistic inquiry, ethnography and social communication” (p. 131).

This study used a triangulation research method to answer the research questions. The triangulation research method combines two or more forms of evidence with respect to an object of research interest (Fielding \& Fielding, 1986). Its goal is to seek a convergence of meaning from more than one direction. If data from two or more methods seems to converge on a 
common explanation, the research finding is enhanced (Lindlof \& Taylor, 2002; Maxwell, 2005). Although the MARS is not in the early stages of development, it has recently reached its critical mass. Therefore, this study combined several participant observations in Taiwan and a content analysis from a popular Taiwanese Facebook Group Page to learn patterns and trends of the MARS experience.

\section{Observation}

Naturalistic research methods included interviewing, observation, and document analysis of data collection. Participant observation has been used in various fields, such as anthropological, sociological, and educational studies (Kawulich, 2005). Observation is defined as "the systematic description of events, behaviors, and artifacts in the social setting chosen for study" (Marshall \& Rossman, 1989, p. 79). Observation is one of the research methods to conduct fieldwork that requires "active looking, improving memory, informal interviewing, writing detailed field notes, and perhaps most importantly, patience" (DeWalt \& DeWalt, 2002, p. x). Naturalistic research methods seem to be good methods to study social interaction within a culture because "the goal for design of research using participant observation as a method is to develop a holistic understanding of the phenomena under study that is as objective and accurate as possible given the limitations of the method" (DeWalt \& DeWalt, 2002, p. 92). This study utilized the naturalistic research method to study how people use a MARS in their everyday life, the focus was the interaction between users and other users as well as between users and the MARS objects. The naturalistic research method was selected because it aimed to blend into people's everyday activities in order to come to a theoretical understanding of the MARS using patterns. It respected people in their daily lives, and took users' actions and experience seriously but did not interfere with their daily lives. Lincoln and Guba (1985) compared positive and naturalist axioms and pointed out that naturalist paradigm focused on (1) realities are multiple, constructed, and holistic; (2) knower and known are interactive, inseparable; (3) only time- and context-bound working hypotheses are possible; (4) all entities are in a state of mutual simultaneous shaping, so that it is impossible to distinguish cause from effects and (5) inquiry is value-bound (p. 37).

In the current study, the observation field data was collected from June 22, 2017, to August 7, 2017 (i.e., the PokéGym system was reworked and the addition of Raids to before the Zapdos arrived). During the time period, the researcher selected two or more PokéGyms when 
there were level 4 or legendary raids happened in Kaohsiung, Taiwan to observe how users used the MARS every day. Kaohsiung has a population of 2,777,873 (The Straits Times, 2017). It is a big city with many Pokémon Go users. The researcher used an online Pokémon Search Map, the name translated as "Everyone Seeks for Pokémon", that showed where Pokémon and raids appeared to find the research locations (please see Figure 3 \& Figure 4). The observation times for each location was in average 30 minutes. Observation times ranged from mornings to nights. Field notes and photos were taken when the situations allowed. The researcher paid special attention to interactions (1) between the MARS users and non-users, (2) between the MARS users and other MARS users, and (3) between the MARS users and Pokémon.

Most of the MARS users learned about the raids from the online Pokémon search map. The number of the MARS users in each raid ranged from 5 to over a hundred depending on the time and location when the raid appeared. Some of the MARS users came alone whereas others came with groups. They also used popular social media such as "LINE" or Facebook to gather their family members and friends to meet at the PokéGyms for battling the Raid Bosses or Legendary Pokémon. Sometimes, they exchange their social media information at the PokéGyms ${ }^{4}$ or PokéStops ${ }^{5}$ with strangers to arrange the next gathering or to exchange information. Most of the MARS users came by scooters. A few of them came by cars, bicycles or foot.

\footnotetext{
${ }^{3}$ LINE is a popular system for communication on mobile media and computers in Taiwan (McCracken, 2015).

${ }^{4}$ PokéGyms are virtual places on landmarks or public spaces in Pokémon Go that provide the MARS users to battle raids and Pokémon from other teams as well as collect Pokémon Balls or other items. Additionally, after winning the PokéGym battles, the MARS users could assign one of their Pokémon to occupy the PokéGyms for collecting Pikachu Coins that allow users to purchase the system-related items from the PokéShop.

${ }^{5}$ PokéStops are virtual places on landmarks or public spaces in Pokémon Go that allow users to collect items, such as Poké Balls and Eggs.
} 
Figure 3: Pokémon Search Map for the rare Pokémon

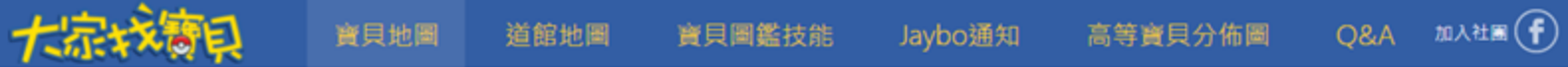

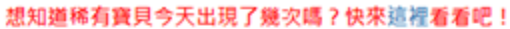

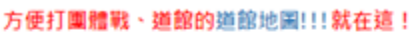

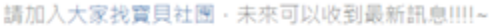

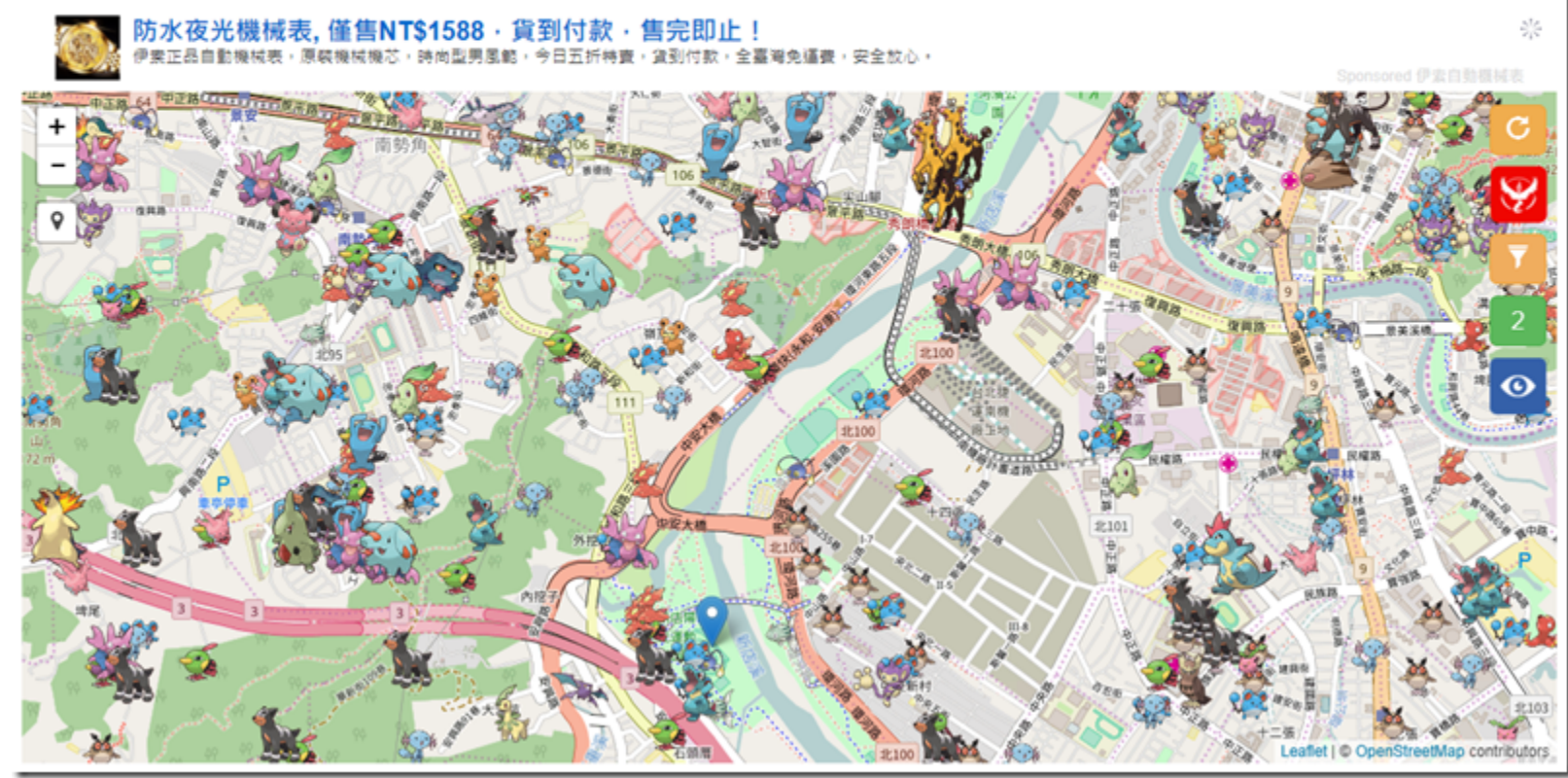

Source: kocpc (2017) 
Figure 4: Pokémon Search Map for PokéGyms and raids

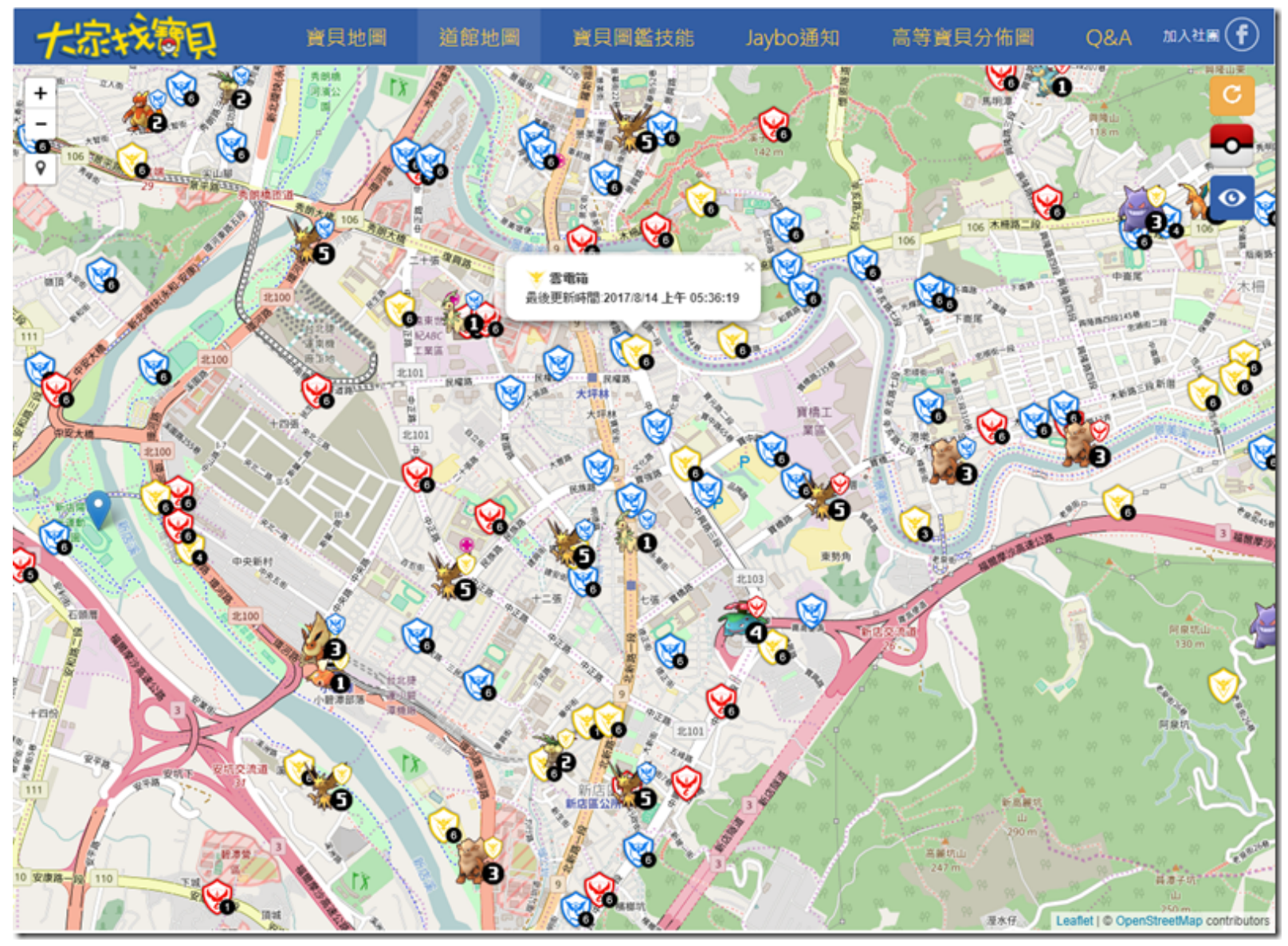

Source: kocpc (2017)

Content Analysis of Posts on the Facebook Group Page

In addition to observation, this study analyzed posts on a Facebook Group Page between June 22, 2017 and August 7, 2017. The "Pokémon Go Kaohsiung" is a public Facebook Group with 18,522 active members as of November 2, 2017 (Pokémon Go Kaohsiung, n.d.) (please see Figure 5). Although anyone can see the group, its members, and posts, the administrators actively monitor group posts to make sure that all posts are Pokémon related and not advertisements. The group had created 4 events to encourage members to come together to catch Pokémon during Christmas and New Year holidays. On September 27, 2017, all posts with photos at that time period were collected as a result of 2,109 posts to be analyzed. Sample posts please see Figure 6. 
Figure 5: Pokémon Kaohsiung Facebook Group

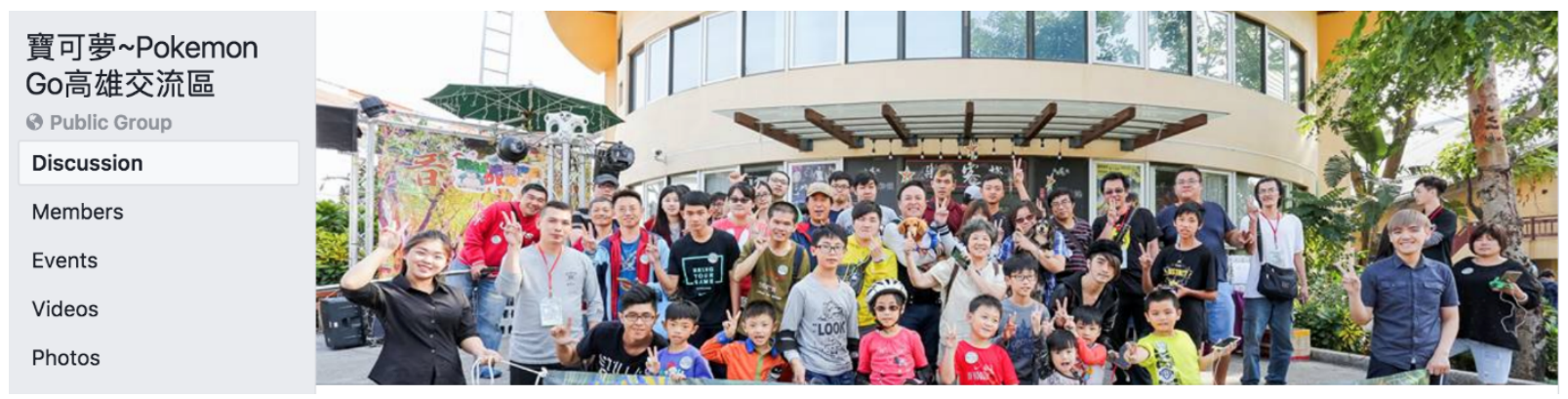

Source: (Pokémon Go Kaohsiung, n.d.)

Figure 6: Samples of the Facebook posts
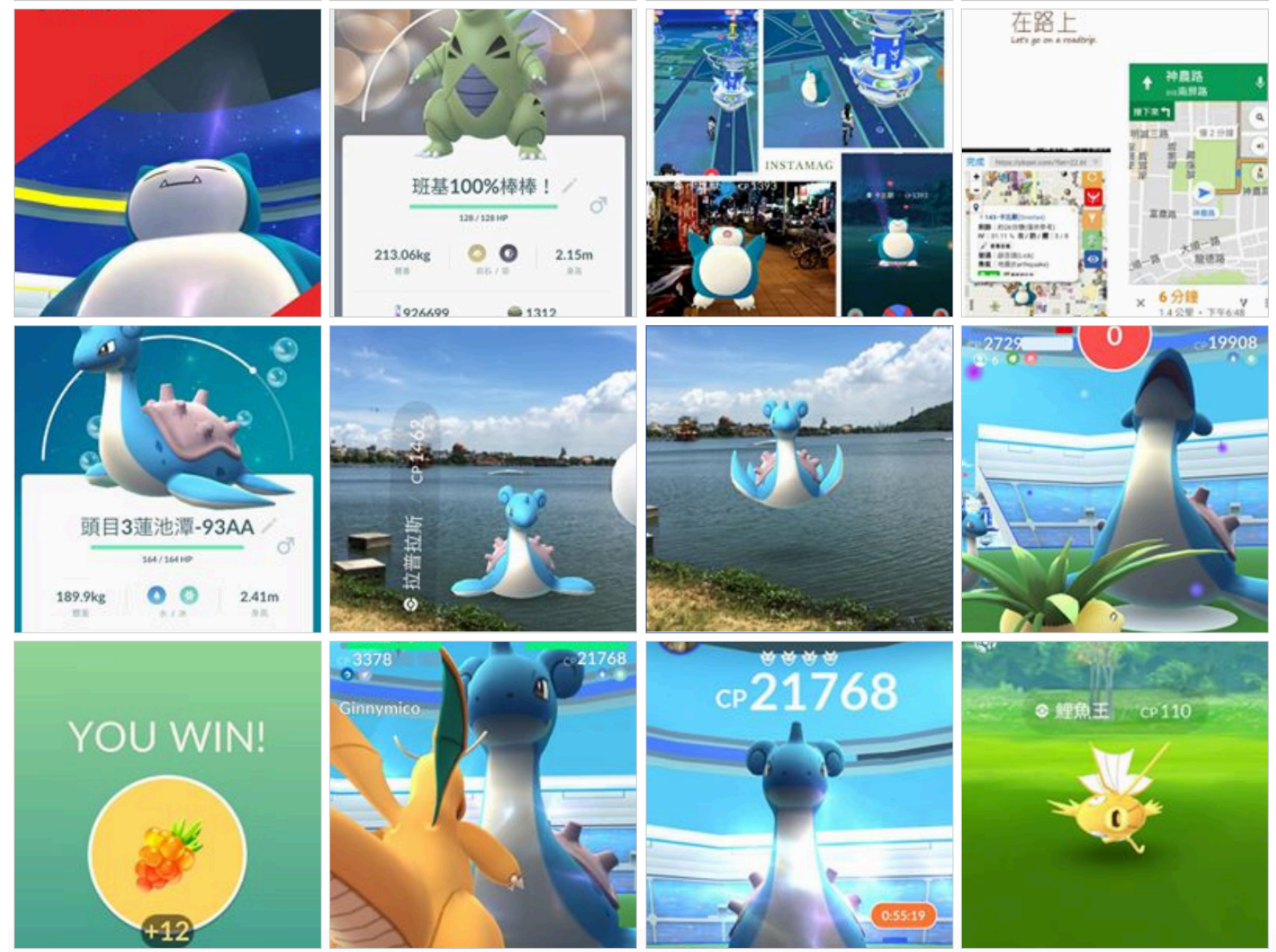

Source: Pokémon Go Kaohsiung (n.d.) 
Content analysis is a research techniques for systemize analysis of texts. It addresses not only manifest content but also theme and core ideas that are found in texts as primary content (Morgan, 1993). Unlike other types of qualitative research, such as discourse analysis, critical theory, and contemporary critical social analyses that have deep interpretation that goes beyond describing and summarizing the overt content found in texts studied, content analysis focuses on more descriptive and seeks to expand on the textual data on which it is based (Drisko \& Maschi, 2016).

The current study is mainly based on the observation data to understand the MARS use pattern and utilized the qualitative content analysis data to enhance the research findings on the observations. The qualitative content analysis aimed to describe the patterns and themes that were found in field observations.

\section{Data Analysis}

After all observations were done and Facebook posts collected, the researcher read several times over the field notes and Facebook posts. The researcher then found categories in the field notes and posts. This technique, called "open coding," was the initial and unrestricted coding of data (Strauss \& Corbin, 1998). Strauss and Corbin (1998) outlined opened coding technique from (1) going through the texts line by line; (2) marking those chunks of the text that suggest a category; and then, (3) naming those categories and having attributes ascribed them.

Guided by Strauss and Corbin's (1998) qualitative data analysis recommendations, a codebook was then created to help the researcher list all categories and the location of each incident in the data records. At this point, an axial coding technique was used to make connections between categories. The axial coding brought previously separate categories together into several broad themes. Once the analysis was completed, several direct quotes from field notes and posts that highlighted those themes and discussion points were incorporated into the data analysis. 


\section{CHAPTER 4}

Findings

The Domestication of the MARS

This study found Pokémon Go MARS users from all age groups and occupations. The MARS users tried the system because their family members or friends introduced the MARS to them. Some of them learned about the system from online, on media or offline at PokéGyms or PokéStops. They discussed the system with their social networks or their Pokémon networks. They become more skillful to train, collect, select, and battle their Pokémon. They compared their avatars' trainer levels, Pokémon skills, and Pokémon collections with others. By showing their trainer levels and rare Pokémon, the MARS users were making their Pokémon statements as if the users were part of the Pokémon elite class to others on the Facebook Group Page as well as at PokéGyms or PokéStops (please see Figure 7 \& Figure 8).

Figure 7: Level up!

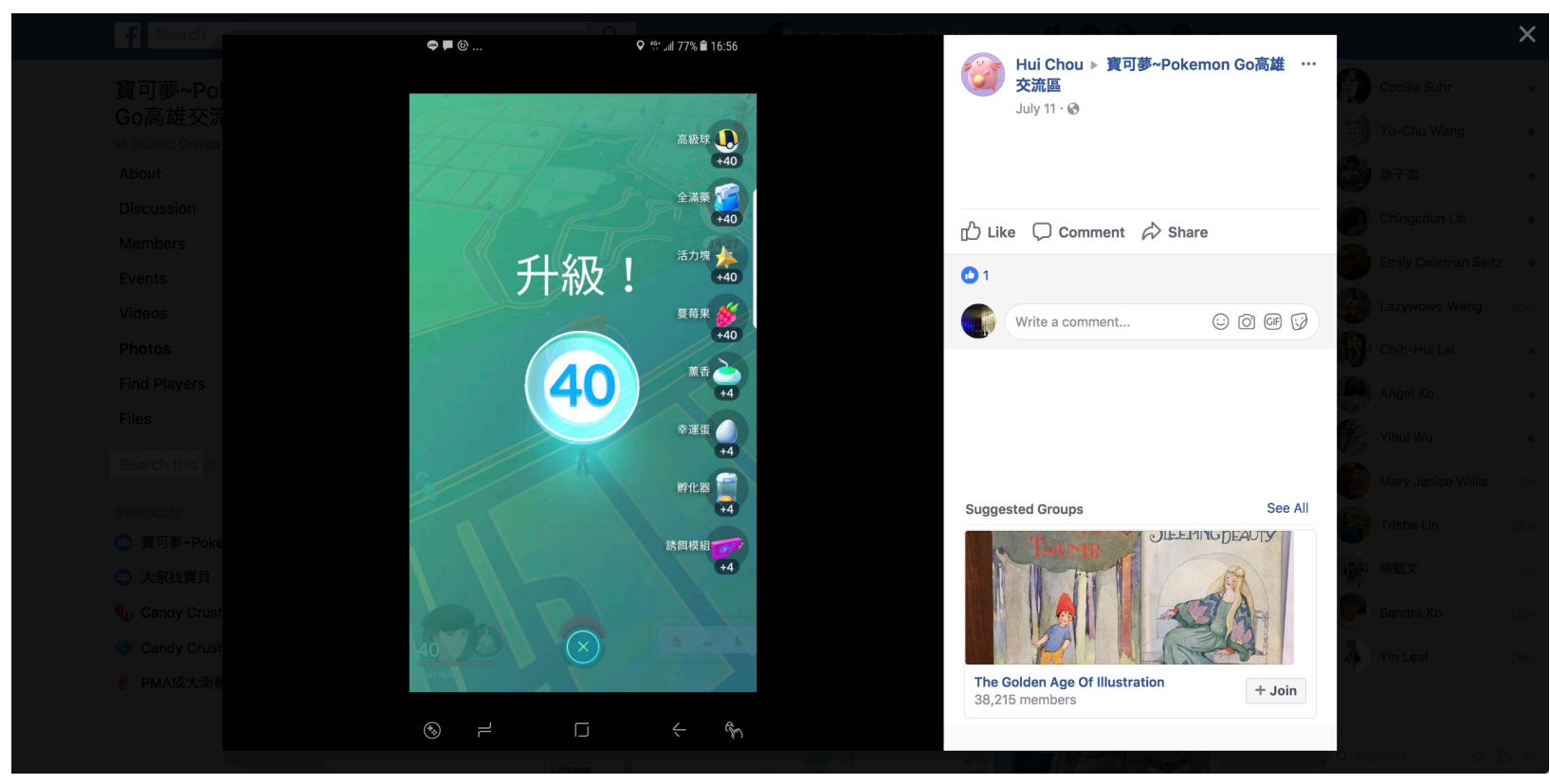


Figure 8: 100\% Tyranitar awesome!

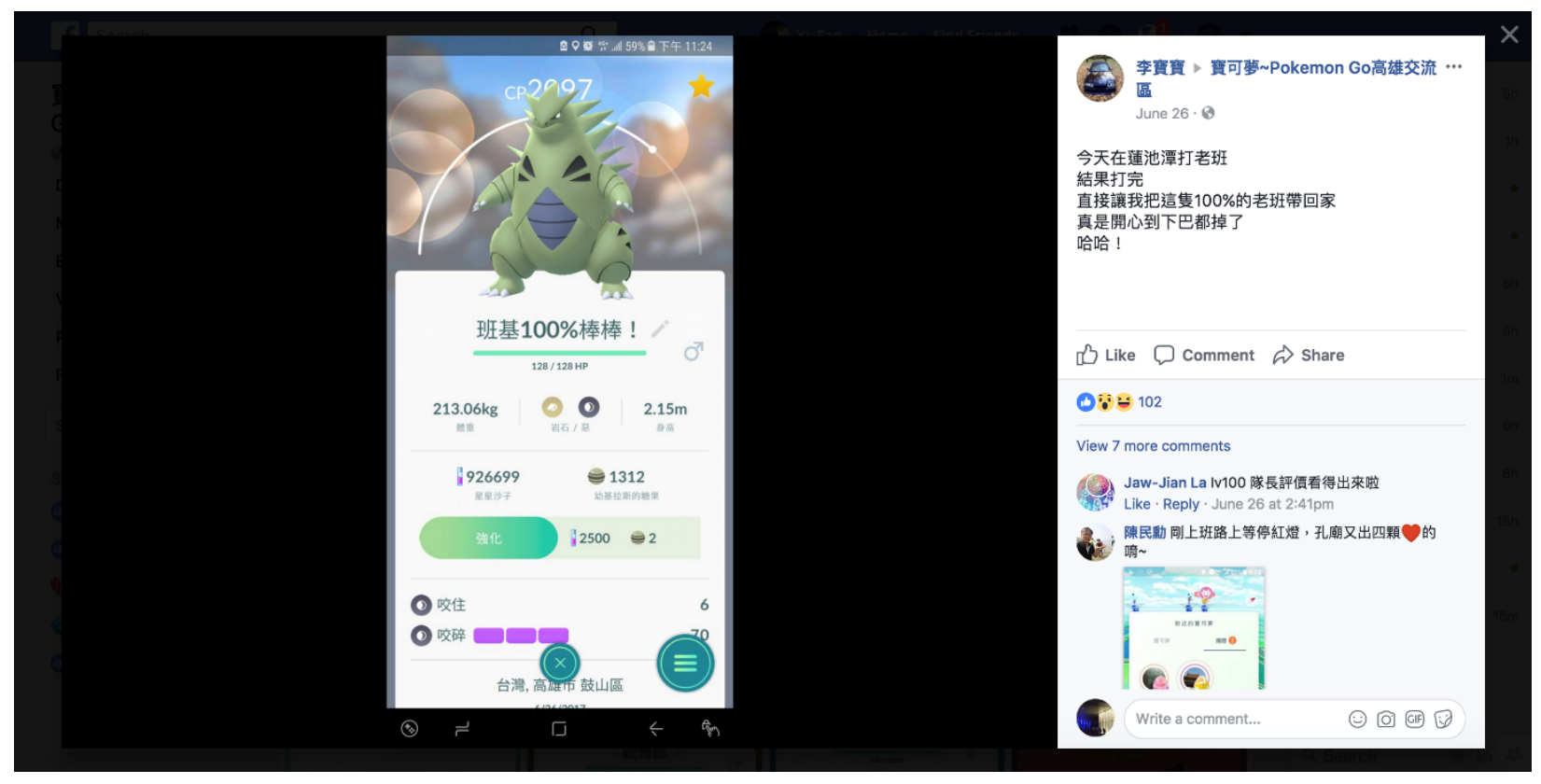

Children went out to catch Pokémon with their parents and grandparents on their scooters after schools or during weekends. High schoolers went alone or with their friends by bicycles before or after school. Housewives were often found alone around 10 o'clock in the morning. They also could be found after dinners with their husbands or children on the street to catch Pokémon together. Young people also went alone or with friends but they used scooters to navigate between PokéGyms and PokéStops in the city.

Female MARS users often came with boyfriends, friends or family members whereas male MARS users might come alone or with other MARS users. The time that they spent at a PokéGym was between 15 minutes and a half hour for a raid. It was not unusual to find the MARS users to have more than one account or use more than one phone. Those extra accounts and mobile phones were for their family members or friends who were not able to attend in person. Examples included a mother who took her son and daughter's phones to combat Legendary Pokémon while her kids were sleeping. A female MARS user used her brother's account on her phone to catch Legendary Pokémon because he was busy at work. A husband helped his working wife to battle Legendary Pokémon with his 5-year-old daughter. His wife "ordered" him to take the kid out to catch some Pokémon "for her". On the Facebook Group 
Page, posts showed that a few MARS users helped their family members or friends to catch region exclusive Pokémon ${ }^{6}$ in different continents when they traveled overseas.

During weekends, parks and streets with many PokéStops had many MARS users with their families and friends, especially when there were special events. Public places with lure modules ${ }^{7}$ often attracted more group users. Those lure modules were placed by other MARS users voluntarily. Sometimes, they announced locations and times they were going to place lure modules on social media to let other users knew ahead of time. Parents and grandparents took their young children to catch Pokémon when the weather was not too hot. Young people came to the PokéGyms in groups for battling Pokémon from other teams or for raids. They navigated around the city based on the Pokémon Search Map. Sometimes, they would travel kilometers to chase a rare Pokémon when the Map sent them the rare Pokémon alarm. Retired seniors were found alone traveling on foot or by bicycles to PokéGyms. Some seniors used more than one mobile phone and had more than one account for themselves. They could be found 24-7 around PokéGyms and PokéStops. Some of them were also higher-level trainers with trainer level 38 or above.

The MARS users with work often stayed less than 5 minutes at a PokéGym. Because of the Pokémon Search Map, the MARS users could manage their work and play time more efficiently. Blue-collar workers joined with their colleagues during lunch breaks or bathroom breaks. As soon as they finished the raid battles, they went right back to their work. White-collar workers were spotted for raid battles before or after work on their scooters or cars. They left right after the raid battles to return to home or work. On the way to and from work, the MARS users were catching Pokémon on buses. They reported that "Pokémon makes commuting fun." In general, more male MARS users than female MARS users were found in Kaohsiung (please see Figure 9).

\footnotetext{
${ }^{6}$ Region exclusive Pokémon are group of Pokémon that are available for capture only encountering them in wild in their specific regions in the real world.

${ }^{7}$ Lure modules use at PokéStops to increase Pokémon Spawn Rates.
} 
Figure 9: Samples of the MARS users battled raids at PokéGyms
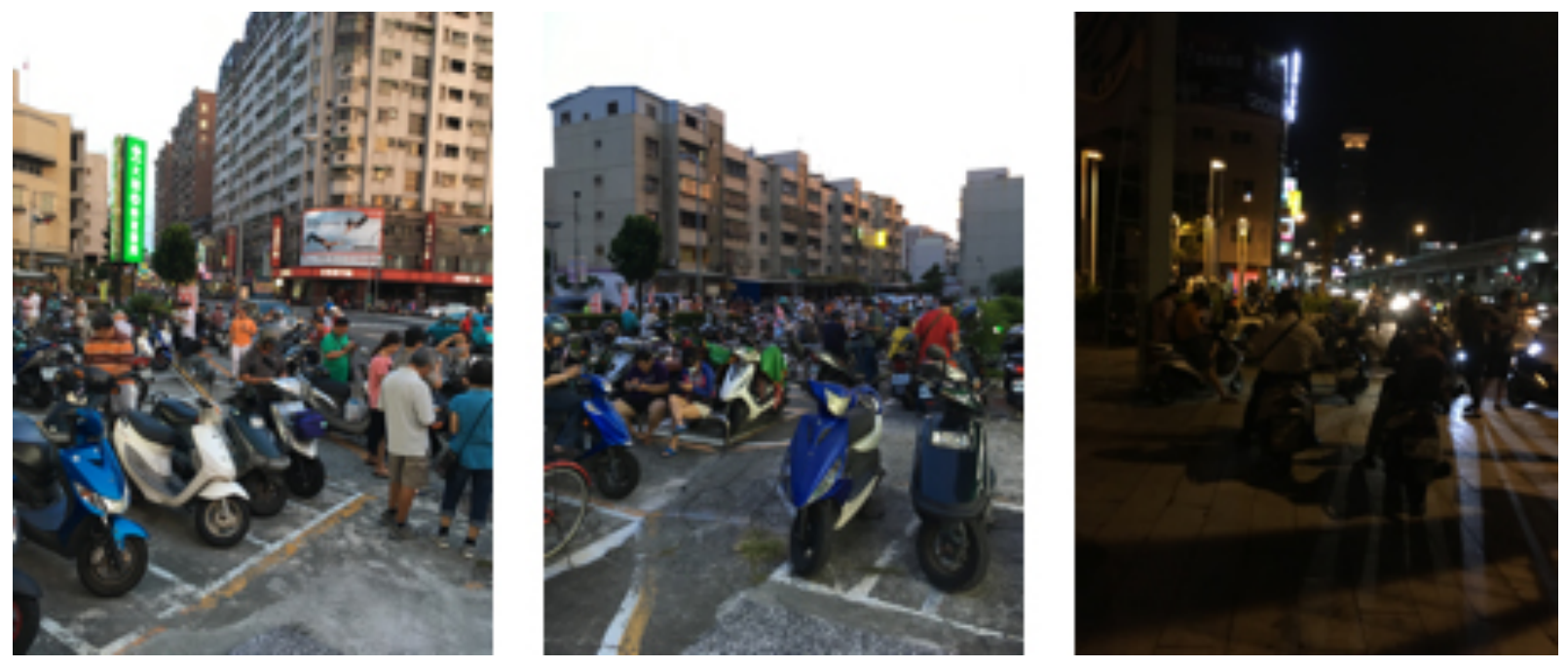

Content is Crucial

When there were new events introduced, such as promotional events or legendary Pokémon, the MARS users spent money to purchase raid passes for battling level 4 or legendary Pokémon. The sales of the Lucky Eggs and the Egg Incubators increased during the events. "I work hard at my real job. So, I can have money to buy those virtual items for leveling up my trainer level” (a female MARS user). "The raid passes won't cost too much, but, I have so much fun" (another female MARS user). Those events also attracted returning the MARS users and new users. For example, here was a conversation at a PokéGym before a raid:

"What are you guys doing here? So many people are here" (a bystander)

"We are playing Pokémon Go." (a MARS user)

"I heard Pokémon Go before. Is this app what I need to download?

How to play? Am I doing this right?” (the bystander)

Another conversation at another location was as followed:

"I stopped to play when I collected all Pokémon. I re-downloaded the system after new Legendary Pokémon were released." (a male MARS user) 
Similar conversations could be found at the Facebook Group Page (please see Figure 10).

Figure 10: I hear the Legendary Birds are available now. Re-downloaded the system back $\ominus$.

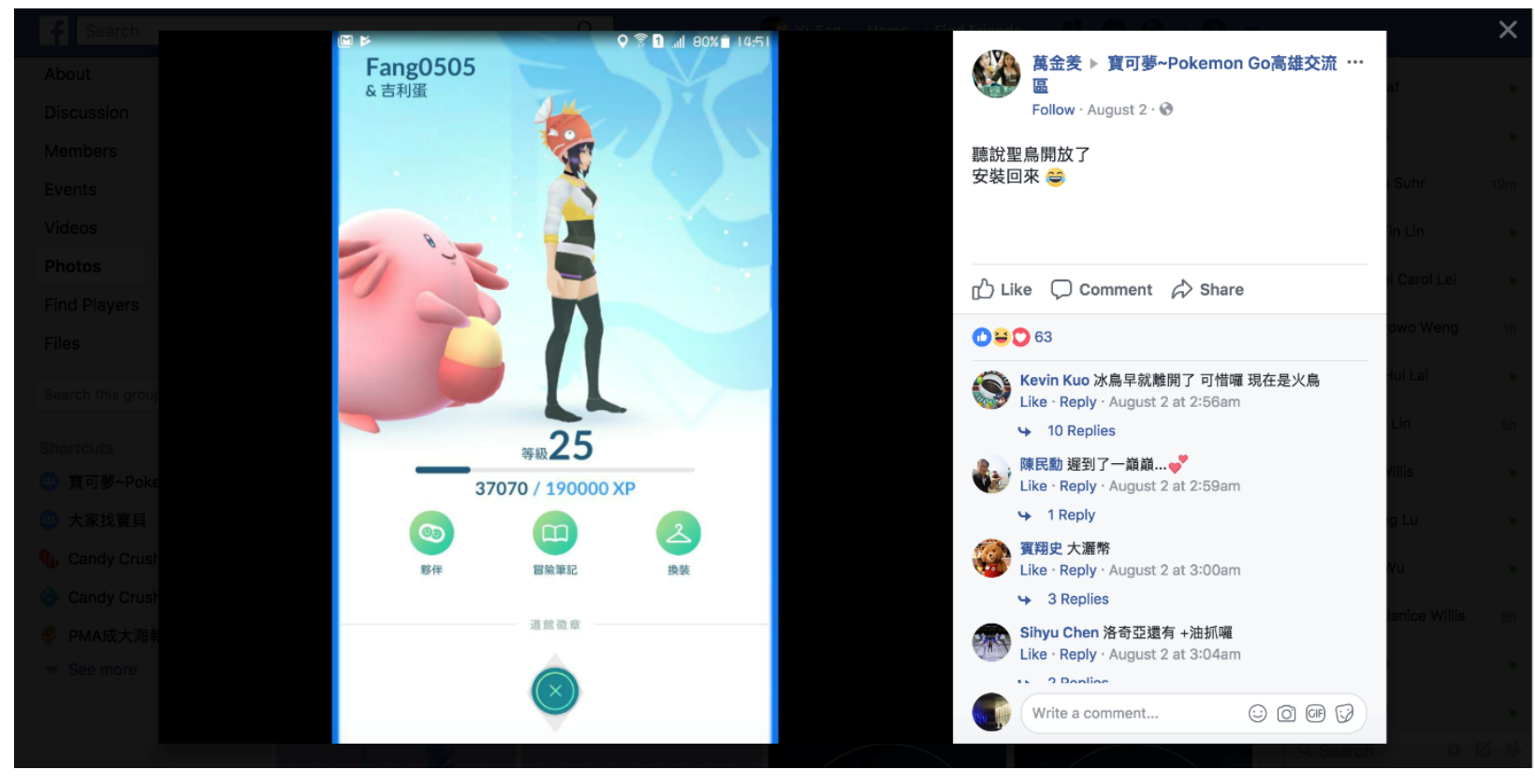

There were exchanges of information at the PokéGyms and on the Facebook Group Page. At PokéGyms before, during, and after raids, the MARS users were helping each other to pick the right Pokémon to battle. It was very natural to chat with other MARS users who were total strangers at PokéGyms about how they got involved in the system and what success stories they had about the system and about the battles. Stories about the MARS users' Pokémon as well as their personal life were also shared at PokéGyms. After the raids, the MARS users exchanged tactics for how to catch the boss or legendary Pokémon. Sometimes, they handed their mobile devices to total strangers to catch the Pokémon for them if they did not have enough confidence to catch them by themselves. If anyone caught the boss or legendary Pokémon, other users at the same location often congratulated the user. They also wanted to know the IV or skills that the Pokémon had.

On the Facebook Group Page, many posts were about raids' locations or alarmed others about forthcoming raids (please see Figure 11). They shared information or posted "how to catch" videos for the level 4 or legendary Pokémon on the Facebook Group Page. Those information and videos often generated more discussions and knowledge/experience sharing on 
the Facebook Group Page. Some posts were about how to win the battles (please see Figure 12), about characteristics of a special Pokémon, about the system itself or about related products (please see Figure 13).

Figure 11: An image posted on the Facebook Group Page to alarm other users the raid location

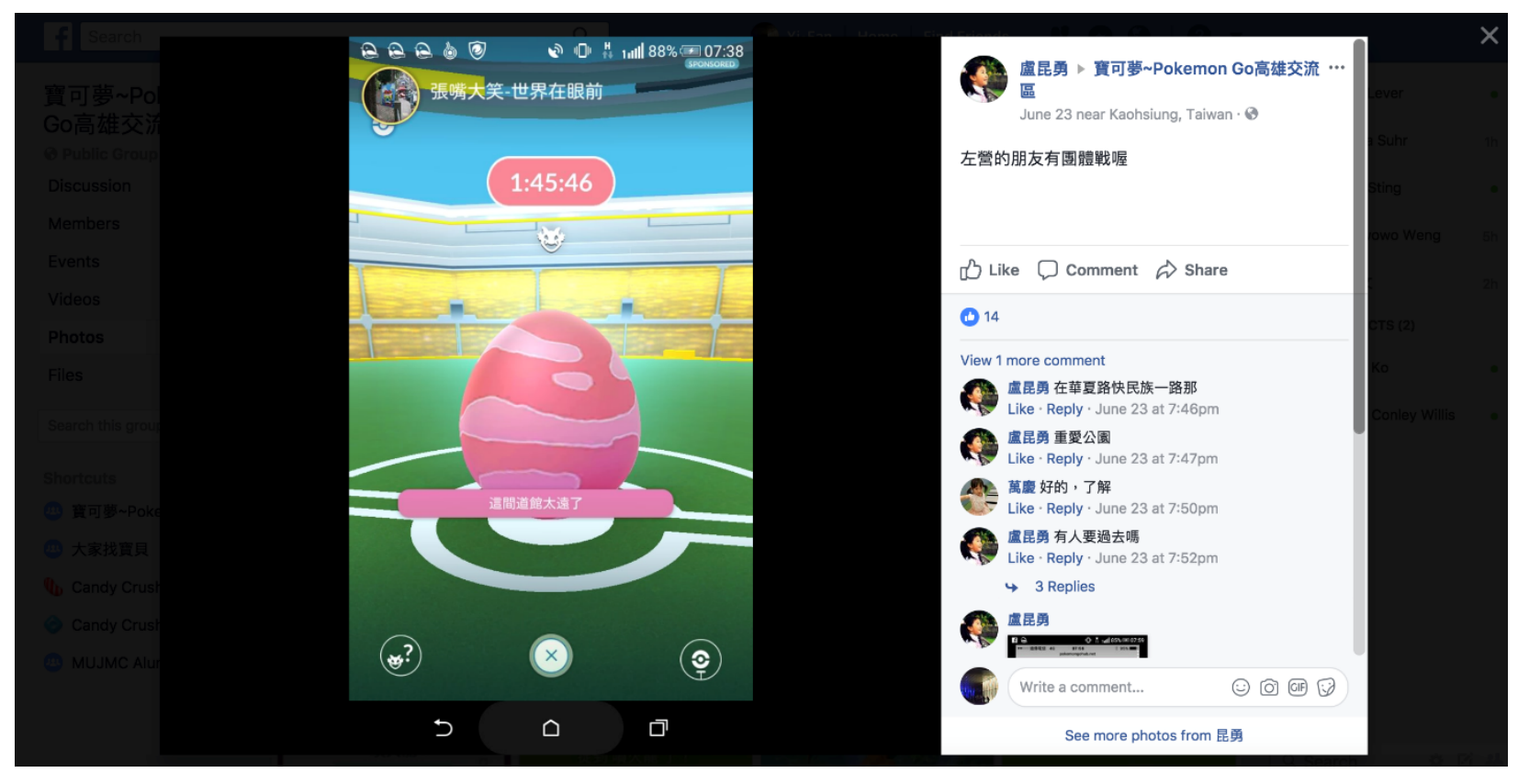


Figure 12: Information of the legendary Pokémon

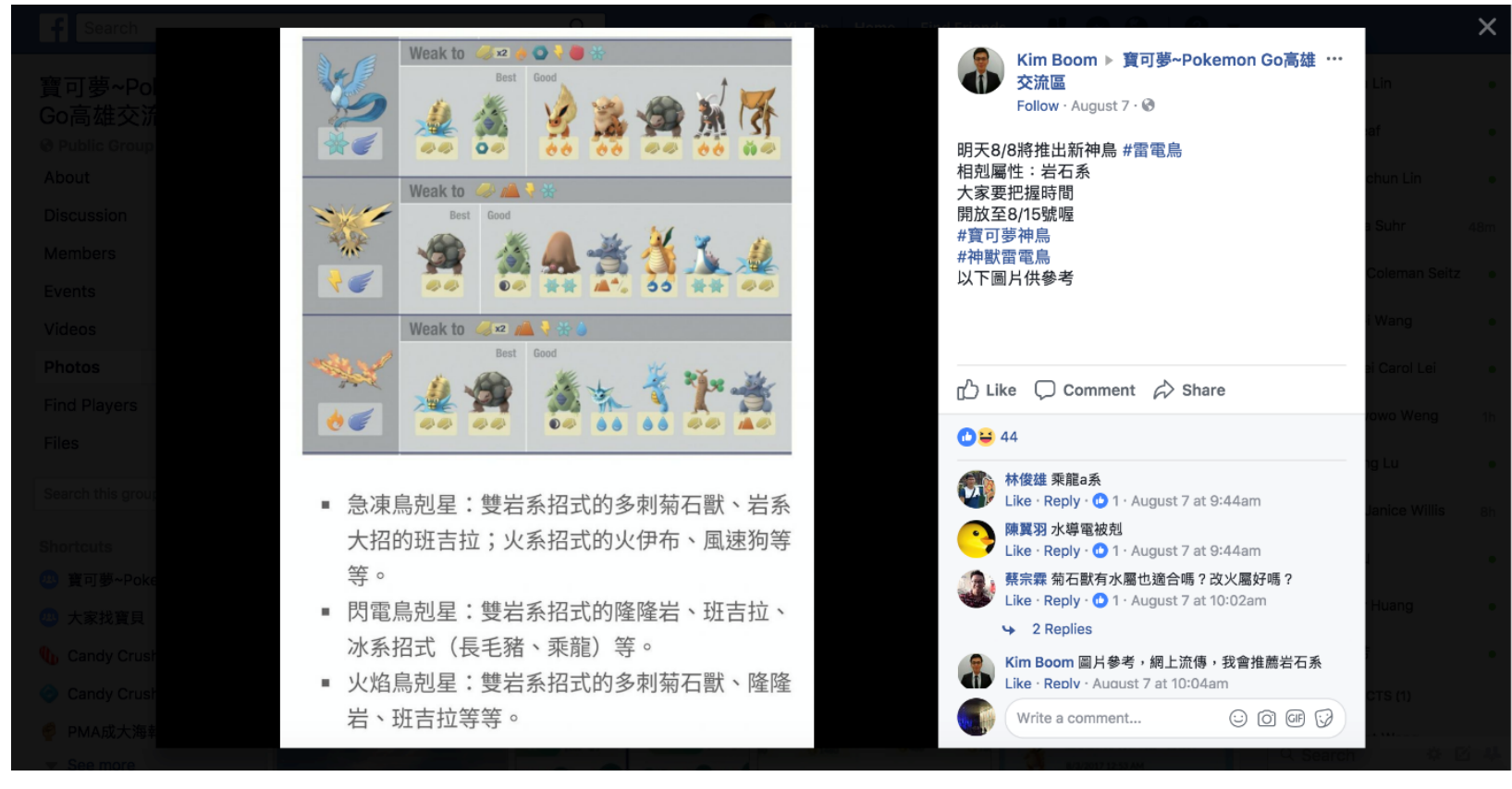

Figure 13: A MARS user questioned about a related product

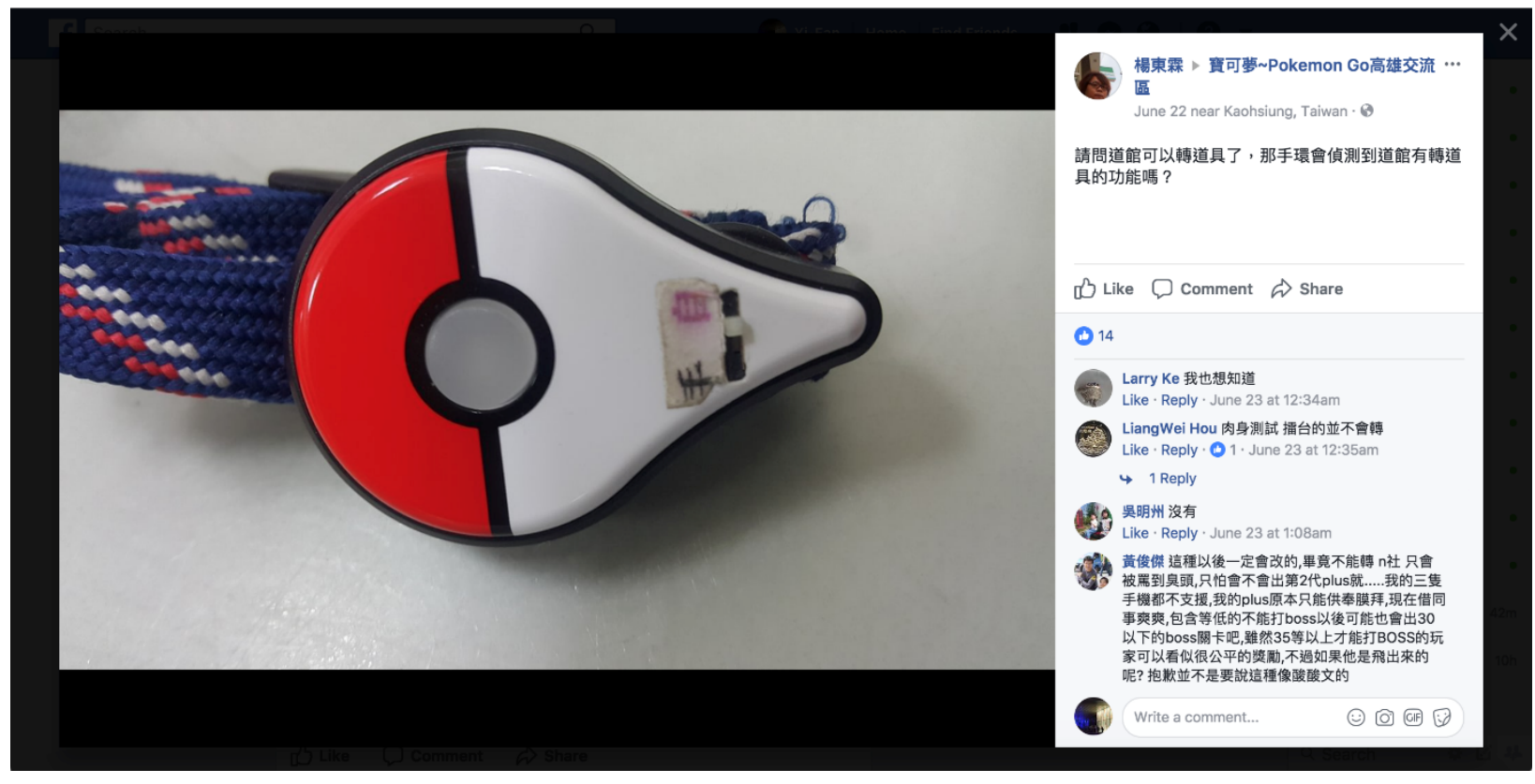




\section{Socialization (social)}

There were not many conversations during raid battles when blue-collar workers were involved. They simply came to the battles and finished the job, then went back to their real-world jobs. Many of them attended several raid battles in a day when their jobs allowed. On the other hand, many conversations were frequently found at PokéGyms among the MARS users. Those conversations were mainly Pokémon related but not limited to it. The MARS users also talked about other news or made small talks with other MARS users at PokéGyms. Those talks included all topics such as government, jobs, personal life, family, and more. They seemed to make new friends or brought their own friends at the PokéGyms with raid battles on-going. At the PokéGyms, the MARS users exchanged their LINE ID or asked their new friends to join the Facebook Group for future communication. They made calls and texted their personal social network to join the raids at PokéGyms when they did not find enough users to battle together. Most of the MARS users started the system because friends or family members got them into it. Some of them stayed with the system because their friends or family members wanted them to go out to battle, catch or chase Pokémon together.

\footnotetext{
"I was really bored of the system and almost gave up, but I keep playing because my boyfriend wants me to play with him. It is one thing that we can do together." (a female MARS users) "I play it during weekend with my wife and daughter together when we are walking at parks." (a male MARS user) "I met some friends at PokéGyms. Those young people taught me many cool stuffs." (a senior male MARS user)
}

On the Facebook Group Page, the MARS users created many LINE groups for organizing times to do raids by regions (please see Figure 14). The Facebook Group also had four events on January 29, 2017, December 31, 2016, December 17, 2016, and September 9, 2016 during the holiday seasons to encourage online members to meet offline and have fun catching Pokémon together. 
Figure 14: A sample of Line group recruitment

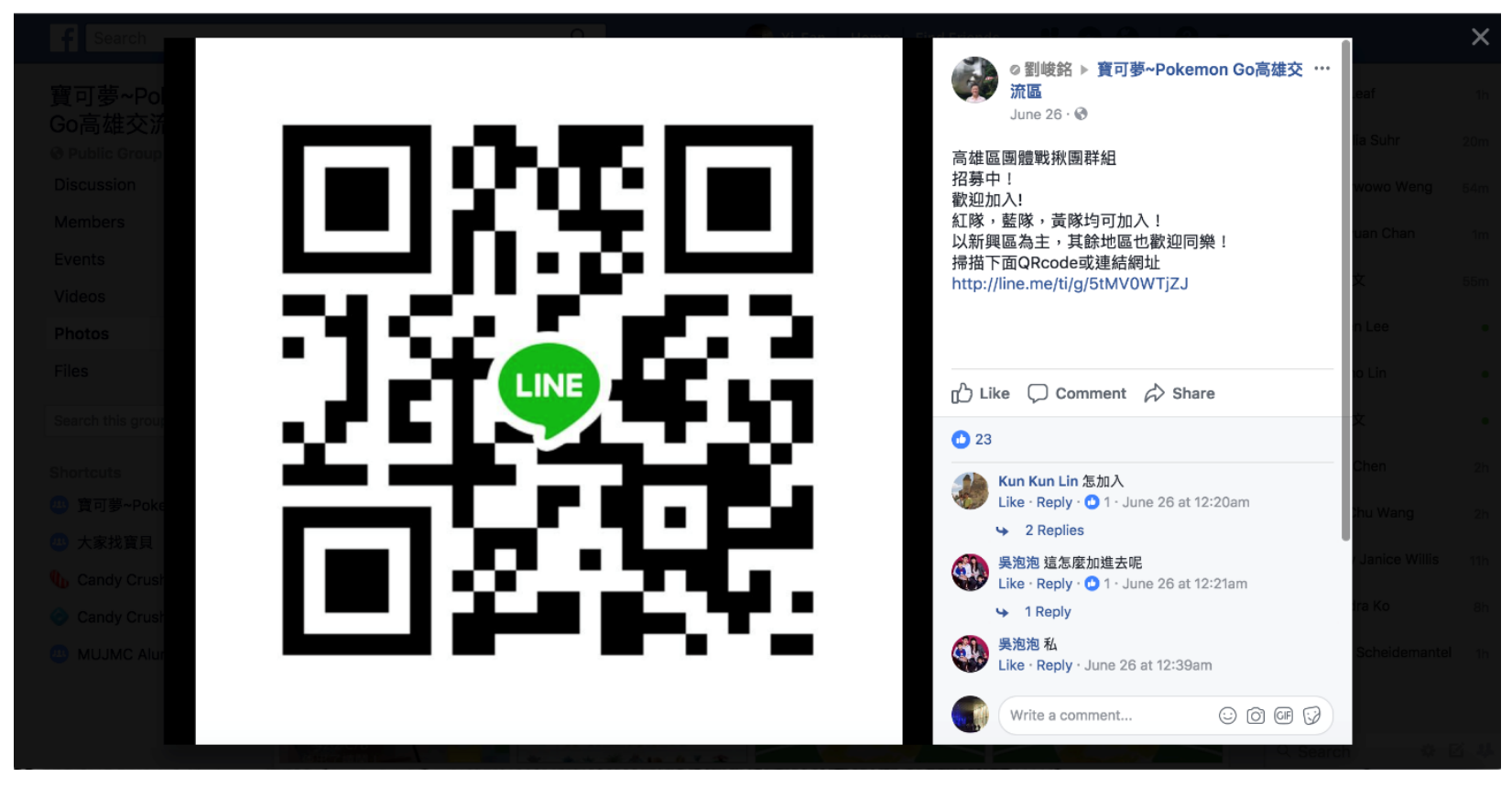

Location (local)

In some PokéGyms, such as PokéGyms located at parks or temples, a group of seniors could be found together and drank Taiwanese tea while they were feeding barriers to their Pokémon at the PokéGyms. They teamed up with other seniors whom they met on daily bases to battle and occupy the PokéGyms. For those PokéGyms, they became virtual public places for seniors to meet people and exchange information. They often battled raids at PokéGyms and collected items from PokéStops near their homes. Similar patterns were found for most of the MARS users except young people. Most of the MARS users used the system between work and home or school and home. During weekends, they went to parks that they often visited to catch Pokémon. Young MARS users were different. They did not have a routing locations to use the MARS. They went everywhere when the Pokémon Search Map or the social media groups sent them notifications of the rare Pokémon or level 4 or legendary raids. 


\section{Companionship (emotion)}

In this study, companionship patterns were found (1) between the MARS users and Pokémon/ avatars, (2) between the MARS users and other users, and (3) among the MARS users- Pokémon/avatars- other users.

Para-social interactions between the MARS users and their Pokémon/ avatars

On the Facebook Group Page, many Pokémon photos were shared. Some para-social interactions were found on those posts (please see Figure 15 and Figure 16).

Figure 15: Super cute

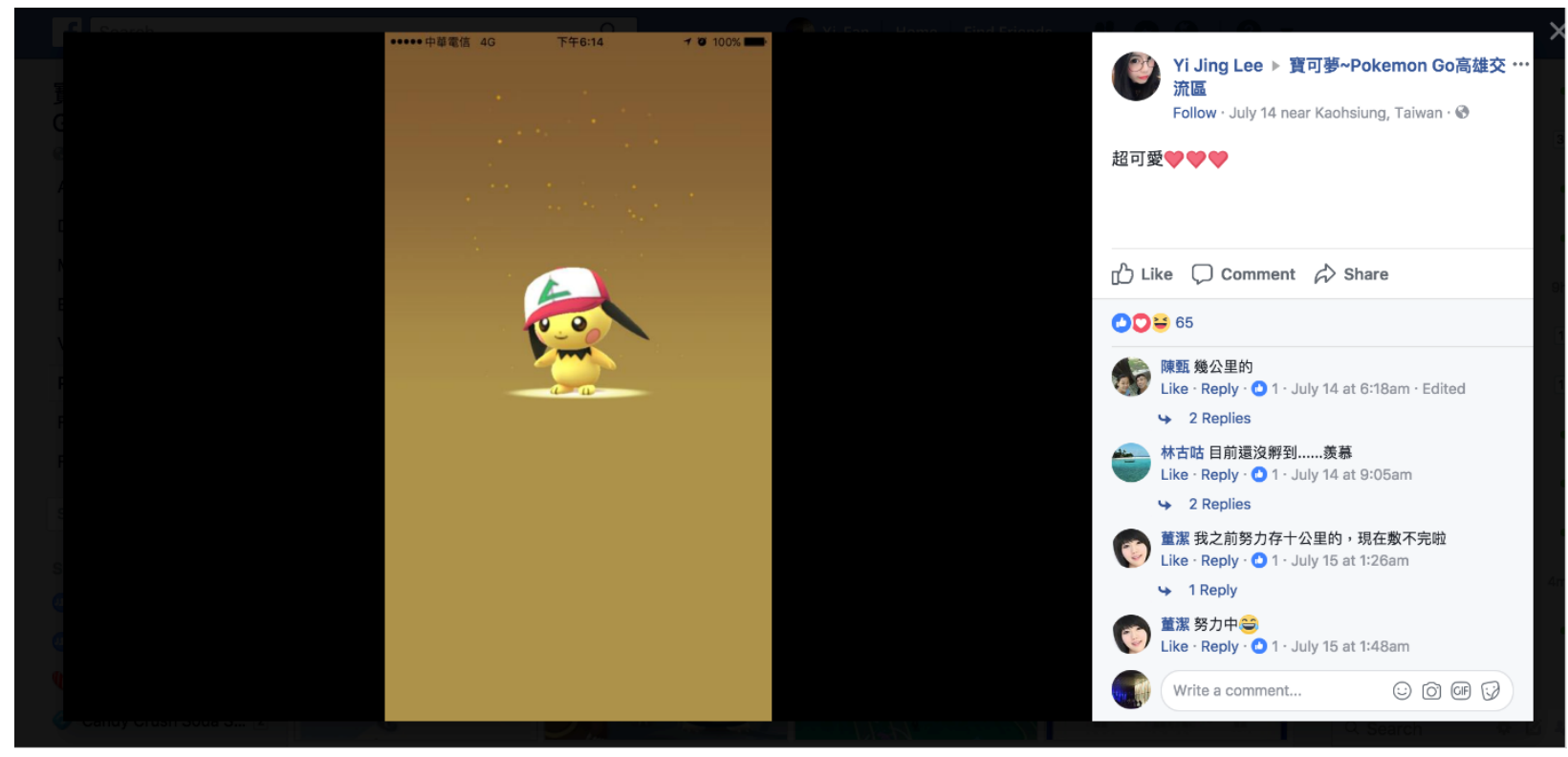


Figure 16: An example on interacting with a Pokémon

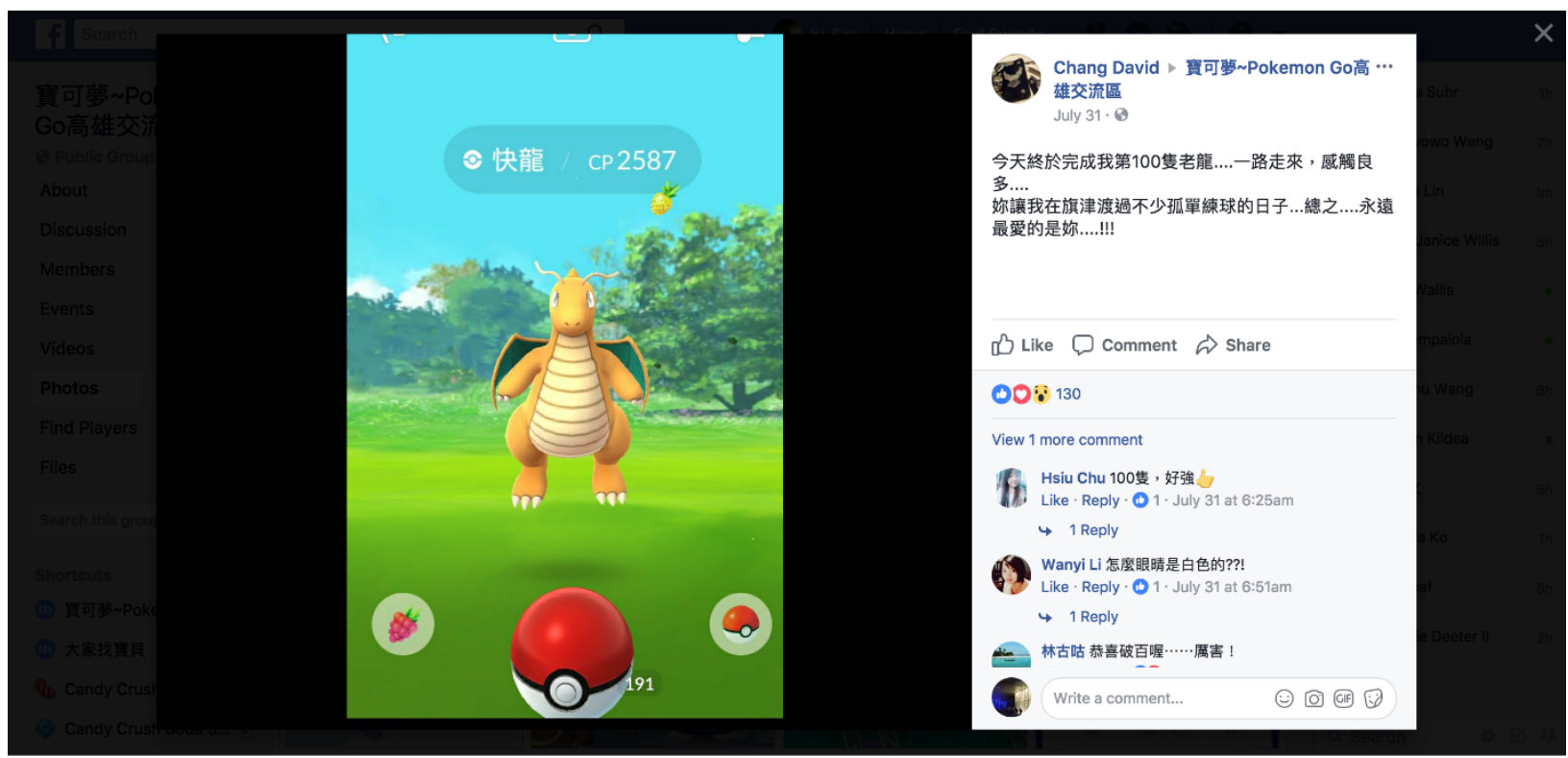

Translation: I finally caught my $100^{\text {th }}$ "Old Dragon" today...[]... In conclusion, you are always the love of my life.

Evidences from both observations and posts on the Facebook Group Page showed that the MARS users talked to their Pokémon all of the time as though they were real people (please see Figure 17 and Figure 18). When they went out, they made sure to turn on the MARS so they could catch wild Pokémon and hatch eggs. The MARS also encouraged its users to bring their Pokémon Buddy ${ }^{8}$ everywhere they went at any time. The MARS users took their Pokémon out for walks on a daily basis. Their Pokémon Buddy went to home and work with them.

"My wife makes me to walk my daughter and Pokémon at park near our home before dinners." (a male MARS user)

"Pokémon keep me company when I commuted to work every day.

It is fun." (a female MARS user)

"Just like walking my dog before. After my dog died, I walk my

Pokémon everyday now." (a male MARS user)

\footnotetext{
${ }^{8}$ In the system, users select a Pokémon as their "Buddy". When the users walk with their Pokémon Buddy, they can earn the Pokémon candies to either power up or evolve the Pokémon to a higher level.
} 
Figure 17: Byebye Articuno. I am right here watching you to leave me.

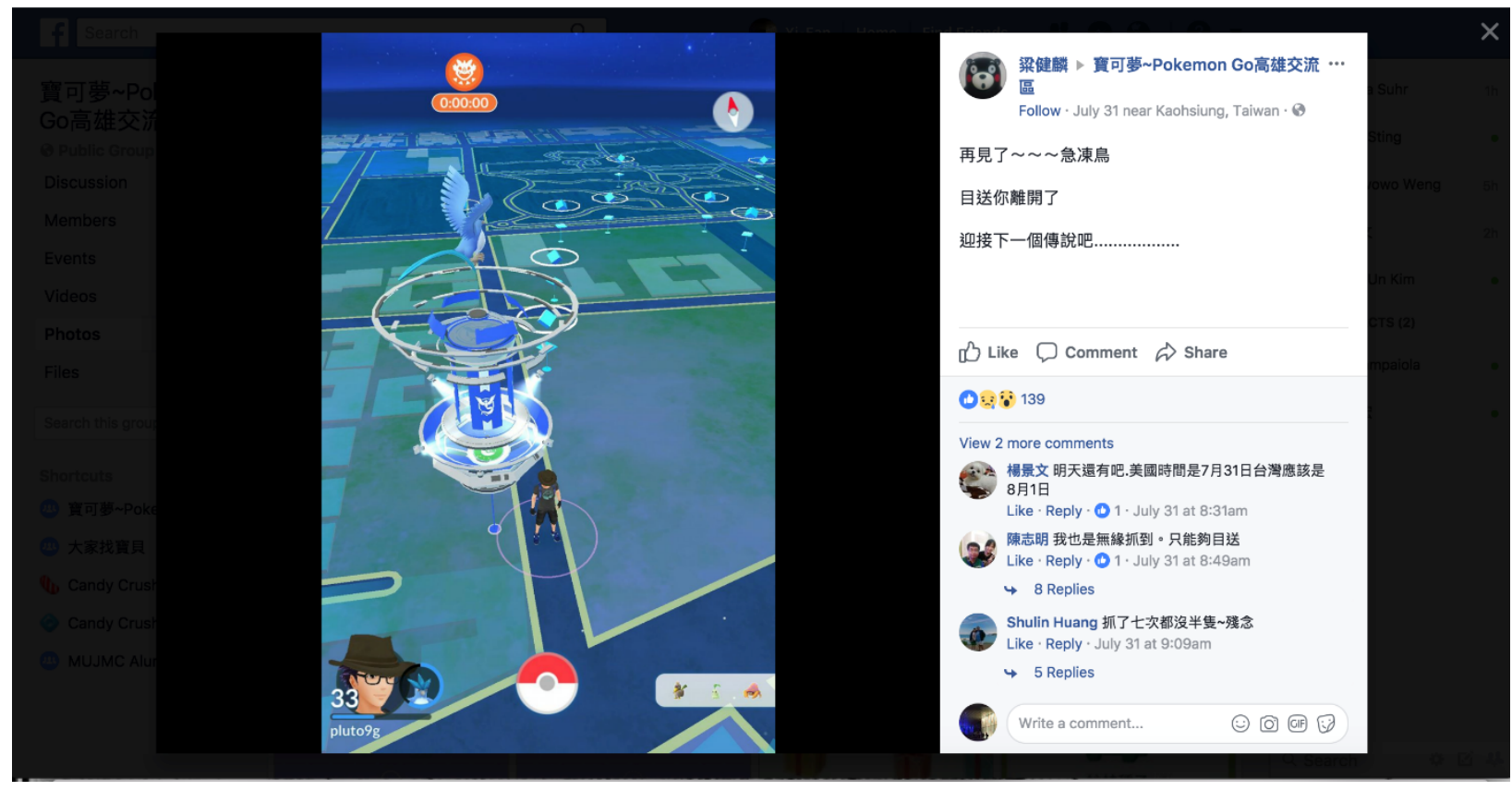


Figure 18: Dear Baby. It is almost 24 hours. If you are not coming home, daddy is going to call the police for assistant.

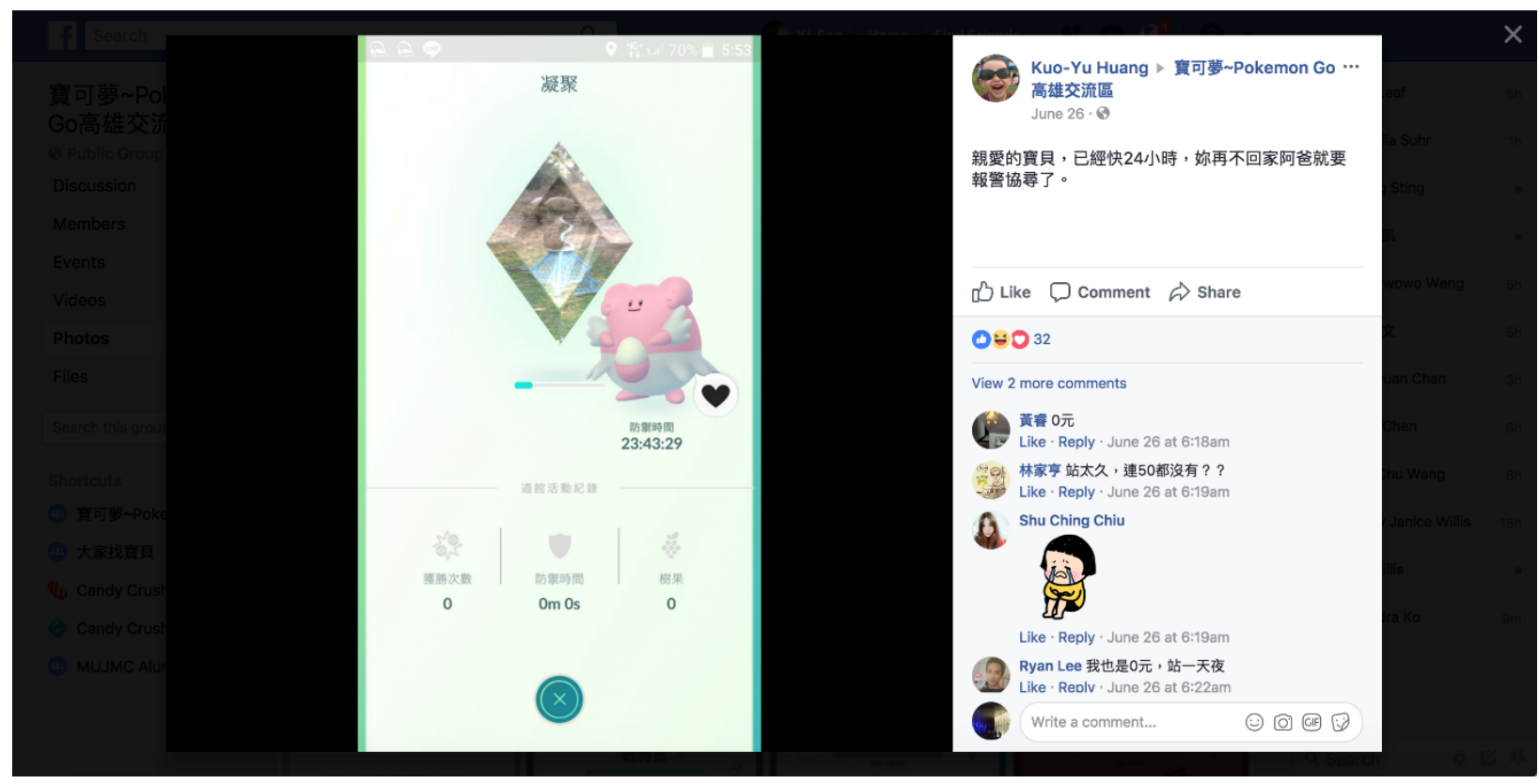

During the raid battles, the MARS users felt the pains of their Pokémon. It seemed that the MARS users developed the para-social relationship with their Pokémon to feel their pain. They communicated with Pokémon as with real people.

"Watch out the Moltres. When it attacks, it really hurts. Hot! Hot!

Hot!" (a male high school MARS user).

“Articuno killed many of my Pokémon. It also hurt." (another male

MARS user response to the first user)

"I know you want to come home with me." (a female MARS user

was trying to catch her first Moltres at a different raid)

Companionship between the MARS users and other users

The MARS users went to PokéStops or PokéGyms to meet other MARS users. They became friends with strangers when they taught each other how to use the system. Meeting their Pokéfriends was an important thing for them. Therefore, they made an effort to meet friends at PokéStops or PokéGyms when they also had the choice to use the system at home. At PokéGyms before raids, they said "hello" to each other. When one or two Pokéfriends did not show up for 
days, they either posted a search on social media to look for those Pokéfriends or to check with other Pokéfriends to see why those people were missing. From the online Facebook Group and the LINE Groups to offline PokéGym battles, the MARS users developed their friendships with other users.

\author{
"My kid did not have time to teach me how to play. I learned some \\ tips from other players." (a male senior MARS user) \\ "I retired and I often don't have things to do. I walked around my \\ house every day to catch Pokémon. My trainer level is 36. My kid \\ used his computer to catch the rare Pokémon in the US from his \\ bedroom but I don't like to do it because I have so much time to \\ spend and it is fun to meet people at PokéStops." (another male \\ senior MARS user)
}

On the Facebook Group Page, posts showed that the MARS users interacted with other users. One post described a MARS user loaning his external battery to a stranger when the stranger only had $8 \%$ of the mobile phone battery power before the raid. Figure 18 showed that another MARS user battled Moltres eight times but she did not catch any. She then asked the other users if they thought the Moltres hated her. There were 46 responses that she got on the post. One of them translated "yes...." (the bottom line on the Figure 19) 
Figure 19: A MARS user asked others if Moltres hated her.

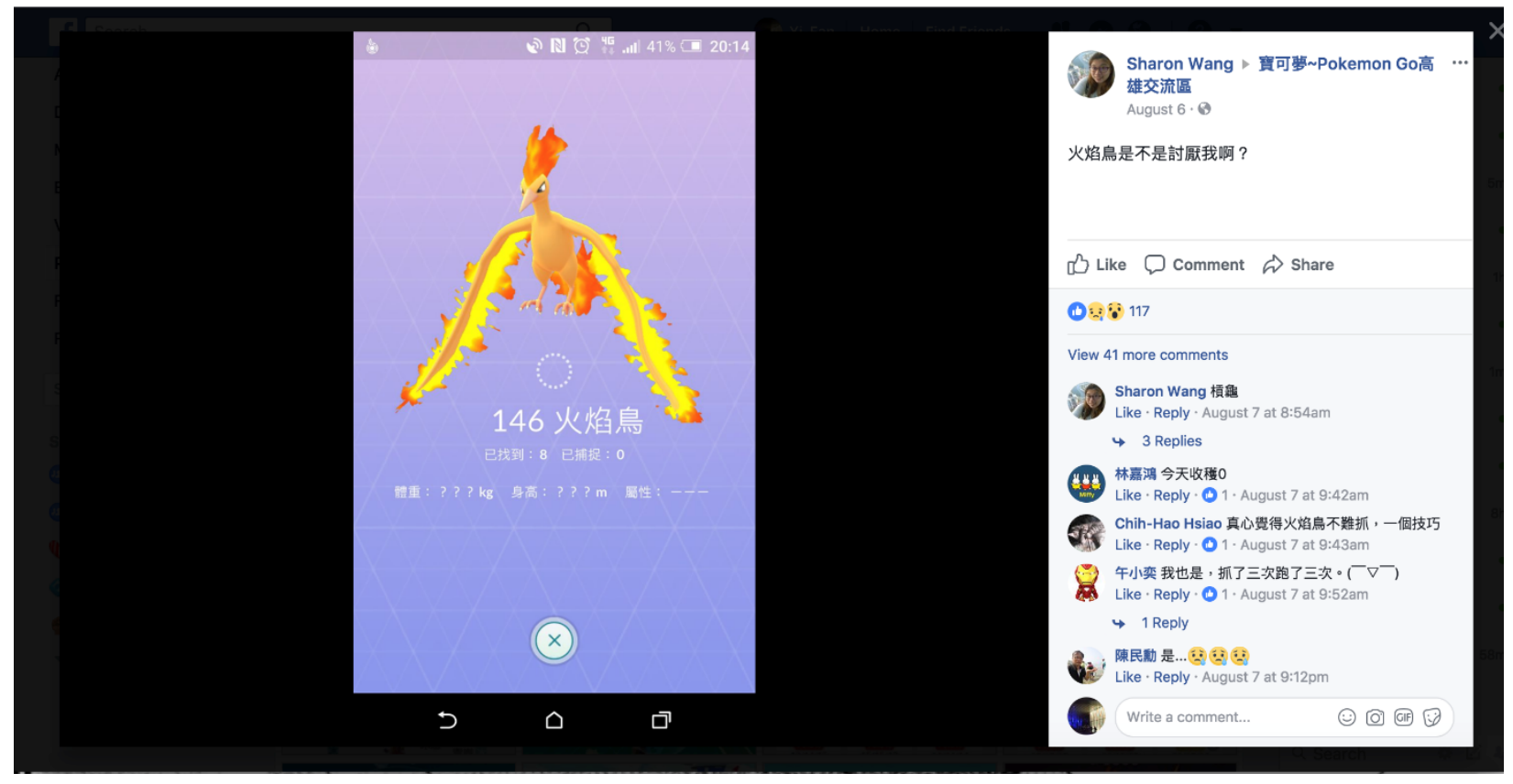

Companionship among the MARS users- Pokémon/avatars- other users

Other interesting findings include that the MARS users also develop companionship with other users and other users' avatars. Those Pokémon and avatars mediated both the humanrelationships and the para-social relationships. They brought their own networks to meet their Pokémon networks that included avatars, Pokémon, and human friends whom they met both online and offline. When they introduced their Pokémon or avatars to other users, it seemed that those Pokémon and avatars were real people or their best friends in the real world. Some of them identified other users' avatars and Pokémon before they connected the avatars and Pokémon to the users. Before raids, the MARS users were busy checking avatars' background on the lobby. Observation notes recorded "I am apologizing for my sister because her level is very low". The "sister" here was indicated her avatar. During the raids, a note showed "Who put the Blissey in the battle? The egg is useless".

One post on the Facebook Group Page described a story about how two MARS users meet at a PokéGym by an accident (please see Figure 20). The story was about a MARS user, Uncle MaDo, reported that when he was waiting for a raid at a PokéGym, a stranger knocked on his car window and asked if they had met at another raid as well as if he knew the Uncle MaDo. 
The user told the stranger that "...everyone calls me the Uncle MaDo". In this case, the stranger met the user's avatar online and matched the real person with the avatar.

Figure 20: A post described how two MARS users met offline for the first time

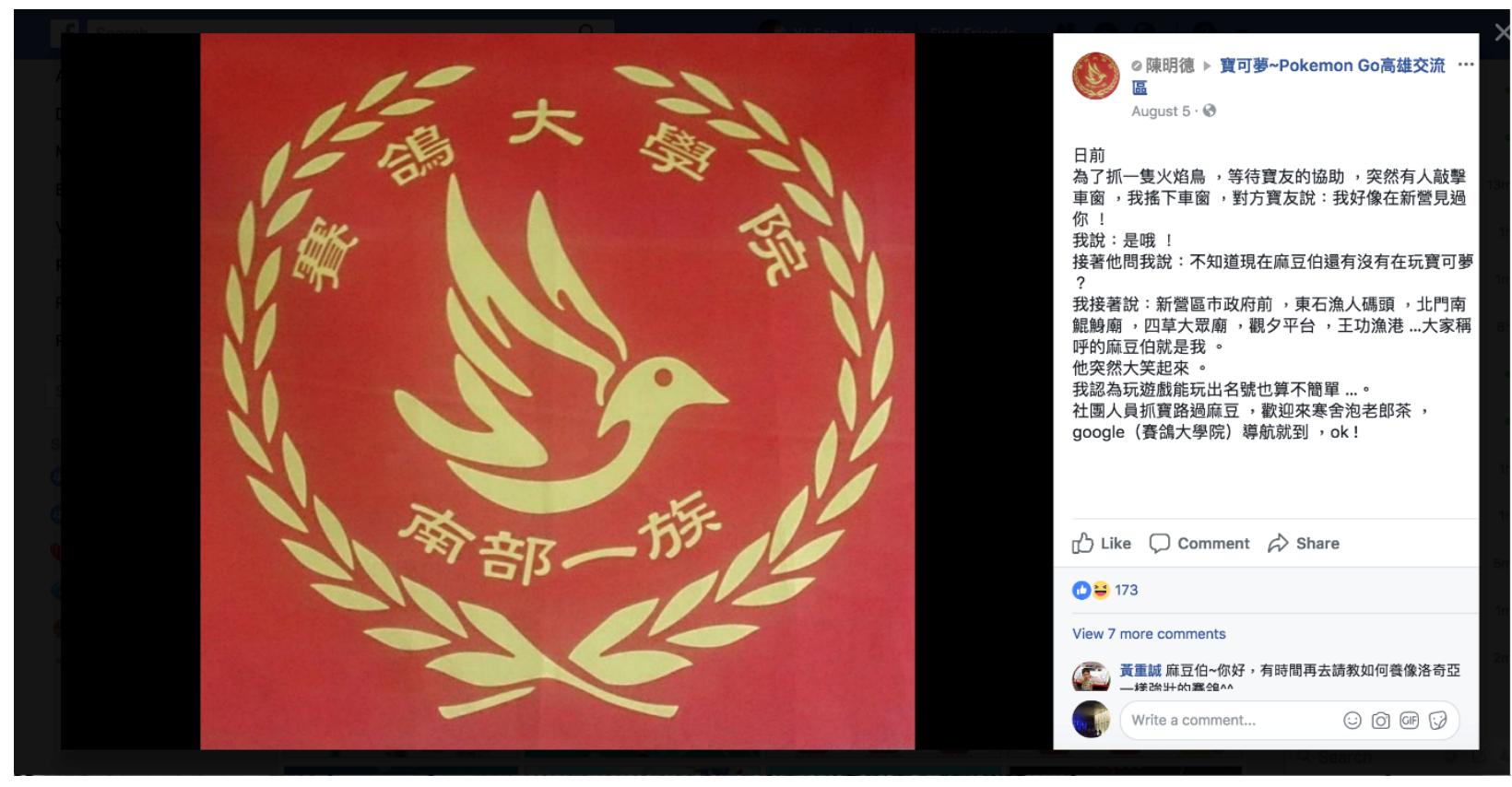

Another interesting example was a male MARS user who pointed to his mobile phone screen to introduce other MARS users' avatars at the lobby to his friend who was a non-user when they had a chance to say "hello" to real people at the same place before a raid. It seemed that the MARS user did not make a strong distinction between offline people and online avatars. Therefore, he introduced avatars but not the people who those avatars represented to his friend at PokéGyms.

Mobile Design: Everyone's System (mobile)

Although Niantic ${ }^{9}$ set its own rules how to use the MARS, Taiwanese users seemed to utilize the system on their own. There were many different online Pokémon Go competitions and offline Pokémon catch events that were organized by users. They were showing off their avatars and their Pokémon with others in both online and offline enlivenments. At these competitions or

\footnotetext{
${ }^{9}$ Niantic is the company that develop both Ingress and Pokémon Go MARS.
} 
events, they brought their family members and friends to join. They used social media, such as LINE or Facebook, to meet other users. The MARS users created and re-created the system to make it more enjoyable for themselves.

The Pokémon Search Map was the key tool to guide those MARS users to where to meet and when to meet, especially for raids. There were many "how to" use the Map online and on media that were generalized by the MARS users to share with others. The Taiwanese hacker who developed the Map made the map free for everyone because he is also a Pokémon Go user. It was the most popular Map before it was banned by Niantic on Aug 14, 2017. Many users thanked the hacker for making their Pokémon Go experience more enjoyable (kocpc, 2017). At PokéStops and PokéGyms, the MARS users shared their experience to learn how to use the Map with other users. After the Map was banned, some MARS users considered stopping using the system because the system was no fun anymore. Those discussions could be found in online posts and conversations at PokéGyms and PokéStops.

This study also found that some MARS users had more than one account or used more than one phone at the same time at PokéGyms and PokéStops. Many of them were for family members and friends who were unable to be present at the locations of raids. A few MARS users took their family or friends' avatars to the oversea for catching region exclusive Pokémon. At PokéGyms, the MARS users were helping strangers to catch Pokémon after raids if the strangers did not have enough confidence to catch them by themselves. Before raids, the MARS users selforganized themselves by teams ${ }^{10}$ to win the battles and to earn more power PokéBalls. It was not unusual to own more than one account for a MARS user because the user was making his/her Pokémon network by friending himself or herself on different accounts.

In summary, this study found that the Taiwanese MARS users utilized the system to fulfill their information, communication, socialization, entertainment, and companionship needs. They also incorporated the system into their everyday life activities.

\footnotetext{
${ }^{10}$ There are three different teams, Team Mystic, Team Valor, and Team Instinct, in Pokémon Go. After level 5, each user could choose a team to join. At raids, the MARS users could earn more power PokéBalls to catch Pokémon if their team had better contribution to the raids.
} 


\section{CHAPTER 5}

\section{Discussions}

This research finds all four phases of the Domestication Approach: appropriation, objectification, incorporation and conversion (Silverstone et al., 2005) among the Pokémon Go MARS users. The MARS users are introduced to the system by their friends or family members as well as strangers. Similar to other mobile media studies' findings that users keep use mobile media because of their family members and friends' requests (e.g., Ling, 2012), some MARS users keep using the system because it is a fun thing to do with their family members and friends and because their family members or friends want them to do so. Some of the children teach their parents how to use the MARS. It is also similar to the findings on how people learn to use the mobile media from younger generations (e.g., Correa, 2014). They are showing off their badges, medals, items, Pokémon and their avatars to others in both online and offline communities as well as both personal social networks and Pokémon networks. It is similar to Katz and Sugiyama's (2006) study that Japanese young mobile phone users use their mobile phones to make their fashion and social network status. The MARS users also make their status statements to others by using the system. The MARS users struggle to find a "place" to fit the MARS into their everyday life. Many of them use the MARS between home and work or near their homes. Workers and students find breaks to catch or battle Pokémon. Housewives and seniors use it based on their time, locations, and relationships availabilities. They incorporate their social networks with their Pokémon networks. They introduce their Pokémon networks to their social networks. The MARS adds a layer of "fun" in their everyday activities.

Katz, Haas, and Gurevitch (1973) point out that utilizing the Uses and Gratification Theory could learn how media users use media to fulfill their socialization, information, entrainment, decision, and companionship needs. Examples include that the MARS users bring their friends to use the system; they also make new friends because of the system; they exchange both Poké-related and non-Poké-related information online and offline while they are at PokéGyms and PokéStops; they use the system for entrainment purposes, especially when new events are introduced; and there are many decision-making process before, during and after using the system. This research also finds that using the MARS fulfills different user's needs.

While using patterns for information, entertainment, socialization and decision needs are similar to other media use, the companionship needs that are fulfilled by online friends (as 
Pokémon, avatars, and human friends whom they have online interactions only) and offline friends (as other MARS users) and by the personal social networks and by Pokémon networks seem to be unique for the MARS use. In this study, from para-social companionship between the Pokémon and the MARS users side, seniors are found to utilize the system to keep them company during the times when their children and family members are not available for them. The findings are similar to Low's (2017) new report. Housewives are using the system when they are free from their housework and their family. Radway (1991) finds women use romance novels to create a fantasy world for escaping from their everyday housework. However, this study does not have enough data to understand if those housewives are utilizing the system to escape from their everyday realities or if there are other motivations to keep them using the system. Many MARS users also use the system to accompany them between home and work and between home and school. They "talk" to their Pokémon and their avatars all of the time. Before raids, they check other users' avatars in the lobbies to learn the avatars' background. Some of them also "walk" their Pokémon daily as their pets.

For the human-to-human companionship side, the MARS users go to PokéGyms and PokéStops to meet their PokéFriends. They build their Pokémon networks on social media and at PokéGyms or PokéStops to battle raids and PokéGyms from opposite teams. They organize events for their online Pokémon networks to meet offline. They bring their personal social networks to their Pokémon networks. They introduce their Pokémon networks to their personal social networks. They invite strangers to join their online Pokémon networks at the offline PokéGyms and PokéStops. Examples are demonstrated by the housewives who use the MARS with their family members after dinners, and other MARS users also incorporate the MARS into their family interactions after dinners or during weekends. They showcase their Pokémon and avatars to other MARS users both online and offline. The MARS adds a layer of the family/ human interaction for those housewives and other MARS users in both online and offline settings as well as at both virtual and physical spaces.

Finally, the companionship among the MARS users, the Pokémon networks, and the personal networks seems intriguing. The intertwining companionship is founded when the online Pokémon and avatars are introduced to the offline human friends. Additionally, it could be found when the MARS users (1) "walk" their children with their Pokémon, (2) "take" their children and grandchildren and Pokémon to parks and events together, (3) "go on dates" with their 
Pokémon and boyfriends and girlfriends, (4) "know" the avatars before or without knowing the MARS users, and (5) "show" how pretty, cute, strong, and good their Pokémon are to others. In summary, similar to Majorek and du Vall's (2016) study, the MARS brings users to meet others from online spaces to face-to-face offline spaces. In this study, the MARS users also bring interactions from offline spaces back to online spaces. Additionally, the interactions are including both face-to-face interaction and online interaction that happen at the same physical location.

\section{Implications and Conclusions}

Traditional media (such as television) make users stay home and keeps users away from outdoor "face-to-face" interaction (Cecil-Karb \& Grogan-Kaylor, 2009). Interactive media (such as mobile media and Internet) invites network friends and strangers to users' homes for interaction and sometimes it might cause social/family issues (Castells, Fernández-Ardèvol, Qiu, \& Sey, 2007; Hijazi-Omari \& Ribak, 2008; Ito, 2005; Ling, 2004). The "face-to-face" interaction has been extended from the real world to the virtual world via interactive media. Social media brings offline networks to online for interactions. Mobile media provides "perpetual contact" with close friends and family anywhere and anytime (Katz \& Aakhus, 2002). In this study, MARS users meet friends from online to offline as well as offline to online. For example, some users first meet at the online Facebook Group and then go to catch or battle Pokémon together. Users also exchange LINE ID or invite others to join the Facebook Group when they meet strangers at PokéStops or PokéGyms for future communication. They share tips and information on how to catch and battle Pokémon in online communities and at PokéStops and PokéGyms. They build friendships with other users and media characters (i.e., Pokémon). The interactions between online and offline and the friendships between real people and media characters seem to be blurred because of the MARS.

Another interesting aspect of this study is how most of the MARS users make the system fit into their everyday life. No matter how Niantic makes rules for users to use the system, the MARS users break the rules to follow the third-party tracker to catch the Pokémon that they want and join the raids that their social networks are in. Some of them have more than one account. They also help their family members to catch Pokémon when the family members are busy. It seems to imply that media content is opened for the users to interpret and use. The users can 
make the content fit their needs. Because the MARS users make their own rules to enjoy the game, they are willing to spend real money on the system to buy items. It becomes a possible business model for Niantic. Additionally, this study also finds location matters to the MARS users. They often use the system near their homes. However, some of them are willing to travel long distances to chase the rare Pokémon. Niantic is already testing to promote locations to its users. For example, Niantic has organized offline events in Japan to draw visitors to quake-hit areas by placing more of the rare Lapras near the coasts of Iwate Prefecture, Miyagi Prefecture and Fukushima Prefecture, areas affected by the 2011 Tsunami (Tassi, 2016). It might be interesting to look into how the MARS could possibly promote locations to its users.

\section{Limitations and Suggestions for Future Studies}

The current research uses qualitative research methods to understand how the MARS users utilize the system in their everyday life. The results map some interesting design directions for future MARS development. Companionship patterns are clearly found in this MARS study. Users seem to make friendships with their Pokémon. In addition, the MARS also allows users to develop friendships with other users. They are also willing to learn and know the virtual avatars. For future study, applying the traditional companionship scales to conduct quantitative research might help to generalize with more accuracy than the researcher's personal experience and impressions. Additionally, there might be a need to explore more about the companionship from personal social networks and Pokémon networks as well as in online and offline situations by using the MARS. 


\section{CHAPTER 6}

Design a Mobile Augmented Reality System to Facilitate Users' Companionship Needs According to the primary research findings, the Pokémon Go MARS users utilize the system in their everyday life to fulfill their information, communication, decision, entertainment, socialization, and companionship needs. They also seem to develop a para-social relationship with their media figures. They take their MARS everywhere they go when they have free time and incorporate the MARS into their everyday activities. Specifically, the current study finds that the MARS seems to increase in value when users enhance their personal social networks and build their MARS network.

A "See What I See" MARS is designed for users who are going to navigate a location accompanied by their social networks. The "See What I See" could be used for people who are visiting tourist attractions, taking a new job at a new location, going to a college for the first time, or finding a required item from a (grocery) store. In current study, the user is situated as a first-time overseas backpacker. Kaohsiung, Taiwan is the selected city because it is ranked the $5^{\text {th }}$ (top one in Asia) "to visit" city in 2018 by the Lonely Plant (Lonely Planet, 2017), one of the famous companies that publishes tourist guides around the world.

\section{"See What I See" MARS Design}

Tourists use digital media to seek trip information, to plan and book trips, to document trips, and to share their tourist experience by writing reviews, blogging, and sharing videos and photos. Ricci (2010) argues that mobile media has become a main platform for tourists to access information. And Gretzel (2013) notes that the increasingly widespread use of mobile media has changed the tourist behavior and decision-making process before and during trips. According to Brown and Chalmers (2003), it is important to understand tourists' needs for using mobile media during trips once it becomes reasonably convenient. Finally, this study uses Kenteris, Gavalas, and Economou's (2009) definition of the "mobile tourism" (mTourism) as using mobile media to access tourist information.

Prior research finds that mobile media users utilize their mobile media to kill time and to bring "dead time" to live in everyday life (Bittman, Brown, \& Wajcman, 2009; O'Hara, Perry, Sellen, \& Brown, 2002). The rise of smartphones, apps, and mobile web has changed the nature of travel and impacted tourists' experience (Wang, Park, \& Fesenmaier, 2012). mTourism 
studies find that mobile media are also used for purposes not directly travel-related when users are travelling. Tourists "pack" their social networks with them while traveling. Chen (2013) finds when mobile media users travel, they "check-in" with their social networks when they have free time and when they are transiting from one point to another. They use their mobile to check things to do, where to go, what to eat, gas prices, and policemen locations. When they are free, they update their experience with their social networks. Their mobile media are used as their companion while they are moving. In her study, location, situation, and human relationships are three key factors in understanding how and why mobile media are used during trips. Other mTourism studies also show that tourists share and interact tourist experience with others (Gretzel \& Fesenmaier, 2009), and those tourist experience are situated in times and locations (Quan \& Wang, 2004) with emotions (Zakrisson \& Zillinger, 2012). White and White (2007) mention that ICTs change the tourist experience because notions of home and away become blurred.

In this "See What I See" MARS design, it does not aim to design a fully functional tourist system because hotels and flight companies are already providing free systems to attract tourists (Wang \& Wang, 2010). Moreover, some tourist attractions, such as cities, museums, zoos, and theme parks also utilize mobile media systems to enhance tourists' experience. For example, Quick Response (QR) codes can be found near the beach for tourists to screen and find places in Rio de Janeiro, Brazil (Haq, 2013). In the United Kingdom, the Museum of London has a free augmented reality (AR) system, Streetmuseum, for tourists to seek historical photographs in locations throughout the city (Sinclair, 2014). However, because Carlsson, Walden, and Yang (2008) note that social aspects in tourism become important and they argue that tourists interact with others and find tourist information and make decisions for their trips using mobile media, this "See What I See" MARS system is about a travel companion design of user-generated situated documentaries for someone(s) special to experience the location when they have "dead time" or "free time" to spend at the location.

\section{Prototype}

In this study, Adobe $\mathrm{XD}$ is used as the tool to develop the prototype. Adobe $\mathrm{XD}$ is a user experience design software for designing websites, mobile apps and it is developed by Adobe company (Adobe, 2017). There are two parts of the "See What I See" MARS design. Part one 
includes some user-generated situated documentaries that are created by the friends or family members from the social networks for the MARS users (i.e. travelers). Based on the friends or family members' perceptions of the users, they map the location with many hotspots (please see Figure 21). On the second part of the design, it is the "See What I See" user-generated situated documentaries MARS on the travelers' mobile devices. Part two include four choices: (1) Points of Interest, (2) Places to Eat, (3) Useful Spots, and (4) Find People, for the MARS users to select when they have free time to spend during trips (please see Figure 22- Figure 27). Please see Figure 28 for a completed prototype.

Figure 21: Mapping hotspots by situated documentaries in Kaohsiung based on the travelers' preferences (part One)

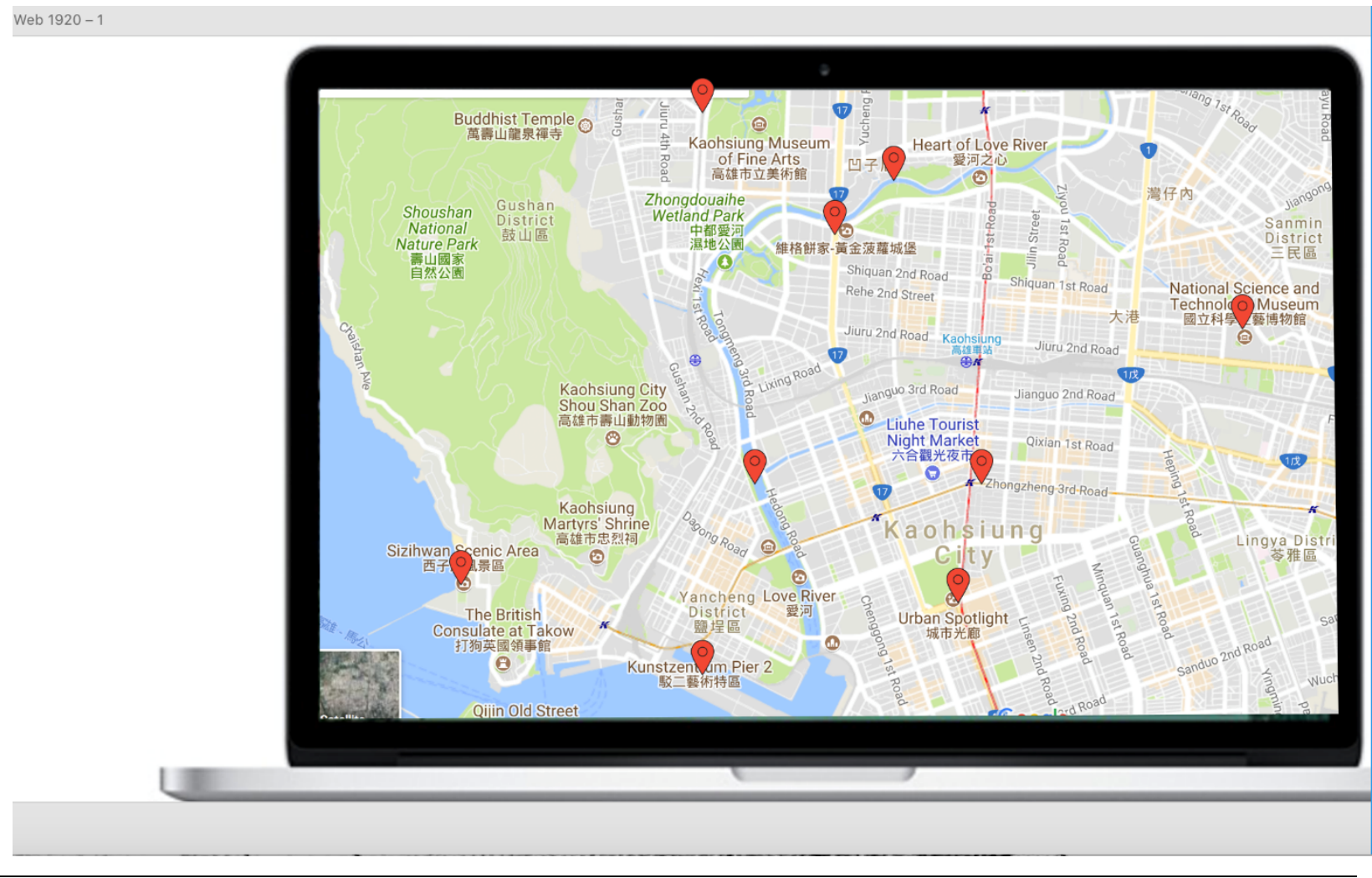


Part two is the "See What I

See" MARS that the travelers

download on their mobile

media. When they open the

system, there is a loading page

with a Kaohsiung photo on it.
Figure 22: Loading page

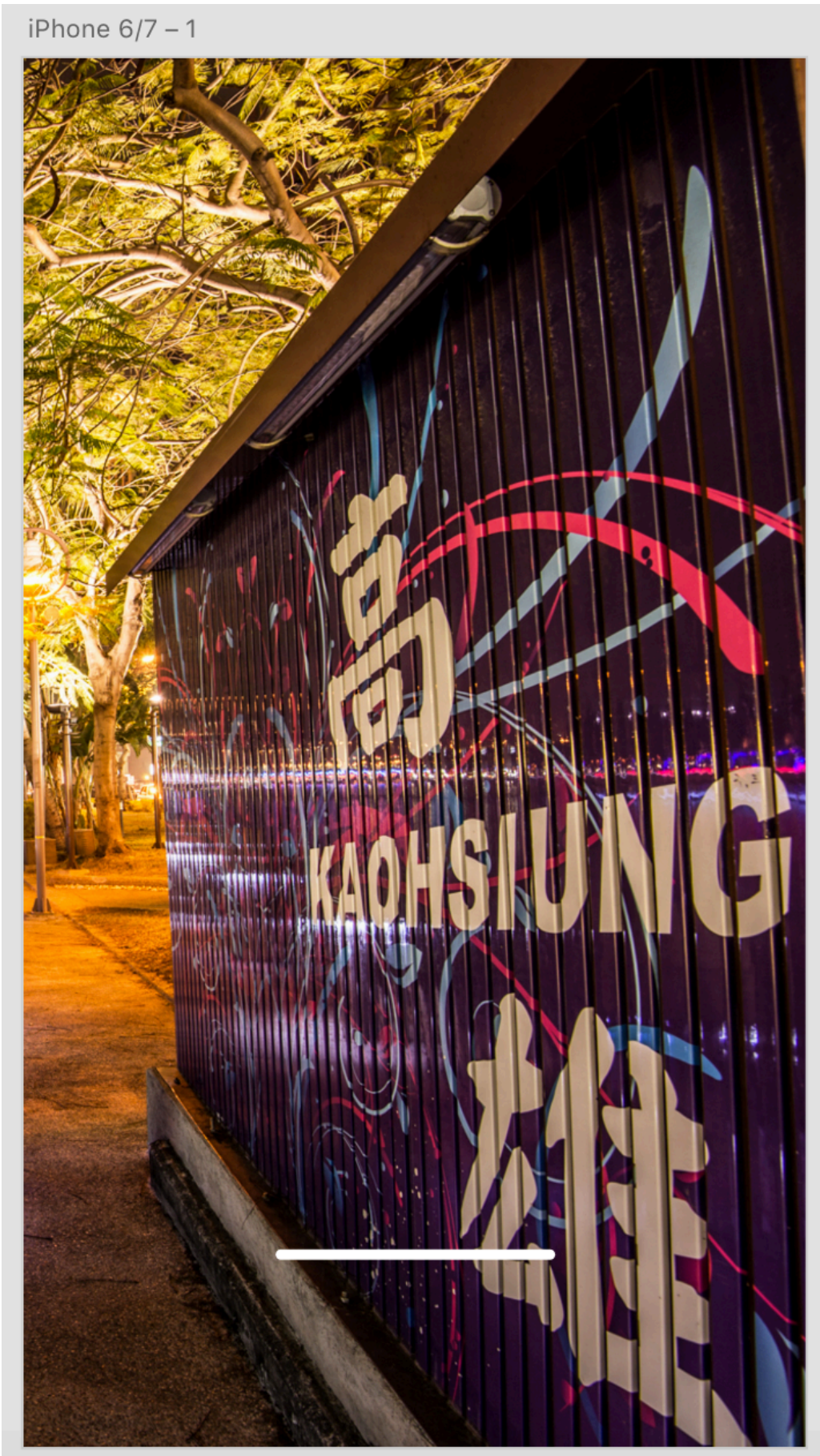


After the loading page, there are four buttons on the

MARS: (1) Points of Interest,

(2) Places to Eat, (3) Useful Spots, and (4) Find People.
Figure 23: Selection

iPhone 6/7 - 2
\begin{tabular}{|lll} 
ill ₹ & $9: 41 \mathrm{AM}$ & * 100\% \\
\end{tabular}

See What I See

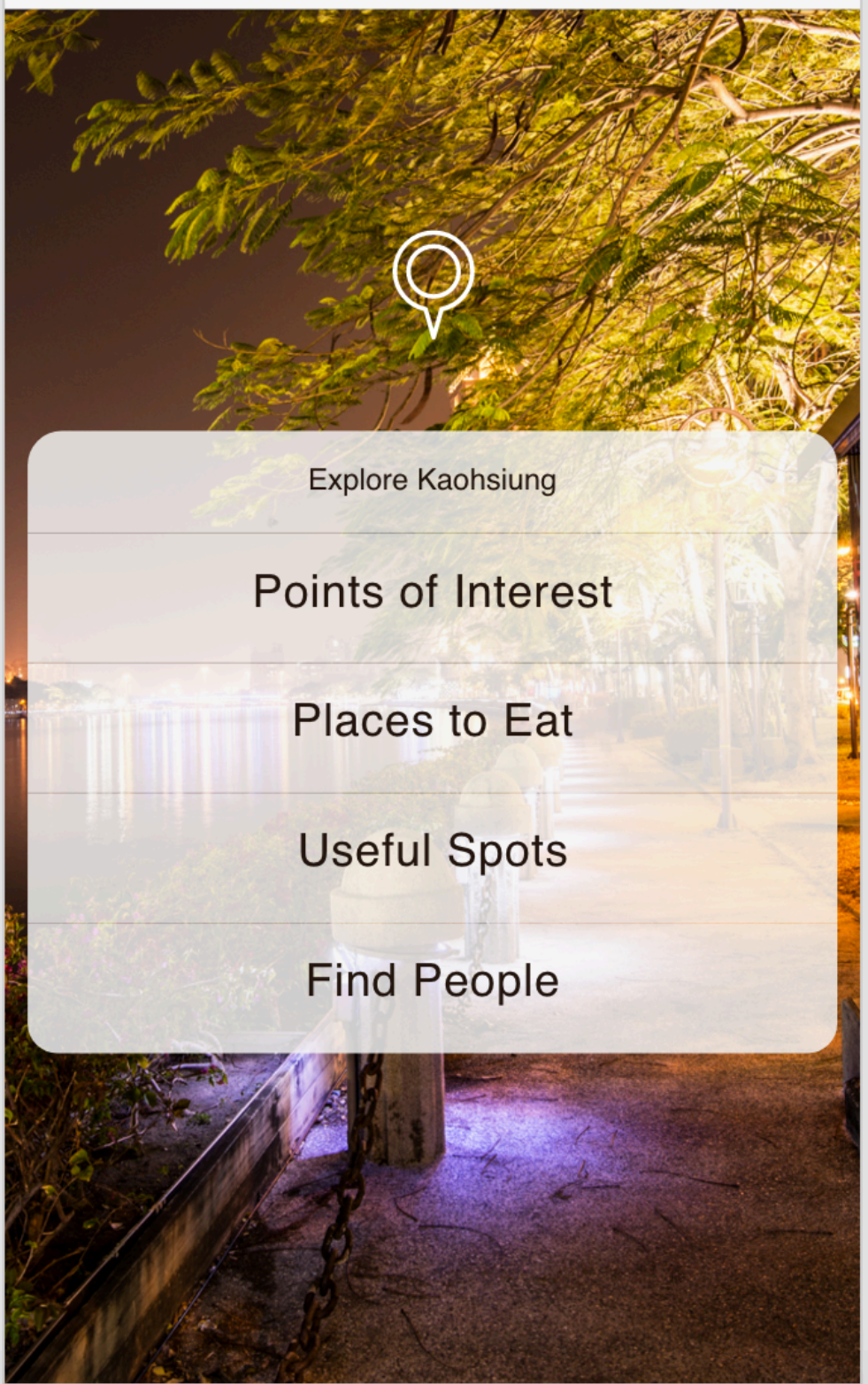


When the travelers arrive at the Formosa Subway Station, the travelers have about 30 minutes free time. Their social networks are in a different time zone so they decide to use the "See What I See" to see any places nearby where their friend map for them. When the MARS is on, they find that there are three hotspots within walking distance in the "Points of Interest". After the travelers pick one of the spots, dots on the floor guide them to the location. When they arrive at the location, they can retrieve a situated documentary that has more information with emoji about the spot on their MARS.
Figure 24: Points of interest

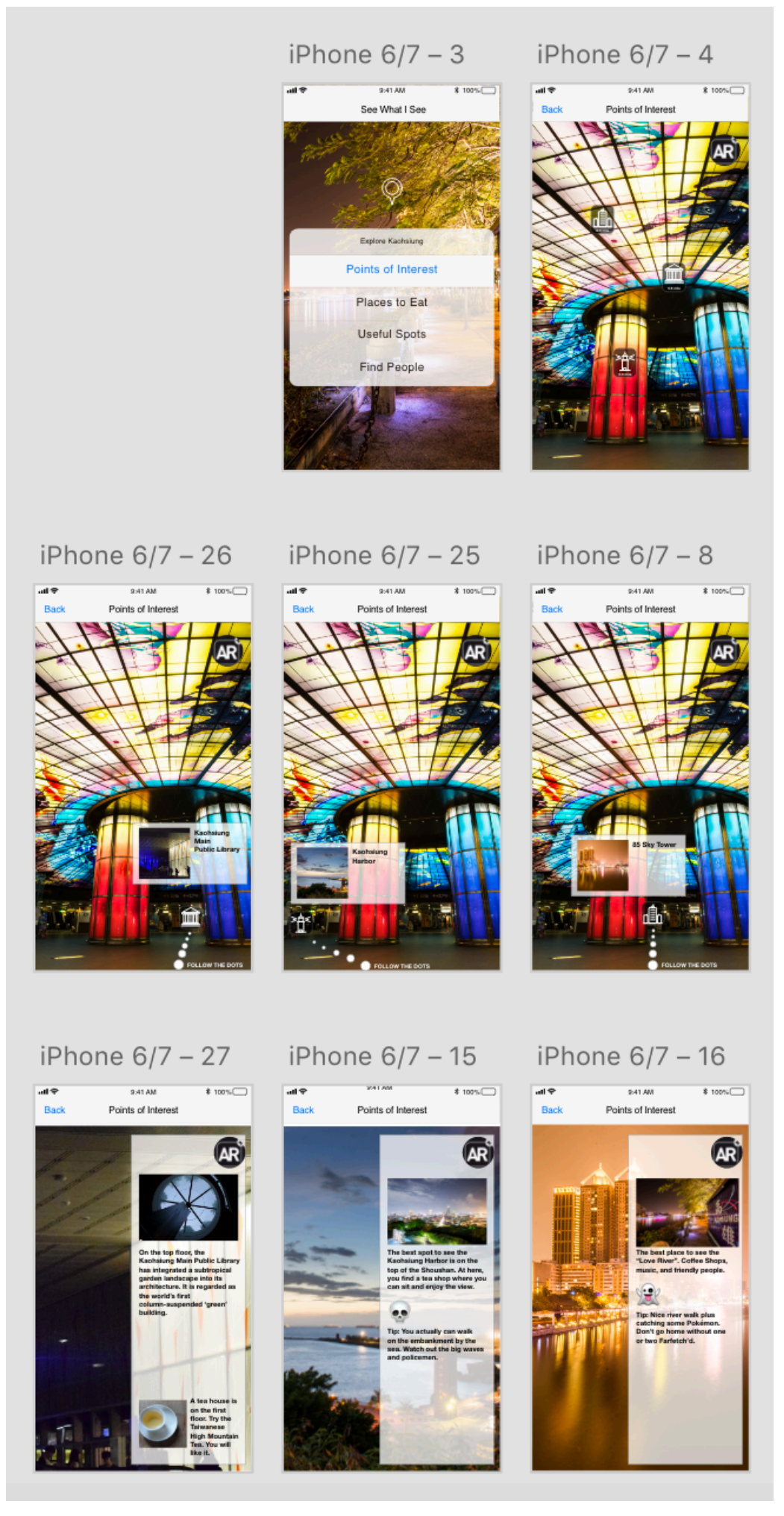


Two places to eat are near the Formosa

Subway Station. When the travelers arrive at either one of the places, more tips about food will show up.
Figure 25: Places to eat

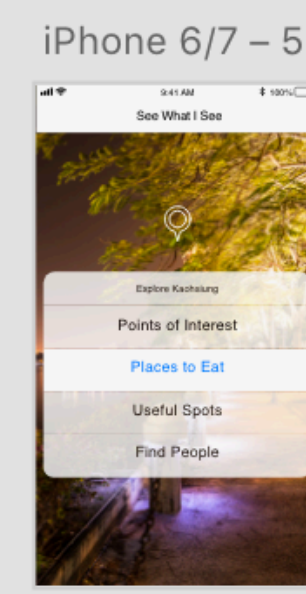

iPhone 6/7 - 6

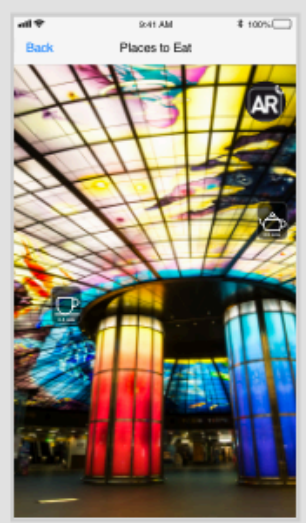

iPhone 6/7 - ...

iPhone 6/7 - 10
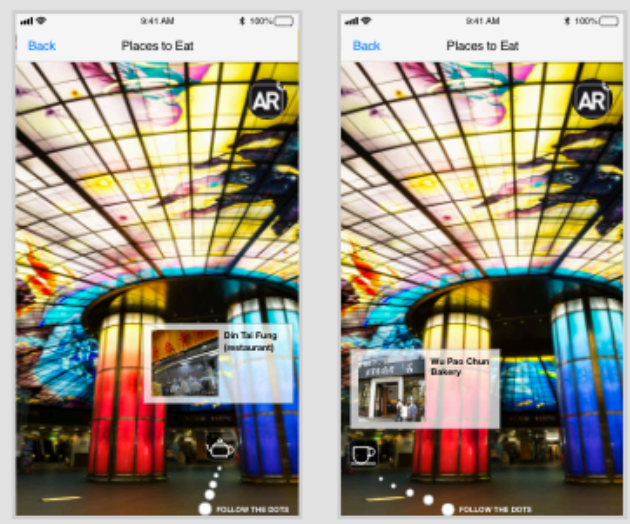

iPhone 6/7 - 18

iPhone 6/7 - 17
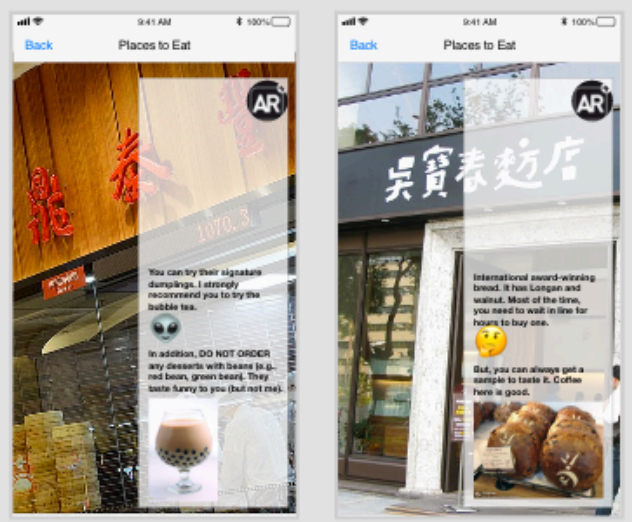
Three useful spots near the Formosa Sunway Station include a restroom, a bank for money exchanging, and a government building for free wifi are mapped.
Figure 26: Useful spots

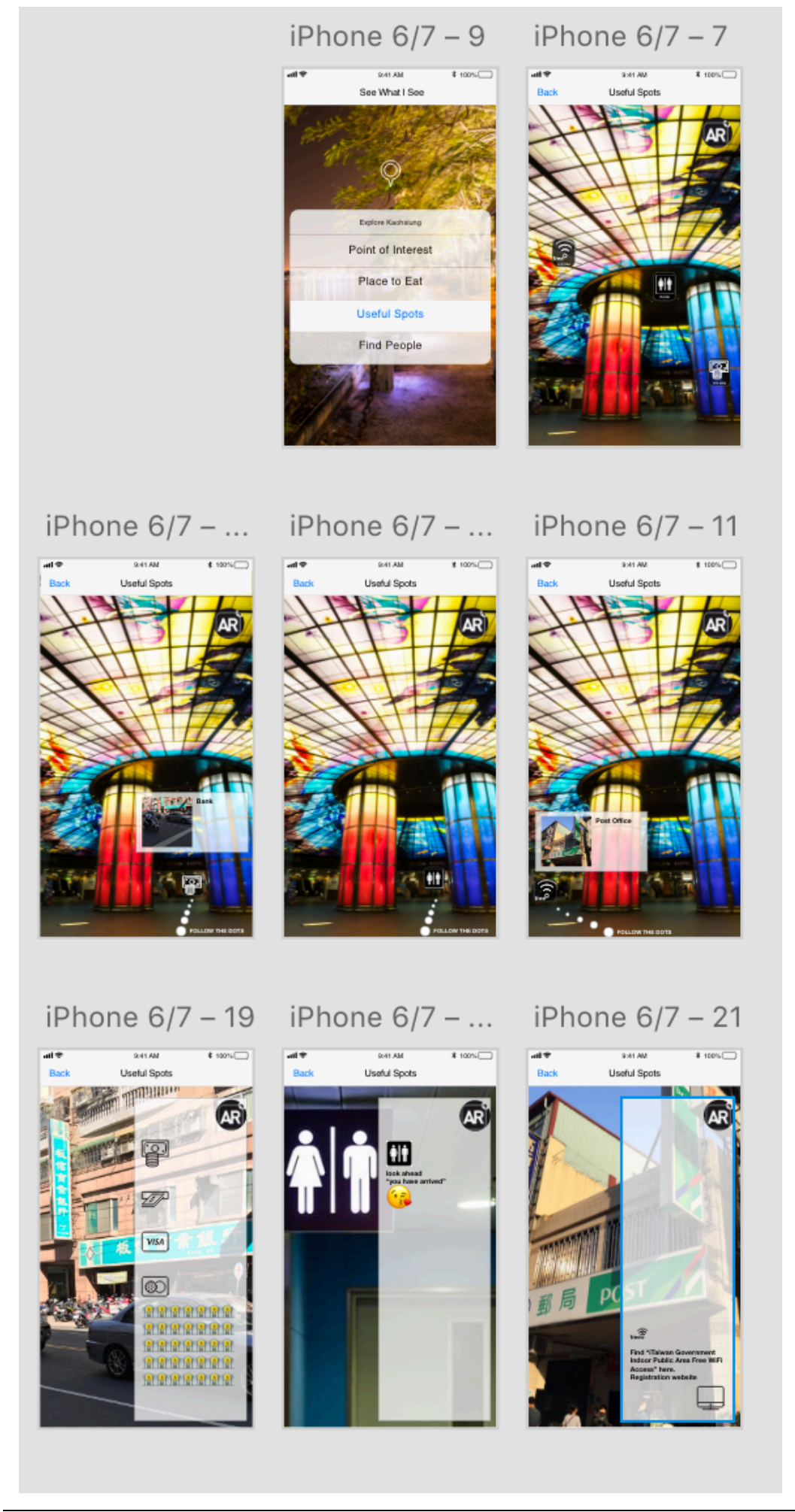


Local contacts are also

included in case of emergency and a perpetual contact button to the person who mapped the location.
Figure 27: Find people

iPhone 6/7-12 iPhone 6/7-13
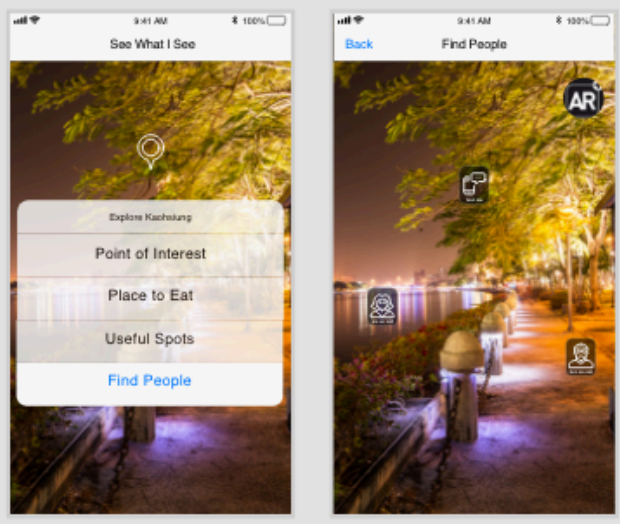

iPhone 6/7-14 iPhone 6/7-...

iPhone 6/7 - ...
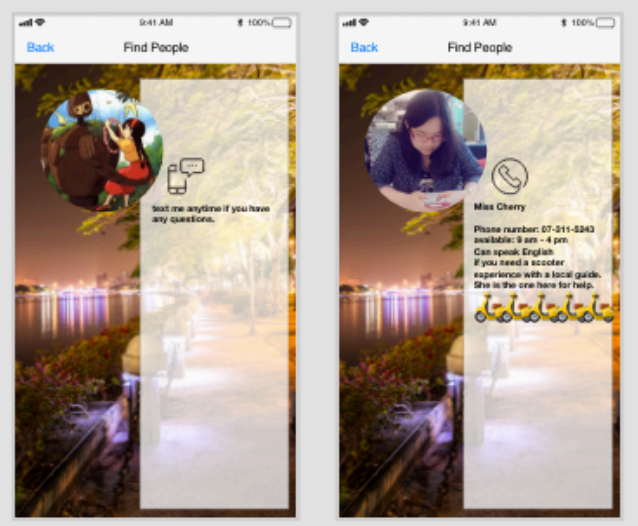
Figure 28: "See What I See” Prototype

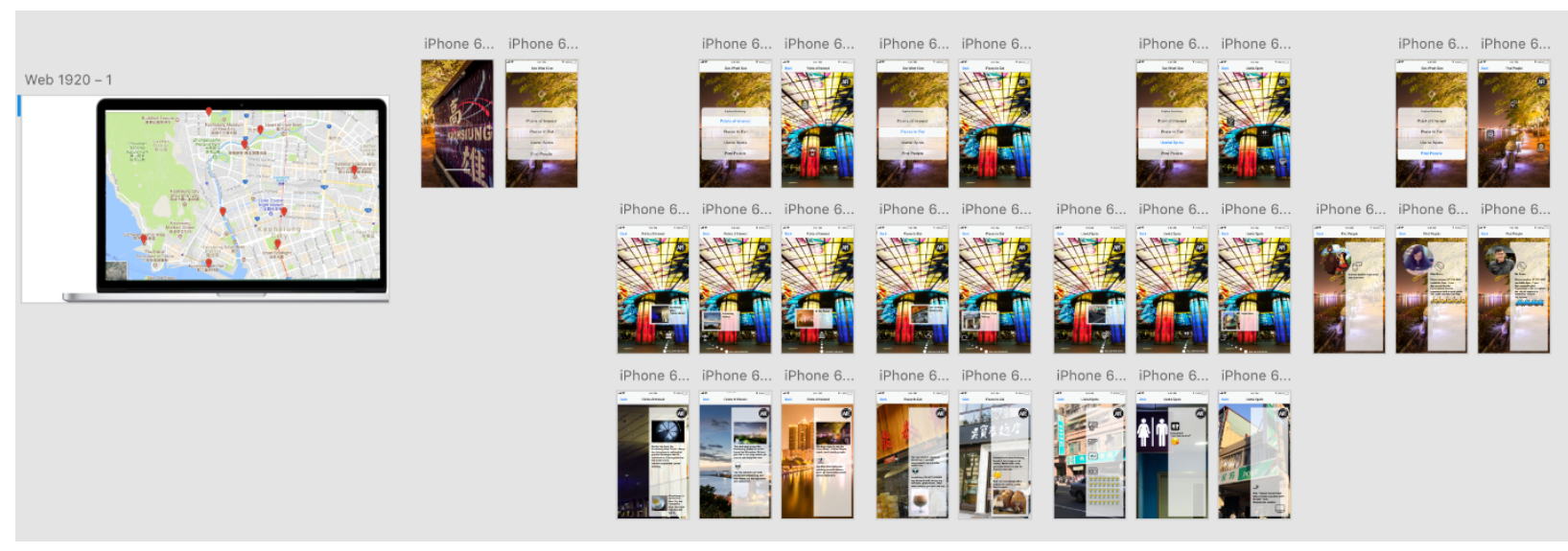

Evaluation the "See What I See" MARS

There were four 7 point Liket type questions that are ranged from strongly disagree to strongly agree (please see Appendix) to evaluate the "See What I See" MARS. The first question is testing if the MARS is useful for its users. The second question is testing if the MARS is easy to use by the users. The third question is testing about the experience of using the MARS whereas the fourth question is testing the companionship that the MARS might provide to its user while they are on the move.

There are 3 females and 2 males who participate in this study on November 17, 2017 at Oxford, OH. Each prototype test is about 15 minutes. Before the testing, the designer explains the "See What I See" MARS and the city of Kaohsiung, Taiwan to those participants. The designer shows a travel webpage of Kaohsiung and the Lonely Plant webpage that recommends traveling to Kaohsiung in 2018 to the participants. The designer then opens the prototype and shows part one to the participant. After that, the participant could click any buttons that they like on the prototype.

Results show that most of the participants think the MARS is a useful system for them to travel to Kaohsiung. Three female participants mark "strongly agree" whereas two male participants mark "agree" with the statement "“'See What I See” would be a useful app for my travel to Kaohsiung." When asking if "“"See What I See” was intuitive and easy to use," all participants strongly agree with the statement except participant \#4 who "somewhat agree" with the statement. She then adds a suggestion as adding "the option for the user to be notified when 
they are near a chosen landmark, so they don't miss something that you picked out for them" for the app. For question 3, ““See What I See” increased my appreciation of Kaohsiung travel experience", participant \#1 and participant \#4 mark "agree" whereas the rest of the participants check "strongly agree." Finally, the last question, "When I used "See What I See", I felt like I was traveling with Yi-Fan", participant \#1 neither agrees nor disagrees whereas participant \#3 marks "agree." The rest of the participants mark strongly agree with the statement. One other suggestion that participant \#4 added is "Add functionality for communication between the two people ("call me," "text me," or ways for the user to share feedback, or make a note that they visited a place that you picked out for them.").

Overall, users have positive experience with the "See What I See" MARS porotype. They see the MARS is easy to use and usefulness. They think the MARS could provide them travel companionship and enhance their travel experience.

\section{Discussions and Conclusion}

The participant \#4 suggests adding a notification and a "places visited" function on the MARS. There might be a possible explanation for it. Although the "See What I See" MARS is a user-generated situated documentary MARS, the designer does not actually modify the prototype to fit each individual participant's needs. Therefore, the designer might need to explain the MARS is for users to use when they are bored and this is not an official mTourism system that mark all important tourist attractions for its users because all travelers often download several mTourism apps before they travel (Chen, 2013). It is a travel companion when the travelers have extra time to add a layer of fun at the location. The MARS could also be considered to be an alternative social network system that the users can post short situated documentaries for their friends and family members but not require or expect their friends and family members to follow all suggestions and recommendations.

Another observation is considering adding one more computer screen on the "See What I See" prototype that shows how to generate situated documentaries. The page could include a textbox to type a message, some emoji to select, a file that allows the users to attach photos or videos and a pin icon that allows the user to pin hotspots on a google map. This screen might allow users to see the whole function of the "See What I See" MARS. 


\section{Suggestions for Future MARS Design}

For this "See What I See" MARS, the results show that users seem to find it usefulness and easy to use to enjoy the "situated documentaries" from the social networks at the location. The users develop the para-social relationship with their custom-made "situated documentaries"

on the move. For the future MARS design, it might add a function for users to add their "situated documentaries" from the location to share with their social networks who are not able to be physically present at the same location or who would love to re-create the experience again. Tourists often use mobile devices to share their tourist experience. In Chen's (2013) study, she finds tourists depend on their mobile media to share their happy moods with their family members and friends when they are travelling. It might be a function to be considered for further MARS design. 


\section{Summary of the Study}

Primary Research

With smartphones and wearable information and communication technologies (ICT) are ubiquitous, mobile augmented reality systems (MARS) open various opportunities for users to experience and interact with virtual information at physical locations (Höllerer \& Feiner, 2005). This study first aims to understand how users domesticated Pokémon Go, a MARS could be seen as the first normalizing MARS for the masses, into their everyday life. Prior studies found that the MARS increased users' physical activities (e.g., Althoff et al., 2016; Howe et al., 2016). Another study found that the MARS had positive effects on the mental health of the adult working population (Watanabe et al., 2017). However, there is a lack of the study on user experience of the MARS uses.

The Domestication Approach (Haddon, 2003; Silverstone et al., 2005) and the Uses and Gratification Theory (Katz et al., 1974) provided the theoretical framework for this study. The Domestication Approach was used to examine the use patterns whereas the Uses and Gratification Theory was utilized to investigate use motivations. A triangulation method combined a participant observation in Kaohsiung, Taiwan and a qualitative content analysis from a popular Taiwanese Facebook Group Page to learn patterns and motivations of the MARS experience. The field data was collected from June 22, 2017, to August 7, 2017 (i.e., the gym system was reworked and the addition of Raids to before the Zapdos arrived). Field notes were taken. In addition, 2,109 Facebook posts were analyzed. Results show that content is crucial when using the MARS. The MARS users domesticate the system into their everyday life. As other media provide to their users fulfillment of their information, communication, decision, entertainment, socialization, and companionship needs, the MARS also facilitates users' needs to reach their goals. A special highlight is that the MARS supports companionship from both personal social networks and Pokémon networks. The online, offline, personal social networks, and Pokémon networks seem to be inter-related because of the MARS. The line between the virtual and the physical spaces are blurred. Moreover, the MARS adds a "layer of fun" for its users when they navigate places. Implications, limitations, and suggestions for future research are discussed. 


\section{Design Research}

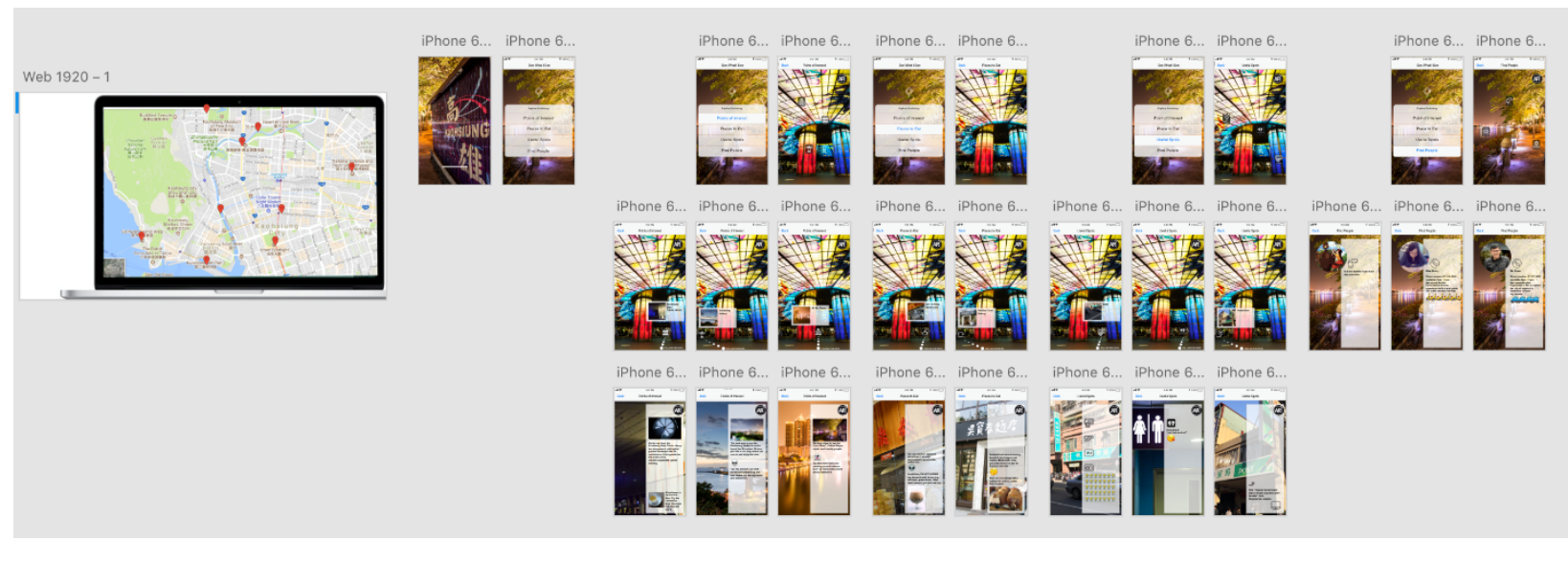

A "See What I See" MARS is designed based on primary research findings on users' companionship needs from their social networks and from their mobile media. It is a usergenerated situated documentary MARS for users to use in everyday life. A prototype was built and tested by five participants, three females and two males on November 17, 2017. The task was situated in first time visiting an international new city. Results show that users report the "See What I See" MARS is highly useful and easy to use. It enhances users' travel experience in a positive way. Users also feel positive companionship from their friends and family members when they use the MARS. 


\section{References}

Adobe. (2017, October 18). What is Adobe XD? Adobe. Retrieved from https://helpx.adobe.com/xd/how-to/what-is-xd.html

Alperstein, N. M. (1991). Imaginary social relationships with celebrities appearing in television commercials. Journal of Broadcasting \& Electronic Media, 35(1), 43-58. https://doi.org/10.1080/08838159109364101

Althoff, T., White, R. W., \& Horvitz, E. (2016). Influence of Pokémon Go on physical activity: Study and implications. Journal of Medical Internet Research, 18(12), e315. https://doi.org/10.2196/jmir.6759

Armstrong, C. B., \& Rubin, A. M. (1989). Talk radio as interpersonal communication. Journal of Communication, 39(2), 84-94. https://doi.org/10.1111/j.1460-2466.1989.tb01031.x

Auter, P. J., \& Palmgreen, P. (2000). Development and validation of a parasocial interaction measure: The audience-persona interaction scale. Communication Research Reports, 17(1), 79-89. https://doi.org/10.1080/08824090009388753

Azuma, R. T. (1997). A survey of augmented reality. Presence: Teleoperators and Virtual Environments, 6(4), 355-385. https://doi.org/10.1162/pres.1997.6.4.355

Baesler, E. J., \& Chen, Y.-F. (2013). Mapping the landscape of digital petitionary prayer as spiritual/social support in mobile, Facebook, and e-mail. Journal of Media and Religion, 12(1), 1-15. https://doi.org/10.1080/15348423.2013.760385

Berker, T., Hartmann, M., Punie, Y., \& Ward, K. J. (2006). Introduction. In T. Berker, M. Hartmann, Y. Punie, \& K. J. Ward (Eds.), Domestication of media and technology (pp. 117). New York, NY: Open University Press.

Bickmore, T. W., Caruso, L., Clough-Gorr, K., \& Heeren, T. (2005). "It"s just like you talk to a friend' relational agents for older adults. Interacting with Computers, 17(6), 711-735. https://doi.org/10.1016/j.intcom.2005.09.002

Bittman, M., Brown, J. E., \& Wajcman, J. (2009). The mobile phone, perpetual contact and time pressure. Work, Employment and Society, 23(4), 673-691. https://doi.org/10.1177/0950017009344910

Brown, B., \& Chalmers, M. (2003). Tourism and mobile technology. In K. Kuutti, E. H. Karsten, G. Fitzpatrick, P. Dourish, \& K. Schmidt (Eds.), Proceedings of the eighth European conference on computer supported cooperative work (pp. 335-354). Dordrecht, Netherlands: Springer Netherlands. https://doi.org/10.1007/978-94-010-0068-0_18

Bull, M. (2000). Sounding out the city: Personal stereos and the management of everyday life. New York, NY: Berg.

Bull, M. (2007). Sound moves: iPod culture and urban experience. New York, NY: Routledge.

Carlsson, C., Walden, P., \& Yang, F. (2008). Travel MoCo- A mobile community service for tourists. In 7th International Conference on Mobile Business (pp. 49-58). Piscataway, NJ: IEEE. https://doi.org/10.1109/ICMB.2008.40

Castells, M., Fernández-Ardèvol, M., Qiu, J. L., \& Sey, A. (2007). Mobile communication and society: A global perspective : a project of the Annenberg Research Network on international communication. Cambridge, MA: MIT Press.

Cecil-Karb, R., \& Grogan-Kaylor, A. (2009). Childhood body mass index in community context: Neighborhood safety, television viewing, and growth trajectories of BMI. Health \& Social Work, 34(3), 169-177. https://doi.org/10.1093/hsw/34.3.169

Chen, C.-Y., Kobayashi, M., \& Oh, L. M. (2005). ShareComp: Sharing for companionship. In CHI '05 extended abstracts on Human factors in computing systems - CHI '05 (pp. 2074 
2078). New York, NY: ACM Press. https://doi.org/10.1145/1056808.1057102

Chen, Y.-F. (2013, June). Click to share: Touristic experiences in real time. In A. Cohen (Chair), Research on Click: Sharing and liking in the Air. Panel presented at the meeting of the $63^{\text {rd }}$ annual conference of the International Communication Association, London, UK.

Chen, Y.-F., \& Katz, J. E. (2009). Extending family to school life: College students' use of the mobile phone. International Journal of Human-Computer Studies, 67(2), 179-191. https://doi.org/10.1016/j.ijhcs.2008.09.002

Cheverst, K., Davies, N., Mitchell, K., \& Friday, A. (2000). Experiences of developing and deploying a context-aware tourist guide. In Proceedings of the 6th annual international conference on mobile computing and networking - MobiCom '00 (pp. 20-31). New York, NY: ACM Press. https://doi.org/10.1145/345910.345916

Colliander, J., \& Dahlén, M. (2011). Following the fashionable friend: The power of social media. Journal of Advertising Research, 51(1), 313-320. https://doi.org/10.2501/JAR-51-1313-320

Conway, J. C., \& Rubin, A. M. (1991). Psychological predictors of television viewing motivation. Communication Research, 18(4), 443-463. https://doi.org/10.1177/009365091018004001

Correa, T. (2014). Bottom-up rechnology transmission within families: Exploring how youths influence their parents' digital media use with dyadic data. Journal of Communication, 64(1), 103-124. https://doi.org/10.1111/jcom.12067

DeWalt, K. M., \& DeWalt, B. R. (2002). Participant observation: A guide for fieldworkers. Walnut Creek, CA: AltaMira Press.

Diddi, A., \& LaRose, R. (2006). Getting hooked on news: Uses and gratifications and the formation of news habits among college students in an Internet environment. Journal of Broadcasting \& Electronic Media, 50(2), 193-210. https://doi.org/10.1207/s15506878jobem5002_2

Drisko, J., \& Maschi, T. (2016). Content analysis. New York, NY: Oxford University Press. https://doi.org/10.1093/acprof:oso/9780190215491.001.0001

ET Today. (2017, November 1).「可以幫我抓炎帝嗎」? 罹癌阿伯臨終留遺願...寶友含淚 完成 | ETtoday生活 | ETtoday新聞雲. ET Today. Retrieved from https://www.ettoday.net/news/20171101/1042887.htm?from=fb_et_news

Ferguson, D. A., Greer, C. F., \& Reardon, M. E. (2007). Uses and gratifications of MP3 players by college students: Are iPods more popular than radio? Journal of Radio Studies, 14(2), 102-121. https://doi.org/10.1080/10955040701583197

Fielding, N. G., \& Fielding, J. L. (1986). Linking data: The articulation of qualitative and quantitative methods in social research. Beverley Hills, CA: Sage Publications.

Geser, H. (2006). Is the cell phone undermining the social order?: Understanding mobile technology from a sociological perspective. Knowledge, Technology \& Policy, 19(1), 8-18. https://doi.org/10.1007/s12130-006-1010-x

Giles, D. C. (2002). Parasocial interaction: A review of the literature and a model for future research. Media Psychology, 4(3), 297-305. https://doi.org/10.1207/S1532785XMEP0403_04

Gretzel, U. (2013). Tourism in a technology-dependent world. In J. Leigh, C. Webster, \& S. Ivanov (Eds.), Future tourism: Political, social and economic challenges (pp. 123-134). New York, NY: Routledge.

Gretzel, U., \& Fesenmaier, D. R. (2009). Information technology: Shaping the past, present and 
future of tourism. In T. Jamal \& M. Robinson (Eds.), The SAGE handbook of tourism studies (pp. 558-580). Thousand Oaks, CA: Sage Publications.

Haddon, L. (2003). Domestication and mobile telephony. In J. E. Katz (Ed.), Machines that become us: The social context of personal communication technology (pp. 43-56). New Brunswick, NJ: Transaction Publishers.

Haq, H. (2013, January 29). Rio de Janeiro brings QR codes to its streets. $B B C$. Retrieved from http://www.bbc.com/travel/story/20130129-rio-de-janeiro-brings-qr-codes-to-its-streets

Hijazi-Omari, H., \& Ribak, R. (2008). PLAYING WITH FIRE: On the domestication of the mobile phone among Palestinian teenage girls in Israel. Information, Communication \& Society, 11(2), 149-166. https://doi.org/10.1080/13691180801934099

Hoffner, C. (1996). Children's wishful identification and parasocial interaction with favorite television characters. Journal of Broadcasting \& Electronic Media, 40(3), 389-402. https://doi.org/10.1080/08838159609364360

Hollerer, T., Feiner, S., \& Pavlik, J. V. (1999). Situated documentaries:Embedding multimedia presentations in the real world. In Third International Symposium on Wearable Computers (pp. 79-86). Piscataway, NJ: IEEE. https://doi.org/10.1109/ISWC.1999.806664

Höllerer, T. H., \& Feiner, S. K. (2005). Mobile augmented reality. In H. A. Karimi \& A. Hammad (Eds.), Telegeoinformatics: Location-based computing and services (pp. 187220). London, UK: Taylor and Francis Books Ltd.

Hollister, S. (2017, July 6). The rise and not-quite-fall of Pokémon Go: App tracking companies say the game peaked early, but it's still crazy popular. CNET. Retrieved from https://www.cnet.com/news/pokemon-go-million-dollar-monthly-active-users/

Horton, D., \& Wohl, R. R. (1956). Mass communication and para-social interaction. Psychiatry, 19(3), 215-229. https://doi.org/10.1080/00332747.1956.11023049

Howe, K. B., Suharlim, C., Ueda, P., Howe, D., Kawachi, I., \& Rimm, E. B. (2016). Gotta catch'em all! Pokémon GO and physical activity among young adults: Difference in differences study. BMJ (Clinical Research Ed.), 355, i6270. https://doi.org/10.1136/BMJ.I6270

Ito, M. (2005). Mobile phones, Japanese youth, and the re-placement of social contact. In R. S. Ling \& P. E. Pedersen (Eds.), Mobile communications: Re-negotiation of the social sphere (pp. 131-148). London, UK: Springer. Retrieved from https://link.springer.com/content/pdf/10.1007/1-84628-248-9.pdf\#page=146

Jenkins, N. (2016, August 22). Pokémon Go may have just shown us what the end of the world looks like. Time. Retrieved from http://time.com/4460911/pokemon-go-taipei-stampedesnorlax-mob-xinbeitou-taiwan/

Katz, E., Blumler, J. G., \& Gurevitch, M. (1974). Utilization of mass communication by the individual. In J. G. Blumler \& E. Katz (Eds.), The use and mass communications: Current perspectives on gratifications research (pp. 19-32). Beverly Hills, CA: Sage Publications.

Katz, E., Haas, H., \& Gurevitch, M. (1973). On the use of the mass media for important things. American Sociological Review, 38(2), 164-181. https://doi.org/10.2307/2094393

Katz, J. E., \& Aakhus, M. A. (2002). Perpetual contact: Mobile communication, private talk, public performance. Cambridge, UK: Cambridge University Press.

Katz, J. E., \& Sugiyama, S. (2006). Mobile phones as fashion statements: Evidence from student surveys in the US and Japan. New Media \& Society, 8(2), 321-337. https://doi.org/10.1177/1461444806061950

Kawulich, B. B. (2005). Participant observation as a data collection method. Forum Qualitative 
Sozialforschung / Forum: Qualitative Social Research, 6(2). https://doi.org/10.17169/FQS6.2 .466

Kenteris, M., Gavalas, D., \& Economou, D. (2009). An innovative mobile electronic tourist guide application. Personal and Ubiquitous Computing, 13(2), 103-118.

https://doi.org/10.1007/s00779-007-0191-y

Ko, H., Cho, C.-H., \& Roberts, M. S. (2005). Internet uses and gratifications: A structural equation model of interactive advertising. Journal of Advertising, 34(2), 57-70. https://doi.org/10.1080/00913367.2005.10639191

kocpc. (2017, August 14). 感謝您這一年的付出 《大家找寶貝》宣布14日晚上九點關閉 網站服務 - 電腦王阿達. Kocpc. Retrieved from https://www.kocpc.com.tw/archives/158650

Kopomaa, T. (2000). The city in your pocket: Birth of the mobile information society. Helsinki: Gaudeamus.

Kounavis, C. D., Kasimati, A. E., \& Zamani, E. D. (2012). Enhancing the tourism experience through mobile augmented reality: Challenges and prospects. International Journal of Engineering Business Management, 4, 1-10. https://doi.org/10.5772/51644

Kourouthanassis, P., Boletsis, C., Bardaki, C., \& Chasanidou, D. (2015). Tourists responses to mobile augmented reality travel guides: The role of emotions on adoption behavior. Pervasive and Mobile Computing, 18, 71-87. https://doi.org/10.1016/J.PMCJ.2014.08.009

Larson, R., Kubey, R., \& Colletti, J. (1989). Changing channels: Early adolescent media choices and shifting investments in family and friends. Journal of Youth and Adolescence, 18(6), 583-599. https://doi.org/10.1007/BF02139075

Lee, G. A., Dünser, A., Kim, S., \& Billinghurst, M. (2012). CityViewAR: A mobile outdoor AR application for city visualization. In 2012 IEEE International Symposium on Mixed and Augmented Reality - Arts, Media, and Humanities (ISMAR-AMH) (pp. 57-64). IEEE. https://doi.org/10.1109/ISMAR-AMH.2012.6483989

Leeds-Hurwitz, W. (1992). Forum introduction: Social approaches to interpersonal communication. Communication Theory, 2(2), 131-139. https://doi.org/10.1111/j.14682885.1992.tb00032.x

Lemish, D., \& Cohen, A. A. (2005). On the gendered nature of mobile phone culture in Israel. Sex Roles, 52(7-8), 511-521. https://doi.org/10.1007/s11199-005-3717-7

Leswing, K. (2017, January 5). "Pokémon Go" was most downloaded iOS app worldwide in 2016, Apple says. Business Insider. Retrieved from http://www.businessinsider.com/pokemon-go-most-downloaded-ios-app-worldwide-20162017-1

Leung, L., \& Lee, P. S. N. (2005). Multiple determinants of life quality: the roles of Internet activities, use of new media, social support, and leisure activities. Telematics and Informatics, 22(3), 161-180. https://doi.org/10.1016/j.tele.2004.04.003

Leung, L., \& Wei, R. (2000). More than just talk on the move: Uses and gratifications of the cellular phone. Journalism \& Mass Communication Quarterly, 77(2), 308-320. https://doi.org/10.1177/107769900007700206

Levy, M. R. (1979). Watching TV news as para-social interaction. Journal of Broadcasting, 23(1), 69-80. https://doi.org/10.1080/08838157909363919

Lincoln, Y. S., \& Guba, E. G. (1985). Naturalistic inquiry. Newbury Park, CA: Sage Publications.

Lindlof, T. R., \& Taylor, B. C. (2002). Qualitative communication research methods. (2nd ed.). 
Thousand Oaks, CA: Sage Publications.

Ling, R. S. (2004). The mobile connection: The cell phone's impact on society. San Francisco, CA: Morgan Kaufmann.

Ling, R. S. (2008). New tech, new ties: How mobile communication is reshaping social cohesion. MIT Press.

Ling, R. S. (2012). Taken for grantedness: The embedding of mobile communication into society. Cambridge, MA: MIT Press.

Ling, R. S., Nilsen, S., \& Granhaug, S. (1999). The domestication of video-on-demand. New Media \& Society, 1(1), 83-100. https://doi.org/10.1177/14614449922225492

Lonely Planet. (2017). Top 10 cities to visit in 2018. Lonely Planet. Retrieved from https://www.lonelyplanet.com/best-in-travel/cities

Low, A. (2017, July 10). These seniors are kicking ass in Pokémon Go: And staying healthy while doing so. CNET. Retrieved from https://www.cnet.com/news/these-seniors-arekicking-ass-in-pokemon-go/

Majorek, M., \& du Vall, M. (2016). Ingress: An Example of a New Dimension in Entertainment. Games and Culture, 11(7-8), 667-689. https://doi.org/10.1177/1555412015575833

Marshall, C., \& Rossman, G. B. (1989). Designing qualitative research. Newbury Park, CA: Sage Publications.

Maxwell, J. A. (2005). Qualitative research design: An interactive approach (2nd ed.). Thousand Oaks, CA: Sage Publications.

McCracken, H. (2015, February 19). How Japan's Line app became a culture-changing, revenuegenerating phenomenon. Fast Company. Retrieved from https://www.fastcompany.com/3041578/how-japans-line-app-became-a-culture-changingrevenue-generat

Morgan, D. L. (1993). Qualitative content analysis: A guide to paths not taken. Qualitative Health Research, 3(1), 112-121. https://doi.org/10.1177/104973239300300107

Nabi, R. L., Stitt, C. R., Halford, J., \& Finnerty, K. L. (2006). Emotional and cognitive predictors of the enjoyment of reality-based and fictional television programming: An elaboration of the uses and gratifications perspective. Media Psychology, 8(4), 421-447. https://doi.org/10.1207/s1532785xmep0804_5

O’Hara, K., Perry, M., Sellen, A., \& Brown, B. (2002). Exploring the relationship between mobile phone and document activity during business travel. In B. Brown, N. Green, \& R. Harper (Eds.), Wireless world: Social and interactional aspects of the mobile age (pp. 180194). New York, NY: Springer-Verlag New York. https://doi.org/10.1007/978-1-4471$0665-412$

Orlik, P. B. (2016). Media criticism in a digital age: Professional and consumer considerations. New York, NY: Routledge.

Papacharissi, Z., \& Mendelson, A. L. (2007). An exploratory study of reality appeal: Uses and gratifications of reality TV shows. Journal of Broadcasting \& Electronic Media, 51(2), 355-370. https://doi.org/10.1080/08838150701307152

Pavlik, J. V. (2001). Journalism and new media. New York, NY: Columbia University Press.

Pavlik, J. V., \& Bridges, F. (2013). The emergence of augmented reality (AR) as a storytelling medium in journalism. Journalism \& Communication Monographs, 15(1), 4-59. https://doi.org/10.1177/1522637912470819

Pavlik, J. V., \& McIntosh, S. (2006). Mobile news design and delivery. In J. Groebel, E. M. Noam, \& V. Feldmann (Eds.), Mobile media: Content and services for wireless 
communications (pp. 87-95). Mahwah, NJ: Lawrence Erlbaum Associates.

Pokémon Go Kaohsiung. (n.d.). 寶可夢 Pokémon Go高雄交流區. Retrieved November 3, 2017, from https://www.facebook.com/groups/1184477268271906/

Pool, I. de S. (1983). Technologies of freedom. Cambridge, MA: Belknap Press of Harvard University Press.

Quan, S., \& Wang, N. (2004). Towards a structural model of the tourist experience: An illustration from food experiences in tourism. Tourism Management, 25(3), 297-305. https://doi.org/10.1016/S0261-5177(03)00130-4

Raacke, J., \& Bonds-Raacke, J. (2008). MySpace and Facebook: Applying the uses and gratifications theory to exploring friend-networking sites. CyberPsychology \& Behavior, 11(2), 169-174. https://doi.org/10.1089/cpb.2007.0056

Radway, J. A. (1991). Reading the romance: Women, patriarchy, and popular literature. Chapel Hill, NC: University of North Carolina Press.

Rakow, L. F., \& Navarro, V. (1993). Remote mothering and the parallel shift: Women meet the cellular telephone. Critical Studies in Mass Communication, 10(2), 144-157. https://doi.org/10.1080/15295039309366856

Rubin, A. M. (1983). Television uses and gratifications: The interactions of viewing patterns and motivations. Journal of Broadcasting, 27(1), 37-51. https://doi.org/10.1080/08838158309386471

Rubin, A. M., \& Perse, E. M. (1987). Audience activity and television news gratifications. Communication Research, 14(1), 58-84. https://doi.org/10.1177/009365087014001004

Rubin, A. M., Perse, E. M., \& Power, R. A. (1985). Loneliness, parasocial interaction, and local television news viewing. Human Communication Research, 12(2), 155-180. https://doi.org/10.1111/j.1468-2958.1985.tb00071.x

Rubin, A. M., \& Step, M. M. (2000). Impact of motivation, attraction, and parasocial interaction on talk radio listening. Journal of Broadcasting \& Electronic Media, 44(4), 635-654. https://doi.org/10.1207/s15506878jobem4404_7

Rubin, R. B., \& Rubin, A. M. (1982). Contextual age and television use: Reexamining a lifeposition indicator. Annals of the International Communication Association, 6(1), 583-604. https://doi.org/10.1080/23808985.1982.11678513

Shibata, T. (2012). Therapeutic Seal Robot as biofeedback medical device: Qualitative and quantitative evaluations of robot therapy in dementia care. Proceedings of the IEEE, 100(8), 2527-2538. https://doi.org/10.1109/JPROC.2012.2200559

Silverstone, R., Hirsch, E., \& Morley, D. (2005). Information and communication technologies and the moral economy of the household. In E. Hirsch \& R. Silverstone (Eds.), Consuming technologies: Media and information in domestic spaces (pp. 9-17). New York, NY: Routledge.

Sinclair, M. (2014, February 28). Streetmuseum app updated - Creative Review. Creative Review. Retrieved from https://www.creativereview.co.uk/streetmuseum-app-updated/

Strauss, A. L., \& Corbin, J. M. (1998). Basics of qualitative research: Techniques and procedures for developing grounded theory (2nd ed.). Thousand Oaks, CA: Sage Publications.

Swanson, D. L. (1977). The uses and misuses of uses and gratifications. Human Communication Research, 3(3), 214-221. https://doi.org/10.1111/j.1468-2958.1977.tb00519.x

Tassi, P. (2016, November 11). "Pokémon Go" is spawning Lapras to help tourism In tsunami affected Japanese regions. Forbes. Retrieved from 
https://www.forbes.com/sites/insertcoin/2016/11/11/pokemon-go-is-spawning-lapras-tohelp-tourism-in-tsunami-affected-japanese-regions/\#29fe17ee $7 \mathrm{e} 2 \mathrm{e}$

The Straits Times. (2017, August 3). Taichung surpasses Kaohsiung to become Taiwan's second-largest city. The Straits Times. Retrieved from http://www.straitstimes.com/asia/east-asia/taichung-surpasses-kaohsiung-to-becometaiwans-second-largest-city

Tong, X., Gupta, A., Lo, H., Choo, A., Gromala, D., \& Shaw, C. D. (2017). Chasing lovely monsters in the wild, exploring players' motivation and play patterns of Pokémon Go: Go, gone or go away? In Companion of the 2017 ACM Conference on Computer Supported Cooperative Work and Social Computing - CSCW'17 Companion (pp. 327-330). New York, NY: ACM Press. https://doi.org/10.1145/3022198.3026331

Tramer, H., \& Jeffres, L. W. (1983). Talk radio-forum and companion. Journal of Broadcasting, 27(3), 297-300. https://doi.org/10.1080/08838158309386496

van Setten, M., Pokraev, S., \& Koolwaaij, J. (2004). Context-aware recommendations in the mobile tourist application COMPASS. In P. M. E. De Bra \& W. Nejdl (Eds.), Adaptive hypermedia and adaptive web-based systems (pp. 235-244). Berlin, Germany: SpringerVerlag. https://doi.org/10.1007/978-3-540-27780-4_27

Vardoulakis, L. P., Ring, L., Barry, B., Sidner, C. L., \& Bickmore, T. (2012). Designing relational agents as long term social companions for older adults. In Y. Nakano, M. Neff, A. Paiva, \& M. Walker (Eds.), Intelligent Virtual Agents. IVA 2012. Lecture Notes in Computer Science (pp. 289-302). Berlin, Germany: Springer. https://doi.org/10.1007/9783-642-33197-8 30

Wang, D., Park, S., \& Fesenmaier, D. R. (2012). The role of smartphones in mediating the touristic experience. Journal of Travel Research, 51(4), 371-387. https://doi.org/10.1177/0047287511426341

Wang, H.-Y., \& Wang, S.-H. (2010). Predicting mobile hotel reservation adoption: Insight from a perceived value standpoint. International Journal of Hospitality Management, 29(4), 598608. https://doi.org/10.1016/j.ijhm.2009.11.001

Watanabe, K., Kawakami, N., Imamura, K., Inoue, A., Shimazu, A., Yoshikawa, T., ... Tsutsumi, A. (2017). Pokémon GO and psychological distress, physical complaints, and work performance among adult workers: A retrospective cohort study. Scientific Reports, 7(1), 10758. https://doi.org/10.1038/s41598-017-11176-2

Weaver, D. H. (1993). Communication research in the 1990s: New directions and new agendas? In P. Gaunt (Ed.), Beyond agendas: New directions in communication research (pp. 199220). Westport, CT: Greenwood Press.

White, N. R., \& White, P. B. (2007). Home and away: Tourists in a connected world. Annals of Tourism Research, 34(1), 88-104. https://doi.org/10.1016/j.annals.2006.07.001

Yovcheva, Z., Buhalis, D., \& Gatzidis, C. (2012). Smartphone augmented reality applications for tourism. E-Review of Tourism Research (eRTR), 10(2), 63-66.

Zakrisson, I., \& Zillinger, M. (2012). Emotions in motion: Tourist experiences in time and space. Current Issues in Tourism, 15(6), 505-523. https://doi.org/10.1080/13683500.2011.615391 


\section{Appendix}

\section{Porotype Testing Questions}

1. "See What I See" would be a useful app for my travel to Kaohsiung. Strongly disagree Strongly agree

2. "See What I See" was intuitive and easy to use.

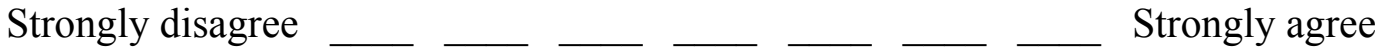

3. "See What I See" increased my appreciation of Kaohsiung travel experience. Strongly disagree Strongly agree

4. When I used "See What I See", I felt like I was traveling with Yi-Fan Strongly disagree Strongly agree

Suggestions and recommendations 